\title{
universidad deleón
}

Departamento de Ciencias Biomédicas

\section{EFECTO DEL ENTRENAMIENTO DE VIBRACIONES SOBRE DIVERSOS PARÁMETROS FUNCIONALES Y FISIOLÓGICOS EN ANCIANOS}

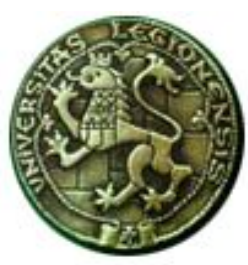

Carlos Cristi Montero

León, 2011 


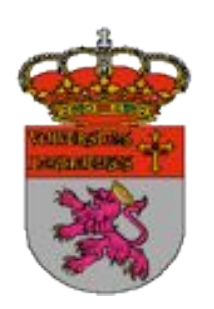

\section{UNIVERSIDAD DE LEÓN}

\section{ADMISIÓN A TRÁMITE DEL DEPARTAMENTO}

(Art. 11.3 del R.D. 56/2005 y

Norma $7^{\mathrm{a}}$ de las Complementarias de la ULE)

El Departamento de Ciencias Biomédicas en su reunión celebrada el día 7 de Junio de 2011 ha acordado dar su conformidad a la admisión a trámite de lectura de la Tesis Doctoral titulada: "Efecto del entrenamiento de vibraciones sobre diversos parámetros funcionales y fisiológicos en ancianos”, dirigida por la Dra. Dña. Pilar Sánchez Collado y la Dra. Dña. María José Cuevas González, y elaborada por D. Carlos Cristi Montero.

Lo que firman, para dar cumplimiento al art. 11.3 del R.D. 56/2005, en León a 13 de Septiembre de 2011.

$\mathrm{V}^{\circ} \mathrm{B}^{\circ}$

El Director del Departamento,

La Secretaria, 


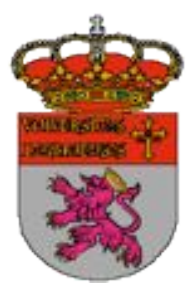

UNIVERSIDAD DE LEÓN

\section{INFORME DE LOS DIRECTORES DE LA TESIS}

(Art. 11.3 del R.D. 56/2005)

Las Dras. Dña. Pilar Sánchez Collado y Dña. María José Cuevas González, como directoras de la Tesis Doctoral titulada: "Efecto del entrenamiento de vibraciones sobre diversos parámetros funcionales y fisiológicos en ancianos" realizada por D. Carlos Cristi Montero, en el Departamento de Ciencias Biomédicas, informan favorablemente el depósito de la misma, dado que reúne las condiciones necesarias para su defensa.

Lo que firman, para dar cumplimiento al art. 11.3 del R.D. 56/2005, en León a 13 de Septiembre de 2011.

Las directoras de la Tesis Doctoral 


\section{AGRADECIMIENTOS}

Según la Real Academia Española, el verbo agradecer tiene un total de 55 conjugaciones. Esto es para mi como si la acción de agradecer tuviera un límite. Que injusto sería dejar a alguien, un momento o un instante fuera de estos agradecimientos, pues todos estos se ha hecho presente de alguna manera, durante estos tres años, para que mis deseos académicos se estén materializando.

Quiero agradecer a cada una de las personas que me han ayudado, consiente $\mathrm{O}$ inconscientemente, a que esta Tesis haya podido llevarse a cabo. A cada una de las personas que cada día, con una sonrisa, me han dedicado parte de su tiempo a resolver mis dudas, me han entregado sus consejos, me han ayudado a ser una mejor persona y profesional, y me han ayudado a sentir que los cerca de 12.000 kilómetros y más de 1.000 días lejos de mi familia no hayan sido en vano.

A mis directoras por su tiempo y dedicación, a mis compañeros por haber hecho del laboratorio un lugar más cálido y amigable, a mis nuevos amigos por haberme hecho sentir como en casa, a mi hermosa familia por todo su apoyo incondicional y a la adorable mujer que me acompaña por su esfuerzo y apoyo. A todos ustedes mis más sinceros agradecimientos.

" Queda prohibido no buscar tu felicidad, no vivir tu vida con una actitud positiva, no pensar en que podemos ser mejores, no sentir que sin ti, este mundo no sería igual..."

P. Neruda

Simplemente, gracias a todos. 
A mi familia, que me lo ha dado todo, incluso cuando no hemos tenido nada. 
Se agradece al Gobierno de Chile por la Beca otorgada para realizar este Doctorado. 


\section{ABREVIATURAS}

\begin{tabular}{|c|c|}
\hline AGL & Ácido Graso Libre \\
\hline ARNm & Ácido Ribonucleico mensajero \\
\hline $\mathrm{CV}$ & Cardiovascular \\
\hline $\mathrm{DMO}$ & Densidad Mineral Ósea \\
\hline E.E.M & Error Estándar de la Media \\
\hline EMGs & Electromiografía de superficie \\
\hline EVCC & Entrenamiento de Vibraciones Cuerpo Completo \\
\hline HDL & High Density Lipoprotein \\
\hline $\mathrm{Hz}$ & Hertzio \\
\hline IMC & Índice Masa Corporal \\
\hline iNOS & Oxido Nítrico isoforma Inducible \\
\hline IL-1 $\beta$ & Interleucina 1 Beta \\
\hline IL-6 & Interleucina 6 \\
\hline IL-10 & Interleucina 10 \\
\hline $\mathrm{MCVI}$ & Máxima Contracción Voluntaria Isométrica \\
\hline $\mathrm{NF}-\mathrm{kB}$ & Factor Nuclear Kappa B \\
\hline $\mathrm{pCr}$ & proteína $\mathrm{C}$ reactiva \\
\hline RCC & Relación Cintura Cadera \\
\hline r.p.m & revoluciones por minuto \\
\hline RT-PCR & Reacción en Cadena de la Polimerasa a Tiempo Real \\
\hline SFT & Senior Fitness Test \\
\hline TNF- $\alpha$ & Factor Necrosis Tumoral alfa \\
\hline $\mathrm{VL}$ & Vasto Lateral \\
\hline VM & Vasto Medial \\
\hline VCC & Vibración de Cuerpo Completo \\
\hline $\mathrm{VO}_{2 \max }$ & Volumen de oxígeno máximo \\
\hline$p$ & Valor estadístico calculado \\
\hline g & Unidades de gravedad \\
\hline $\mathrm{N}$ & Newton \\
\hline 1RM & Una Repetición Máxima \\
\hline ) & Micro voltios \\
\hline
\end{tabular}




\section{ÍNDICE DE CONTENIDOS}

1. INTRODUCCIÓN Y OBJETIVOS............................................... 1

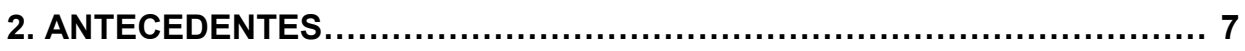

2.1. ENVEJECIMIENTO ................................................... 9

2.1.1. Envejecimiento de la población............................... 9

2.1.2. Caso de España................................................. 10

2.1.3. Adultos mayores institucionalizados.......................... 11

2.2. INVOLUCIÓN FISIOLÓGICA DEBIDA AL ENVEJECIMIENTO......... 12

2.2.1. Cambios en la fuerza de las extremidades superiores e inferiores....................................... 14

2.2.2. Disminución de la activación neuromuscular................... 17

2.2.3. Capacidad aeróbica.......................................... 18

2.2.4. Flexibilidad..................................................... 19

2.2.5. Equilibrio..................................................... 19

2.2.6. Composición corporal............................................. 20

2.3. ENVEJECIMIENTO, INFLAMACIÓN Y ENFERMEDADES ........... 21

2.3.1. Inflamación crónica …......................................... 23

2.4. ACTIVIDAD FÍSICA Y ENVEJECIMIENTO ............................ 27

2.4.1. Inactividad física, capacidad funcional e independencia.... 29

2.4.2. Senior Fitness Test ............................................ 31

2.4.3. Beneficios de una vida activa................................... 34

2.4.4. Recomendaciones de actividad física en la población de adultos mayores.......................................... 36

2.4.5. Tipos de ejercicio físico........................................ 38

2.4.5.1. Ejercicio Aeróbico..................................... 39

2.4.5.2. Ejercicio de Resistencia................................. 39

2.5. EJERCICIO VIBRATORIO.......................................... 40

2.5.1. Variables que influyen en las vibraciones........................43 
2.5.2. Cuantificación de la carga de trabajo................................. 45

2.5.3. Beneficios del EVCC en la población adulta mayor........... 46

2.5.4. Efecto a nivel neuromuscular y esquelético ..........................48

2.5.4.1. Efecto a nivel neuromuscular.............................. 48

2.5.4.2. Efecto a nivel esquelético.................................49

2.5.5. Beneficios relacionados con la independencia...................... 50

2.5.6. Efecto del EVCC sobre marcadores de inflamación............... 51

2.5.7. Recomendaciones generales para el entrenamiento

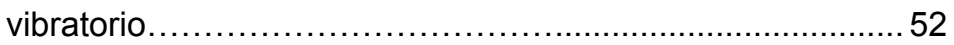

2.5.8. Contraindicaciones, indicaciones, ventajas y

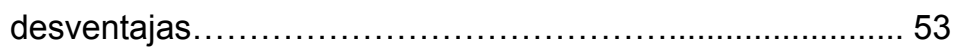

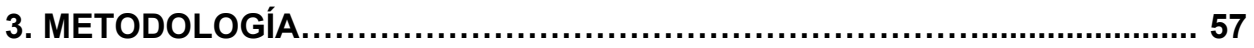

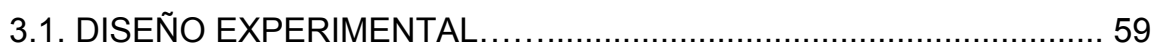

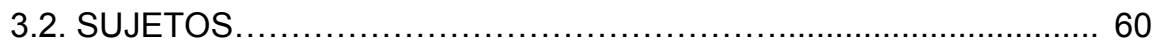

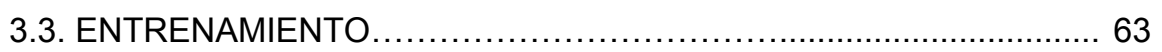

3.3.1. Ejercicio de tipo estático y dinámico..................................... 63

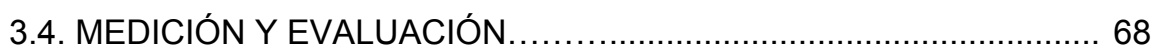

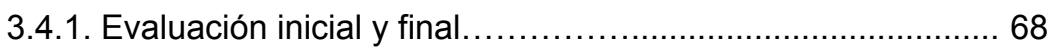

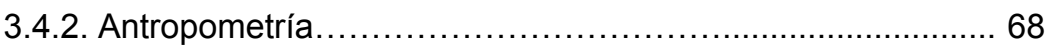

3.4.3. Electromiografía de superficie....................................... 70

3.4.4. Evaluación de la Fuerza y Potencia muscular..................... 72

3.4.4.1. Evaluación de MCVI............................................ 72

3.4.4.2. Evaluación de la Potencia Pico........................... 75

3.4.5. Evaluación de la Capacidad Funcional............................. 77

3.4.6. Obtención de las muestras sanguíneas........................... 80

3.4.6.1. Determinaciones plasmáticas.............................. 80

3.4.6.2. Aislamiento de Leucocitos.................................... 80

3.4.6.3. Cuantificación de proteínas totales ..................... 81

3.4.6.4. Cuantificación del ARNm por RT-PCR................... 82 
3.5. TRATAMIENTO ESTADÍSTICO. 86

4. RESULTADOS. 88

4.1. EFECTOS DEL EVCC SOBRE LOS COMPONENTES DE LA BATERÍA SENIOR FITNESS TEST.

4.1.1. Efecto del EVCC sobre la fuerza del tren superior $e$ inferior y equilibrio dinámico

4.1.2. Efecto del EVCC sobre la flexibilidad del tren superior e inferior 92

4.1.3. Efecto del EVCC sobre la resistencia aeróbica. .93

4.2. EFECTO DEL EVCC SOBRE LA EVALUACIÓN DE LA FUERZA, POTENCIA y ACTIVIDAD ELECTROMIOGRÁFICA DEL TREN INFERIOR.

4.2.1. Efecto del EVCC sobre la MCVI y sobre la Fuerza Relativa. 95

4.2.2. Efecto del EVCC sobre la Potencia Pico $20 \%, 40 \%$ y $60 \%$ de la MCVI. 96

4.3 EFECTO DEL EVCC SOBRE LA EMGs. .97

4.4. VALORES DE MCVI Y POTENCIA PICO DE JÓVENES

$Y$ ANCIANOS. .98

4.5 EFECTO DEL EVCC SOBRE LOS VALORES ABSOLUTOS

Y RELATIVOS DE LA FUERZA DE JÓVENES Y ANCIANOS. 99

4.6. EFECTO DEL EVCC SOBRE LA POTENCIA PICO DE JÓVENES Y ANCIANOS. 100

4.7. MARCADORES DE INFLAMACIÓN DE JÓVENES Y ANCIANOS.... 101

4.7.1. Contenido de ARNm de diversos marcadores de inflamación. 101

4.7.2. Contenido proteico de diversos marcadores de inflamación. 102 
5. DISCUSIÓN.

107

5.1. EFECTO DEL EVCC SOBRE LA CAPACIDAD FUNCIONAL DE LOS ANCIANOS. 109

5.1.1. Fuerza y equilibrio dinámico. 110

5.1.1.1.Efectos del EVCC sobre la fuerza del tren superior. 110

5.1.1.2. Efectos del EVCC sobre la fuerza del tren inferior. 114

5.1.1.3. Efectos del EVCC sobre la actividad EMGs 118

5.1.1.4. Efectos del EVCC sobre la potencia muscular. 119

5.1.1.5. Efectos del EVCC sobre el equilibrio dinámico 122

5.1.2. Flexibilidad 125

5.1.2.1. Efectos del EVCC sobre la flexibilidad del tren superior e inferior. 125

5.1.3. Resistencia aeróbica. 129

5.1.3.1. Efectos del EVCC sobre la resistencia aeróbica..... 129

5.2. EFECTO DEL EVCC SOBRE LA INFLAMACIÓN........................... 133

5.3. PUNTOS IMPORTANTES A CONSIDERAR................................. 140

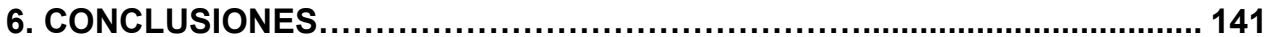

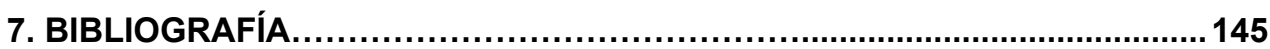

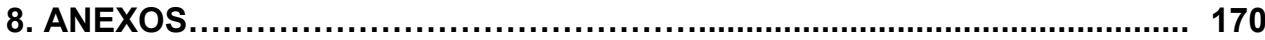




\section{ÍNDICE DE TABLAS}

Tabla 1. Componentes de la aptitud física relacionados con la salud.

Tabla 2. Cualidades físicas relacionadas con las habilidades orientadas al deporte y a la salud

Tabla 3. Cuadro que asocia los parámetros físico-fisiológicos necesarios con la función y las actividades diarias

Tabla 4. Objetivo de cada una de las pruebas de la batería SFT.

Tabla 5. Beneficios del efecto agudo y crónico del ejercicio de vibraciones.

Tabla 6. Características generales de los ancianos y los jóvenes del estudio

Tabla 7. Descripción de los ejercicios utilizados durante las 9 semanas de entrenamiento

Tabla 8. Detalle del número de series por cada ejercicio realizado durante las 9 semanas de EVCC.

Tabla 9. Planificación de la carga de entrenamiento durante las 9 semanas de entrenamiento.

Tabla 10. Resultado de la Batería SFT.

Tabla 11. Resultado sobre la MCVI, fuerza relativa, potencia al $20 \%, 40 \%$ y $60 \%$ y EMGs en ancianos...

Tabla 12. Resultado sobre la MCVI, fuerza relativa, potencia al $20 \%, 40 \%$ y $60 \%$ y electromiografía en jóvenes.

Tabla 13. Porcentaje de variación tras el EVCC del contenido de ARNm a través de la técnica RT-PCR

Tabla 14. Porcentaje de variación tras el EVCC del contenido de proteínas a través de la técnica Western Blot. 


\section{ÍNDICE DE ESQUEMAS}

Esquema 1. Incremento porcentual de la población adulta mayor desde

el año 1950 al 2050

Esquema 2. Efectos de la sarcopenia en las cualidades físicas y su repercusión en la salud

Esquema 3. Principal vía molecular proinflamatoria involucrada en el envejecimiento y enfermedades relacionadas con la edad......... 23

Esquema 4. Efectos metabólicos de la obesidad.................................. 25

Esquema 5. Rol de la inflamación en los procesos fisiopatológicos y la posible acción de la restricción calórica y del ejercicio........... 26

Esquema 6. Estrategia global para un envejecimiento saludable.................... 31

Esquema 7. Beneficios de la actividad física regular................................. 36

Esquema 8. Recomendaciones de actividad física aeróbica en la población

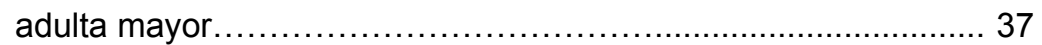

Esquema 9. Recomendaciones de actividad de fortalecimiento muscular en la población adulta mayor.................................................. 37

Esquema 10. Tipos de plataformas vibratorias y tipo de transferencia del estímulo.

Esquema 11. Tipo de variables que influyen en el ejercicio sobre plataforma de vibraciones.

Esquema 12. Parámetros que definen la aceleración:

frecuencia y amplitud.. 46

Esquema 13. Plan de trabajo 59

Esquema 14. Selección y exclusión de los participantes 61 


\section{ÍNDICE DE IMÁGENES}

Imagen 1. Bus de dos pisos de Londres, utilizado en el estudio de Jeremy Morris en la década de los 50 .

Imagen 2. Plataforma de vibración Fitvibe Excel utilizada en este estudio.

Imagen 3. Tipo de ejercicio dinámico (Sentadilla).

Imagen 4. Ejercicios de tipo estáticos utilizados las primeras dos semanas.

Imagen 5. Ejercicios de tipo dinámico y estático utilizados las siguientes siete semanas......

Imagen 6. Báscula InBody 230.

Imagen 7. Posición de electrodos sobre el VL y VM. Y medición de la señal menor a $5 \mathrm{k} \Omega$.

Imagen 8. Marca con un rotulador hecha en el muslo para asegurar la posición del electrodo.

Imagen 9. Medición ángulo articular con un goniómetro.

Imagen 10. Posición más idónea para cada sujeto, maquina extensión de rodillas.

Imagen 11. Dos tipos de calentamiento empleado previo a las evaluaciones, en compañía de un guía, y en un tapiz rodante.

Imagen 12. Evaluación de MCVI, EMGs y galga extensiométrica.

Imagen 13. Lectura en línea de la evaluación de la potencia a través del programa Real Power.

Imagen 14. Seis test evaluados en la batería SFT 


\section{ÍNDICE DE FIGURAS}

Figura 1. Efectos del EVCC sobre las pruebas del SFT. 90

Figura 2. Resultados de la valoración del test sentarse y levantarse, test ir y venir, flexión de codo PRE y POST EVCC.

Figura 3. Resultados de la valoración del test alcanzar los pies, y alcanzar las manos PRE y POST EVCC.

Figura 4. Resultados de la valoración del test de caminar 6 minutos PRE y POST EVCC................................................................ 93

Figura 5. Resultados de la valoración de la MCVI PRE y POST EVCC............ 95

Figura 6. Resultados de la fuerza relativa PRE y POST EVCC................... 95

Figura 7. Resultados de la valoración de la potencia al $20 \%, 40 \%$ y $60 \%$ de la MCVI PRE y POST EVCC

Figura 8. Resultados de la valoración del la EMGs del VL y VM

PRE y POST EVCC

Figura 9. Comparación porcentual de la MCVI y fuerza relativa de los ancianos PRE y POST EVCC con los valores de referencia de jóvenes.

Figura 10. Comparación porcentual de la potencia al $20 \%, 40 \%$ y $60 \%$ de los ancianos PRE y POST EVCC con los valores de referencia

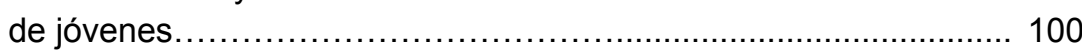

Figura 11. Cuantificación de la proteína $C$ reactiva..................................... 103

Figura 12. Cuantificación de la citoquina IL-6 ........................................... 104

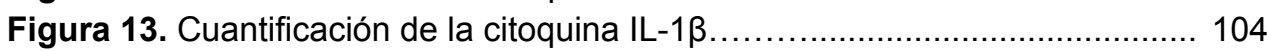

Figura 14. Cuantificación de la citoquina TNF-a.......................................... 105

Figura 15. Cuantificación de la citoquina IL-10 .............................................. 105 


\section{Introducción y Objetivos}


El envejecimiento involucra diversos cambios a nivel fisiológico, proceso que además se caracteriza por la pérdida de las capacidades físicas, con el consiguiente deterioro funcional, y por un aumento en los marcadores de inflamación sistémica. Este ambiente, promueve la pérdida de masa muscular, que a su vez se relaciona directamente con una reducción en la fuerza muscular de estas personas. Todo ello, sumado a la disminución de sus niveles de actividad física, incrementan la debilidad muscular, reduciendo así, la capacidad de producir fuerza rápida. Ambos componentes son los factores de riesgo más comunes asociados a caídas y pérdida de la independencia en los ancianos, pudiendo afectar enormemente su calidad de vida. También se ha podido constatar que el incremento en los factores de inflamación a nivel sistémico está asociado a diversas enfermedades que elevan el riesgo funcional en la población mayor. Un bajo nivel de fuerza muscular es un fuerte e independiente predictor de mortalidad en personas mayores. Así como también altos contenidos de TNF- $\alpha$ están asociados con una elevada mortalidad en los ancianos.

Por tanto, la actividad física y el ejercicio físico, se convierten en una herramienta que podría ayudar a mantener los niveles de fuerza y potencia muscular, permitiendo que estas cualidades físicas no disminuyan tan acentuadamente con el envejecimiento; y a que los niveles de inflamación en el organismo se mantengan estables, o bien, disminuyan. Según algunos autores, la discapacidad y la debilidad, podrían ser debidas no solamente al proceso natural de envejecimiento, si no que también al desuso de la musculatura a medida que avanza la edad, siendo la inactividad física un factor de riesgo importante que debe ser modificado. Por ello, el entrenamiento de resistencia es una intervención habitual en este tipo de población, ayudando a aumentar el volumen muscular, la fuerza, la potencia y la función muscular y mejorando de paso, la ejecución de tareas básicas tan necesarias como es el caso de la marcha. 
Recientemente, el entrenamiento de vibraciones de cuerpo completo (EVCC), ha emergido como una alternativa para aumentar la fuerza muscular en los ancianos, ya que posee un gran potencial, debido principalmente a su fácil utilización y al breve periodo de tiempo necesario para cada sesión de entrenamiento. Además se ha convirtido en una herramienta idónea para emplear en la población mayor, en personas con movilidad reducida, o en sujetos con una baja condición física. Es por esto que ha ido ganando gran atención y esta siendo ampliamente utilizada.

Sin embargo, debido a la reciente incorporación de las vibraciones en el área del entrenamiento físico, aún no existen pautas contrastadas de protocolos de ejercicios con sus intensidades y tiempos de duración bien establecidas. A pesar de esto, el uso del entrenamiento de vibraciones (a frecuencias y amplitudes adecuadas) se ha relacionado con cambios favorables en los niveles hormonales, fuerza, potencia, masa muscular, activación mioeléctrica, capacidad de salto, densidad mineral ósea y equilibrio, entre otros. Por tanto, el entrenamiento de vibraciones resulta de gran utilidad no solo en el ámbito deportivo sino también en el de la salud. Aunque existen evidencias que apoyan los beneficios mencionados anteriormente con un EVCC, no obstante, hasta la fecha no existen estudios que valoren de forma global estos beneficios a nivel de la capacidad funcional de estas personas. Tampoco hay investigaciones que hayan determinado si este tipo de entrenamiento tiene algún efecto sobre la inflamación sistémica que presentan los ancianos.

Considerando lo expuesto, el presente estudio se diseñó con la finalidad de establecer las posibles relaciones existentes entre el EVCC, la capacidad funcional y los marcadores de inflamación a nivel sistémico, en una población de ancianos institucionalizados. Por tanto, los objetivos planteados son los siguientes: 
Introducción y Objetivos

1. Determinar el efecto del EVCC sobre los niveles de Máxima Contracción Voluntaria Isométrica, la función neuromuscular y los niveles de potencia muscular.

2. Constatar el efecto del EVCC sobre la capacidad funcional de los ancianos medida a través de la Batería Senior Fitness Test (SFT), valorando la fuerza, la resistencia aeróbica, la flexibilidad y el equilibrio dinámico.

3. Evaluar el papel del EVCC sobre diversos marcadores de inflamación. 
2. Antecedentes 


\subsection{ENVEJECIMIENTO}

\subsubsection{Envejecimiento de la población}

El termino "adulto mayor" incluye a las personas mayores de 65 años, o bien a sujetos entre 50 y 64 años con una condición clínica significativa o una limitación física que afecte su movilidad, a su condición física o nivel de actividad física; Por tanto, este término abarca tanto al espectro etario como al de las capacidades fisiológicas de cada sujeto (Skinner, 2005).

Esta clasificación clarifica la idea de que la edad fisiológica y la cronológica no siempre son coincidentes. De esta forma, como sujetos con igual edad cronológica pueden diferir dramáticamente en su respuesta frente a una sesión de ejercicio, siendo muy difícil distinguir los efectos del envejecimiento por causas fisiológicas, por falta de actividad física o por causa de una enfermedad (ACSM, 2009a).

La segunda Asamblea Mundial sobre el envejecimiento organizada por las Naciones Unidas, presentó sólidos fundamentos demográficos sobre este tema, señalándose cuatro conclusiones fundamentales, considerando el periodo comprendido entre 1950 y 2050, respecto al problema del envejecimiento de la población:

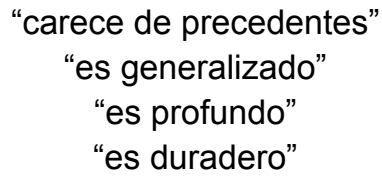

Sobre la primera conclusión, se cree que para el 2050, por primera vez en la historia, la población mayor a 60 años superará a la de los jóvenes; segundo, es un problema generalizado, abarcando tanto a hombres como a mujeres; tercero, es un problema profundo desde el punto de vista económico, social y político; y por último, 
es un problema duradero, ya que desde el siglo $X X$ ha sido visible este incremento (UN, 2002) (Esquema 1).

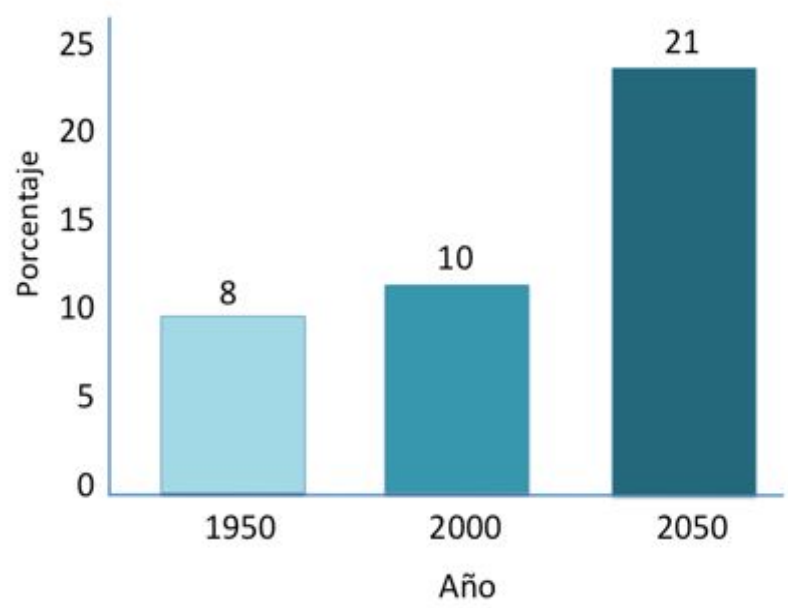

Esquema 1. Incremento porcentual de la población adulta mayor desde el año 1950 al 2050. Extraido de UN, 2002.

\subsubsection{Caso de España}

España, al igual que otros países desarrollados, acarrea un grave problema en su demografía, debido a que el porcentaje de su población mayor de 65 años ha ido aumentando con el paso del tiempo, incrementándose de un $13,8 \%$ en 1991 , a un $16,8 \%$ en 2010 (INE, 2010a).

Desde el año 2001, el número de personas mayores comenzó a ser superior al de niños de 0 a 14 años. Lo que provocaría que la tasa de dependencia se elevaría a casi el doble en el año 2049 (INE, 2010b). Todo esto puede generar un fuerte impacto sanitario y en los servicios sociales, debido al mayor grado de soledad, discapacidad, dependencia y morbilidad en la población (Carbonell et al., 
2009); Incrementando además la descompensación entre la población trabajadora y la población jubilada. Esto obliga de alguna manera, a dirigir el esfuerzo científico y sanitario no sólo a tratar las diversas enfermedades que se asocian a la vejez, sino también, a promover un envejecimiento saludable (Carbonell et al., 2009).

\subsubsection{Adultos mayores institucionalizados}

Los ancianos institucionalizados son pacientes de alto riesgo. Gottesman y Bourestom en 1974, describieron que los ancianos residentes prácticamente no hacen ningún tipo de actividad física durante el día, siendo confirmado estos datos por estudios más recientes (Król-Zielinska et al., 2011). Los niveles de actividad física disminuyen drásticamente una vez que estas personas ingresan en estos centros (Ruuskanen y Parkatti, 1995; Schmid et al., 2003) no cumpliendo con las recomendaciones mínimas de actividad física para esta población (Włodarek y Kołota, 2009).

Diversos estudios han demostrado grandes diferencias en el nivel de actividad física, equilibrio, fuerza del tren inferior, flexibilidad (Schroeder et al., 1998), velocidad al caminar (Cunningham et al., 1993), y habilidad motora (Król-Zielinska et al., 2011), entre mayores que viven y no viven institucionalizados, siendo más sanos y con una mejor capacidad funcional los ancianos que no viven en estas instituciones (Noro y Aro, 1997).

Si se considera que la pérdida de la movilidad funcional está asociada con una elevada tasa de mortalidad entre pacientes institucionalizados, y que la evidencia científica indica que esta pérdida en la funcionalidad física es debido solo parcialmente al proceso de envejecimiento, y que en mayor medida es debida a la pérdida de los niveles de actividad física (Rikli y Jones, 2001; Bastone et al., 2004; 
Król-Zielinska et al., 2011), fomentar la práctica de ejercicio físico e incrementar la capacidad funcional de estas personas se hace fundamental para mejorar su calidad y expectativas de vida.

\subsection{INVOLUCIÓN FISIOLÓGICA DEBIDA AL ENVEJECIMIENTO}

El envejecimiento es un proceso fisiológico tremendamente influenciable, esto quiere decir, que puede recibir estímulos tanto "negativos" (acelerándolo), o bien, estímulos "positivos" (retardándolo). El envejecimiento en humanos implica una progresiva involución tanto funcional como morfológica que dan como resultado una disminución gradual del rendimiento físico, lo que conduciría a la alteración funcional y a la muerte (Timiras, 1996). Por todo ello, potenciar hábitos saludables como la práctica de ejercicio, seguir una alimentación equilibrada, entre otros, podría de alguna manera ayudar a disminuir la probabilidad de pérdida de la funcionalidad, ayudando además a combatir y prevenir la génesis de diversas enfermedades ligadas con el avance de la edad (Castillo et al., 2005).

A medida que un sujeto envejece, ya sea por efecto de causas fisiológicas naturales, por falta de actividad física, o bien, por causa de alguna enfermedad, su organismo va sufriendo una serie de cambios a nivel fisiológico como en sus cualidades físicas que van afectando su estado de bienestar o de salud (ACSM, 2009a) (Tabla 1). Las cualidades físicas han sido definidas, como un conjunto de atributos o características que la persona posee o adquiere, estando relacionadas con la capacidad de realizar actividad física (Caspersen et al., 1985) (Tabla 2). 


\begin{tabular}{ll}
\hline \multicolumn{1}{c}{ Nivel } & \multicolumn{1}{c}{ Factores } \\
\hline Morfológico & Flexibilidad \\
\hline Muscular & Potencia \\
& Fuerza \\
& Resistencia \\
\hline Motor & Agilidad \\
& Equilibrio \\
& Coordinación \\
& Velocidad de movimientos \\
\hline Cardiorespiratorio & Capacidad de ejercicio submáximo \\
& Potencia aeróbica máxima \\
\hline
\end{tabular}

Tabla 1. Componentes de la aptitud física relacionados con la salud. Modificado de Bouchard et al., 2007.

El envejecimiento se caracteriza por una pérdida de las cualidades físicas, con el consiguiente deterioro funcional. A medida que avanza la edad se produce una pérdida de fuerza en las piernas, siendo ésta mucho mayor que la que se produce en los brazos. La capacidad aeróbica disminuye y la flexibilidad experimenta una reducción progresiva. En personas mayores los trastornos del equilibrio son comunes, viéndose alterada la marcha. La masa libre de grasa disminuye conforme aumenta la edad, y además, la masa grasa tiende a incrementarse (Carbonell et al., 2009). 


\begin{tabular}{ll}
\hline \multicolumn{1}{c}{ Orientadas al Deporte } & \multicolumn{1}{c}{ Orientadas a la Salud } \\
\hline $\begin{array}{l}\text { Agilidad: Capacidad de cambiar de } \\
\text { posición del cuerpo en el espacio con } \\
\text { velocidad y precisión. }\end{array}$ & $\begin{array}{l}\text { Resistencia cardiovascular: } \\
\text { Capacidad del sistema respiratorio y } \\
\text { circulatorio en suplir de oxígeno al } \\
\text { organismo durante una actividad }\end{array}$ \\
$\begin{array}{l}\text { Coordinación: Capacidad de utilizar } \\
\text { física sostenida. }\end{array}$ \\
$\begin{array}{l}\text { los sentidos como la vista y la } \\
\text { cuerpo para la realización de tareas }\end{array}$ & $\begin{array}{l}\text { Composición corporal: Cantidad } \\
\text { relativa de masa muscular, grasa, } \\
\text { sin problemas y con precisión. }\end{array}$ \\
$\begin{array}{l}\text { Equilibrio: Mantener el balance } \\
\text { mientras se esta de pie o en } \\
\text { movimiento. }\end{array}$ & $\begin{array}{l}\text { Fuerza muscular: Capacidad de los } \\
\text { músculos de ejercer fuerza. }\end{array}$ \\
$\begin{array}{l}\text { Potencia: Capacidad o ritmo al cual } \\
\text { uno puede realizar un trabajo. }\end{array}$ & $\begin{array}{l}\text { Resistencia muscular: Capacidad de } \\
\text { los músculos de trabajar } \\
\text { continuamente sin fatiga. }\end{array}$ \\
$\begin{array}{l}\text { Tiempo de reacción: El tiempo } \\
\text { trascurrido entre un estímulo y el } \\
\text { comienzo de la reacción. }\end{array}$ & $\begin{array}{l}\text { Flexibilidad: Rango de movimiento } \\
\text { de una articulación. }\end{array}$ \\
$\begin{array}{l}\text { Velocidad: Capacidad de realizar un } \\
\text { movimiento dentro de un periodo } \\
\text { corto de tiempo. }\end{array}$ & \\
\hline
\end{tabular}

Tabla 2. Cualidades físicas relacionadas con las habilidades orientadas al deporte y a la salud. Extraído de ACSM, 2009a y modificado de Caspersen et al., 1985.

\subsubsection{Cambios en la fuerza de las extremidades superiores e inferiores}

La fuerza es una cualidad física que se ve perjudicada a medida que se avanza en edad, siendo notable a partir de los 50 años, afectando casi dos veces más a los hombres que a las mujeres (Goodpaster et al., 2006). Esta pérdida de 
masa y de potencia muscular, es inevitable y es parte del proceso natural del envejecimiento, denominado por Rosenberg en 1989 como "Sarcopenia".

Pero éste no es el único factor que contribuye a la pérdida de la fuerza conforme avanza la edad (lannuzzi-Sucich et al., 2002), también afectan otros como el nivel inicial de fuerza, los bajos niveles de actividad física, estados patológicos de salud, o las caídas (Lexell et al., 1988; López-Chicharro y Fernández-Vaquero, 2006; Goodpaster et al., 2006; Forrest et al., 2007; Beliaeff et al., 2008; Sayer et al., 2008).

No existe un umbral de pérdida de masa muscular a partir del cual se pueda categorizar a una persona de sarcopénica (Serra, 2006). Además el punto a partir del cual aparece la dependencia varía en función de los factores mencionados anteriormente. Por tanto, mantener la fuerza y la resistencia muscular, debería tener especial consideración para evitar que aparezcan problemas como dolores de espalda, osteoporosis o la imposibilidad de realizar actividades tan habituales como levantarse de una silla, subir escaleras o caminar de manera independiente (LópezChicharro y Fernández-Vaquero, 2006) (Esquema 2).

Bajos niveles de masa muscular, un bajo nivel de fuerza muscular y un alto nivel de grasa se asocian con limitaciones en la movilidad (Visser et al., 2005). Además, varios estudios confirman que un bajo nivel de fuerza muscular, tanto de piernas como de presión manual, es un fuerte e independiente factor predictivo de mortalidad en personas mayores (Newman et al., 2006; Ruiz et al., 2008), de ahí, que deba ser la fuerza una cualidad preferente para incluir en el diseño de programas de intervención para este tipo de población (Carbonell et al., 2009). 


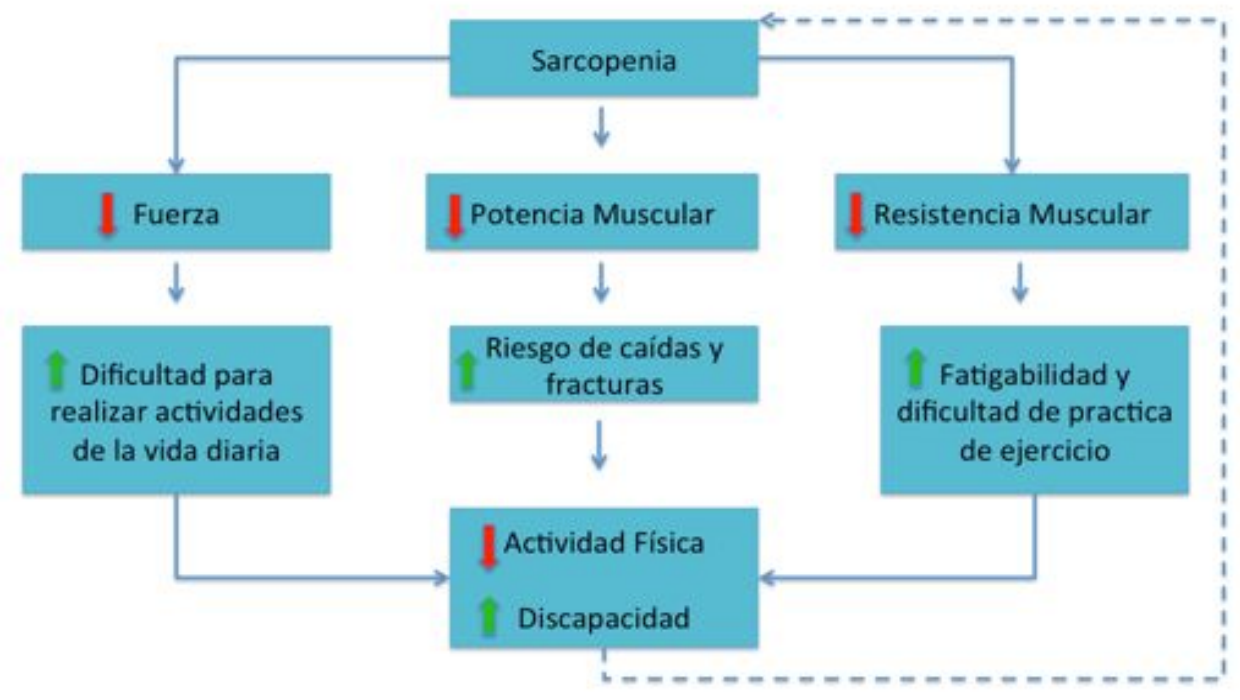

Esquema 2. Efectos de la sarcopenia en las cualidades físicas y su repercusión en la salud. Extraido de López-Chicharro y Fernández-Vaquero, 2006.

Respecto a la fuerza del tren superior se puede señalar que el nivel medio de descenso en hombres es de 2,8\% al año (Forest et al., 2005), mientras que en las mujeres es de 2,4\% al año (Forest et al., 2007). A partir de los 64 años la fuerza del tren superior experimenta su mayor caída (Carbonell et al., 2009).

Sobre la fuerza del tren inferior, la perdida de fuerza y potencia en las piernas es más acentuada que la que se produce en los brazos (Landers et al., 2001). En hombres y mujeres entre 70 a 79 años de edad, el ritmo de pérdida anual de fuerza de piernas es de $3,4 \%$ y $2,6 \%$ respectivamente, siendo el ritmo medio de pérdida de masa muscular anual de 1\% (Goodpaster et al., 2006). Además, cabe destacar dos periodos con mayores descensos en la fuerza, uno a partir de los 44 años y la otro a partir de los 64 años (Carbonell et al., 2009). 


\subsubsection{Disminución de la activación neuromuscular}

La fuerza muscular se relaciona con la función de movilidad en los adultos mayores, y la producción de energía eficaz, la cual requiere de una rápida activación neuromuscular (Clark et al., 2011).

Con el envejecimiento, se producen cambios tanto cualitativos como cuantitativos en las unidades motoras. Las investigaciones en esta área confluyen en que el aumento de la edad se acompaña de una reducción en el número de unidades motoras funcionales (López-Chicharro y Fernández-Vaquero, 2006), y que esto se traduce en una disminución de la activación neuromuscular relacionada con la edad, que puede contribuir al déficit de fuerza muscular y la función de movilidad (Clark et al., 2011).

La electromiografía de superficie es una de las técnicas más utilizadas en la actualidad para cuantificar la actividad neuromuscular, debido principalmente a que es una técnica no invasiva. Existe consenso en que, los cambios descritos a nivel neuromuscular están directamente relacionados con la pérdida de la movilidad y función, afectando la independencia y la calidad de vida de los ancianos (Lauretani et al., 2003).

De los estudios que han observado aumentos de fuerza en sujetos mayores desentrenados y que han sido sometidos a un programa para el aumento de esta cualidad, destacan que la ganancia de fuerza durante las primeras semanas puede atribuirse, en gran parte, al mayor número de unidades motoras activadas y/o aumento de la frecuencia de descarga en los músculos agonistas entrenados, aumentando de esta manera la magnitud de la señal electromiográfica (Komi, 1986; Häkkinen et al., 1996; Sale, 1988). 


\subsubsection{Capacidad aeróbica}

El primer estudio sobre envejecimiento y actividad física fue realizado por Sid Robinson a finales de 1930 , el cual demostró que el consumo de oxígeno máximo desciende de forma estable en personas con un nivel de actividad física normal desde los 25 a los 75 años de edad.

El envejecimiento provoca además un descenso del rendimiento cardiovascular debido a la disminución del gasto cardiaco máximo, el descenso del volumen sistólico y de la frecuencia cardiaca máxima, justificando de esta manera, el deterioro del volumen minuto (Hollenberg et al., 2006; López-Chicharro y FernándezVaquero, 2006).

El ritmo de descenso del $\mathrm{VO}_{2 m a ́ x}$ no es constante a lo largo de la vida, pero se acelera marcadamente con cada década, siendo este efecto mayor en los varones que en las mujeres (Hollenberg et al., 2006; Stathokostas et al., 2004), aunque estas diferencias entre sexos tienden a disiparse en las últimas décadas de vida (Weiss et al., 2006). Un $10 \%$ por década ha sido establecido como la disminución media del $\mathrm{VO}_{2 \text { máx }}$ (Hawkins y Wisswell, 2003) y en personas sobre los 55 años de edad, la pérdida sería de un $14,7 \%$ en varones y de un $7 \%$ en mujeres.

Al igual que la fuerza, la capacidad aeróbica debería trabajarse de manera prioritaria, debido a que su descenso tiene sustanciales implicaciones en la independencia funcional y la calidad de vida de las personas mayores (Fleg et al., 2005). 


\subsubsection{Flexibilidad}

La flexibilidad es una cualidad que experimenta una reducción progresiva, pero no lineal, conforme avanza la edad. Desde edades tempranas los valores medios de flexibilidad tienden a ser mayores en mujeres que en varones, acentuándose esta diferencia a partir de los 60 años, siendo la mujer entre un 20 y un $40 \%$ más flexible que el varón. Es importante señalar que el efecto del género sobre la flexibilidad es más débil en comparación con la edad (Araujo, 2008; Doriot y Wang, 2006).

El efecto de la edad sobre cada articulación y rango de movimiento parece ser específico. Según diversos autores (Grimston et al., 1993; Doriot y Wang, 2006; Troke et al., 2005; Sforza et al., 2002), al ser comparado el rango máximo de movimiento del tren superior entre jóvenes y personas mayores, se puede observar que:

- La perdida máxima se encuentra en la articulación del cuello (40\%).

- La flexión lateral del tronco disminuye un $33 \%$.

- La articulación del hombro disminuye un $25 \%$ en la flexión y un $10 \%$ en la aducción.

- No se observaron diferencias en la articulación del codo y muñeca.

- La articulación de la rodilla tiende a disminuir conforme aumenta la edad.

- En la columna lumbar, la flexión frontal y la flexión lateral disminuyen un 45 y un $48 \%$ respectivamente.

\subsubsection{Equilibrio}

Diversas actividades del día a día como estar de pie, inclinarse, subir escaleras, caminar y responder a perturbaciones externas pueden disminuir su rendimiento en las personas mayores a causa de los trastornos del equilibrio. Éste se ve afectado por la progresiva pérdida de la función sensorio-motora, tales como 
déficit en la propiocepción, la visión, el sentido vestibular, la función muscular y el tiempo de reacción, lo que aumenta considerablemente el riesgo de caídas en esta población (Sturnieks et al., 2008; Baloh et al., 2003).

Al aplicar un test de equilibrio estático de dificultad creciente, las personas mayores muestran mayores variaciones del centro de presiones, del desplazamiento de las articulaciones, así como en la actividad electromiográfica, a la de adultos jóvenes (Amiridis et al., 2003). También los jóvenes son capaces de mantener el equilibrio sin ayuda de la visión por más tiempo que los ancianos (48,2 segundos comparado a 4,5 segundos, respectivamente) (Madhavan y Shields., 2005).

El sentido dinámico de la posición disminuye con la edad (Madhavan y Shields, 2005), lo que altera la velocidad y el patrón de ejecución al subir un escalón (Benedetti et al., 2007), y modifica el patrón de la locomoción, con reducción de la velocidad de la marcha (Lauretani et al., 2003; Hollman et al., 2007; Laufer, 2005; Samson et al., 2001), lo que implica graves riesgos de que el pie contacte con obstáculos (Sparrow et al., 2006). Todas estas ocasiones de peligro se incrementan si se les añade la realización de una tarea cognitiva (Hollman et al., 2007).

\subsubsection{Composición corporal}

La masa libre de grasa permanece estable durante las primeras décadas de la vida en ambos sexos, pero después, experimenta un descenso acelerado que empieza alrededor de los 50 años en los varones y de los 60 años en las mujeres (Fleg et al., 2005; Janssen et al., 2000; Rossi et al., 2008; Fantin et al., 2007). Así también se ha demostrado un aumento de la masa grasa conforme aumenta la edad (Coin et al., 2008). Además, se ha encontrado una clara asociación entre la edad o un bajo nivel de condición física y parámetros de composición corporal. Las 
personas mayores son más propensas a tener una baja masa libre de grasa, y una alta o muy alta masa grasa corporal (Kyle et al., 2004).

Los hombres pasan de un porcentaje de grasa de $15 \%$ a los 17 años a un $28 \%$ a los 60 años de edad. Las mujeres por su parte, aumentan su porcentaje de grasa desde un $25 \%$ a los 17 años, hasta un $39 \%$ a los 60 años. Varias son las causas de estos efectos, como por ejemplo, la pérdida de masa libre de grasa y el descenso de los niveles de actividad física (López-Chicharro y Fernández-Vaquero, 2006).

Considerando el caso de España, un estudio realizado por Andreyeva et al., (2007), revela que España tiene la prevalencia más alta de obesidad en Europa, entre varones $(20,2 \%)$ y mujeres $(25,6 \%)$ mayores de 50 años.

\subsection{ENVEJECIMIENTO, INFLAMACIÓN Y ENFERMEDADES}

El envejecimiento es un proceso deletéreo, que acontece en todo ser vivo con el tiempo, como expresión de la interacción entre el programa genético del individuo y su medio ambiente (Mora, 1999). Dificil es decir cuándo comienza el envejecimiento, pero desde un punto de vista estrictamente cronológico se podría indicar que este comienza entre los 60 y los 65 años de edad (López-Chicharro y Fernández-Vaquero, 2006).

El envejecimiento es un mecanismo fundamental de protección, que garantiza la preservación y el progreso de las especies a través de la modificación, trasmisión y la mejora del material genético (Ostojić et al., 2009). No existe una única teoría que explique el envejecimeinto (Toussaint, 1993; Troen, 2003), fundamentalmente por la naturaleza multicausal de esta. Justamente es por esta razón que no se puede desechar ninguna de las teorías al respecto. 
El envejecimiento va acompañado de una declinación fisiológica y el incremento de enfermedades relacionadas con la edad (Chung et al., 2009). Siendo el resultado del balance entre el daño y la reparación, lo que va deteriorando poco a poco las vías de reparación, que incluyen proteólisis, daño al ADN y daño al metabolismo respiratorio mitocondrial, entre otros, explicando la alta tasa de aparición de enfermedades a medida que avanzan los años (Haigis y Yankner, 2010).

Aunque se han propuesto varias teorías para poder aclarar las causas fundamentales del envejecimiento (Dice, 1993), hoy en día es ampliamente aceptada la hipótesis de "estrés oxidativo" (Yu y Yang, 1996), la que incluye la importancia del rol antioxidante (Chung et al., 2009). Kim et al., (2002), proponen el término "inflamación molecular", para enfatizar la importancia de los mecanismos moleculares en el desarrollo de la inflamación durante el envejecimiento. Por su parte, se ha demostrado que éste grado de inflamación está relacionada con una diversidad de enfermedades, tales como, el síndrome metabólico, sarcopenia, demencia, aterosclerosis, cáncer y osteoporosis, siendo denominada por McGeer y McGeer en 1995, como "enfermedades inflamatorias" (Chung et al. 2009).

Por lo tanto, es necesario un adecuado balance tanto en el estado redox como en el sistema de tamponamiento ácido-base del organismo, para una óptima homeostasis celular (Esquema 3). Cambios en este balance tienen un importante impacto sobre las vías de señalización y actividad transcripcional, elevando la producción de moléculas proinflamatorias como ciclooxigenasa 2 , IL-1 $\beta$, IL-6, TNF- $\alpha$ y oxido nítrico sintetasa isoforma inducible, derivadas del incremento en la producción de radicales libres (Kim et al., 2002; Chung et al., 2006). También factores de transcripción como el nuclear KB (Kim et al., 2002), juegan un importante rol en el proceso de envejecimiento y la generación de enfermedades (Chung et al., 2006). 


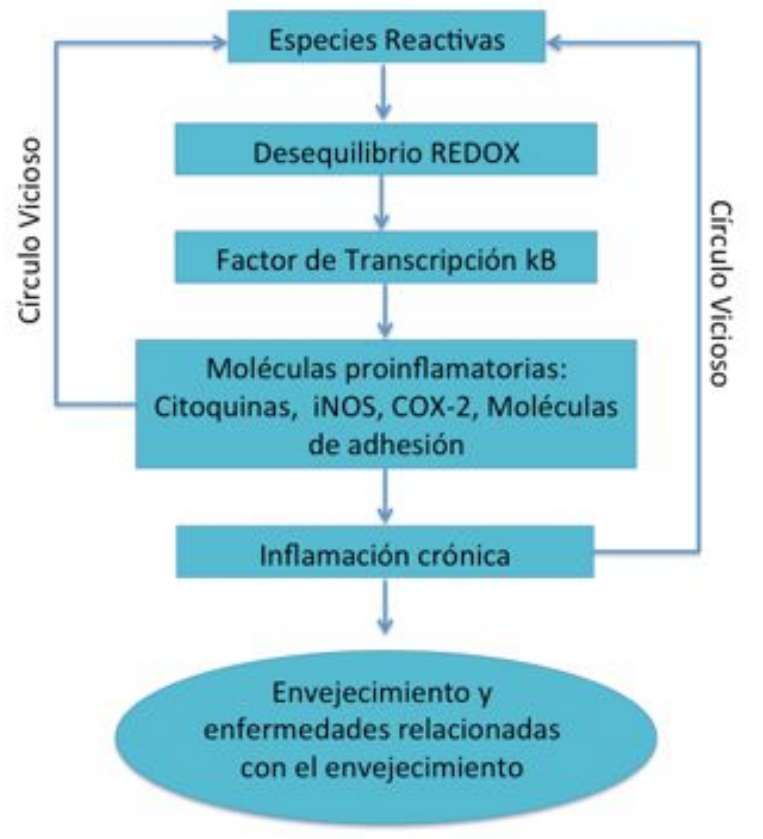

Esquema 3. Principal vía molecular proinflamatoria involucrada en el envejecimiento y enfermedades relacionadas con la edad. Extraído de Chung et al., 2009.

Si a lo anteriormente mencionado, sumamos hábitos de vida poco saludable como el tabaco, mala alimentación y la inactividad física, nos encontraremos en un ambiente precursor de enfermedades, principalmente no transmisibles o crónicas, las que dan cuenta de casi el $60 \%$ de las muertes en el mundo (WHO, 2002).

\subsubsection{Inflamación crónica}

La inflamación crónica es un importante factor de riesgo asociado a la génesis de diversas enfermedades relacionadas con el envejecimiento, el cual conlleva una sobrerregulación en la síntesis de moléculas proinflamatorias como TNF- $\alpha$, IL-1 $1 \beta$, IL6 , proteína $\mathrm{C}$ reactiva, NF-kB, entre otras, debido supuestamente a dos factores 
principales (Beenakker et al., 2010; Chung et al., 2009). El primero, es por un desequilibrio en las reacciones oxido-reducción encargadas de amortiguar las sustancias oxidantes en nuestro organismo, induciendo estrés oxidativo (Chung et al., 2009), y el segundo, por una desregulación en el sistema inmune (Brod, 2000).

Enfermedades como aterosclerosis, artritis, cáncer, diabetes, osteoporosis, demencia, enfermedad vascular, obesidad y síndrome metabólico pueden estar relacionadas con los cambios acontecidos durante el envejecimiento normal, a causa del estado crónico de inflamación (Yu y Chung, 2006). Una sobreproducción y baja amortiguación de sustancias reactivas durante el envejecimiento, son unas de las mayores causas en la activación de macrófagos por el sistema inmune, que podrían llegar al acortamiento de la vida útil de las personas mayores (Brod, 2000). Debemos sumar también que los macrófagos se infiltran en el tejido adiposo, aumentando sustancialmente la secreción de citoquinas proinflamatorias, incrementando aún más el estado de inflamación general del organismo (Weisberg et al., 2003; Pickup y Crook, 1998).

La obesidad cumple un importante rol en este proceso de inflamación (Robinson et al., 2007). Durante el envejecimiento se va redistribuyendo la grasa corporal (Yaffe, 2007), acumulándose principalmente en la zona visceral (Di Stefano et al., 2007; Weiss, 2007). De esta manera los adipocitos y macrófagos van secretando una gran cantidad de citoquinas, causando una inflamación de carácter sistémico que incrementa la vulnerabilidad a la génesis de muchas enfermedades relacionadas con la edad (Pou et al., 2007) (Esquema 4). 


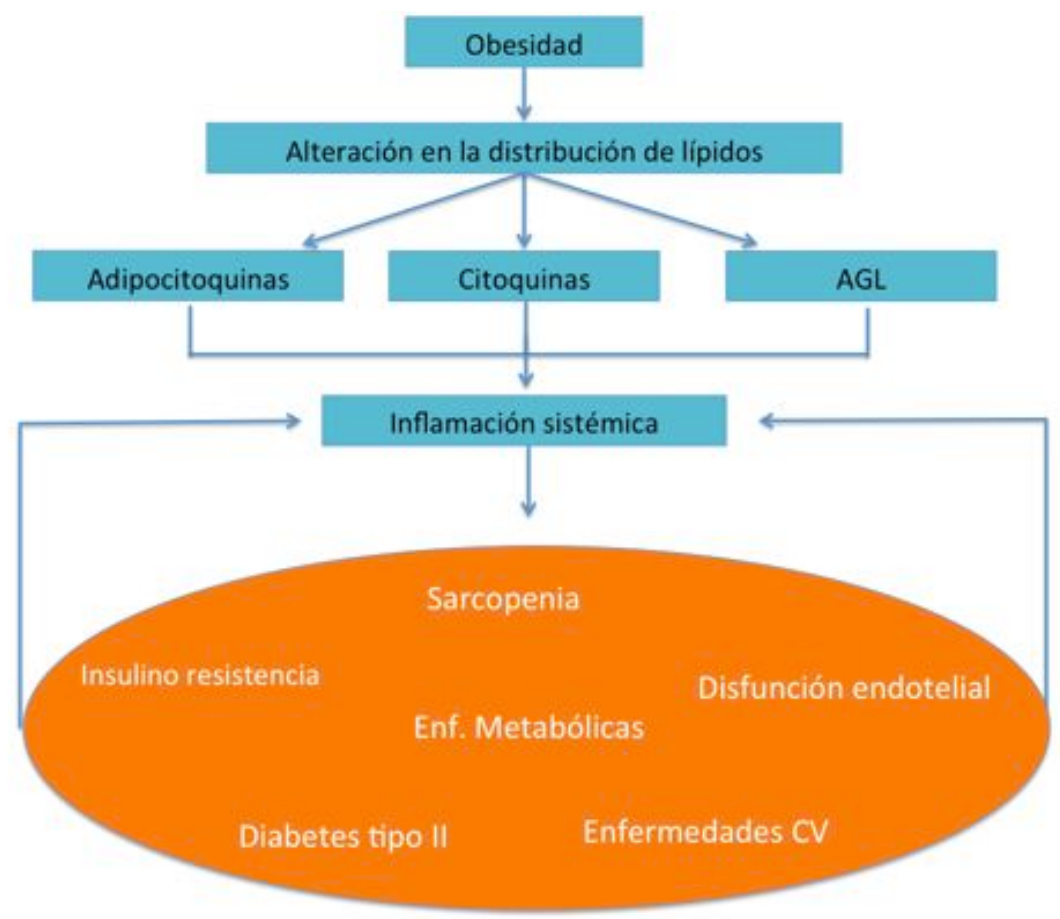

Esquema 4. Efectos metabólicos de la obesidad. Extraído y modificado de Weiss, 2007.

Estos factores inflamatorios ayudan a la progresión del estado catabólico (Roth et al., 2006), elevando la degeneración muscular relacionada con la edad. Varios estudios han señalado que la acumulación de lípidos parece desempeñar un importante papel en el proceso inflamatorio y posiblemente en la aparición de la sarcopenia, resistencia a la insulina, diabetes mellitus tipo 2, disfunción endotelial y enfermedad cardiovascular, entre otras (Weiss, 2007; Roth et al., 2006).

Lo anteriormente expuesto es bastante interesante, ya que debemos considerar que la prevalencia de obesidad (IMC igual o mayor de $30 \mathrm{~kg} / \mathrm{m} 2$ ) en la 
población mayor de 65 años en España se estima en un 35\% (Aranceta-Bartrina et al., 2005).

Para prevenir y tratar el incremento del proceso oxidativo, el cual se encuentra presente en la población adulta mayor y que como se mencionó anteriormente, se produce a causa del envejecimiento normal, surgen dos alternativas no farmacológicas: la restricción calórica y el ejercicio físico. Ambos han demostrado grandes beneficios al mejorar el estado antioxidante del organismo, suprimiendo además factores de transcripción involucrados en el proceso inflamatorio, y de esta manera enlentecer la evolución de las enfermedades crónicas, potenciarndo una mayor expectativa de vida, con una menor declinación funcional en los ancianos (Chung et al., 2009) (Esquema 5).

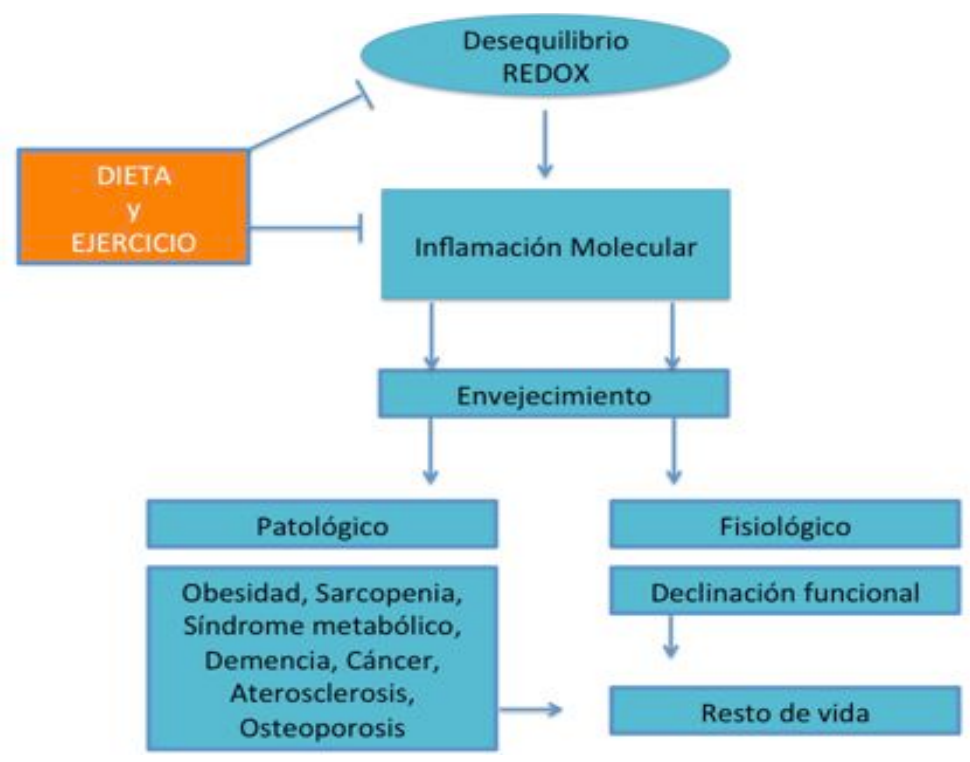

Esquema 5. Rol de la inflamación en los procesos fisiopatológicos y la posible acción de la restricción calórica y del ejercicio. Extraido de Chung et al., 2009. 


\subsection{ACTIVIDAD FÍSICA Y ENVEJECIMIENTO}

Se entiende por actividad física, cualquier movimiento del cuerpo producido por los músculos esqueléticos que tiene como resultado elevar el gasto energético por encima de sus valores basales (Caspersen et al., 1985). Si una actividad física se realiza repetidamente con un propósito determinado, como por ejemplo, el de mejorar algún componente de la condición física se denomina ejercicio físico (Caspersen et al., 1985). El aumento de la actividad física diaria como del ejercicio físico, generan un incremento en la condición física del sujeto. Ésta es entendida como la habilidad para realizar un trabajo físico diario con rigor y efectividad, retardando la aparición de la fatiga, buscando además, la máxima eficacia y evitando las lesiones (Blázquez, 1990).

Tanto la actividad como la condición física han sido relacionadas con la salud y la longevidad desde tiempos ancestrales. Ya en China alrededor del año 2.500 a. de C. se estimó el primer uso de ejercicio con la finalidad de promover la salud. Los médicos Griegos (V-IV a. de C.) implantaron la tradición de mantener la salud a través de un correcto "régimen", que incluía una correcta combinación entre alimentación y ejercicio. Posteriormente Hipócrates (460-370 a. de C.), llamado el padre de la medicina moderna, escribió... "todas las partes del cuerpo que tienen una función, si son usadas con moderación y realizan las funciones a las que están destinadas, llegarán a ser saludables, desarrollándose y envejeciendo lentamente, pero si se dejan inactivas, estas generaran enfermedades, tendrán un crecimiento defectuoso y envejecerán con rapidez" (Hardman y Stensel., 2009).

Es así como en la década del 50, un memorable estudio realizado por Morris et al., (1953), demostró la incidencia de ataque al corazón entre los conductores sedentarios comparado con los activos corta boletos de los típicos autobuses de dos pisos de la ciudad de Londres (Hardman y Stensel., 2009) (Imagen 1). 


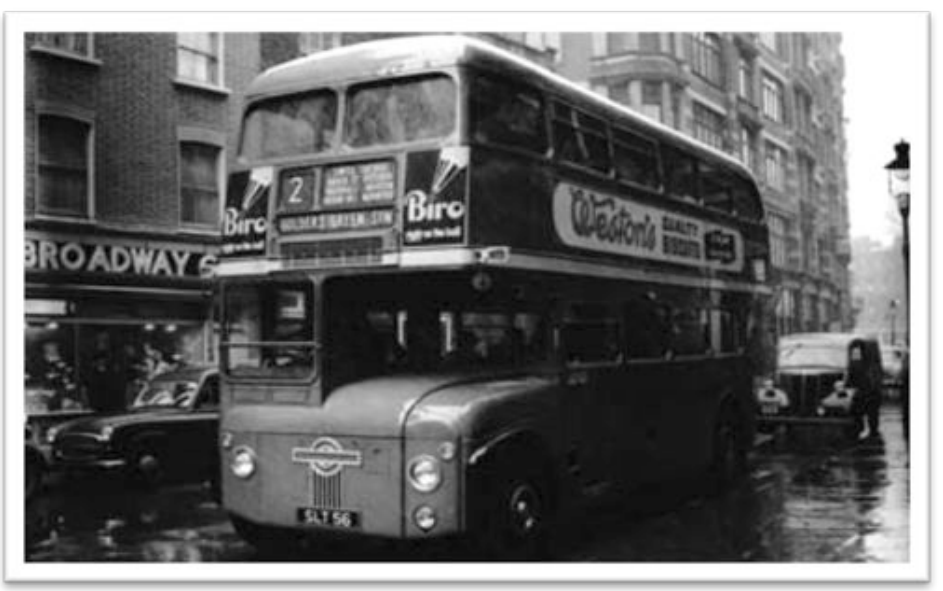

Imagen 1. Bus de dos pisos de Londres, utilizado en el estudio de Jeremy Morris en la década de los 50 .

Ya en los 80 Bortz (1982) y Hollosky (1983), se planteaban diversas interrogantes al respecto. El primero de estos autores especulaba si los marcadores de envejecimiento, de esa época, no eran más bien el resultado de un estilo de vida sedentario, en lugar del proceso mismo de envejecimiento. Esta información nos ayuda a entender lo reciente que es la investigación, en actividad física, en la población adulta mayor. Desde entonces ha surgido una abundante cantidad de artículos científicos que han esclarecido la función que cumple el ejercicio físico en el envejecimiento y su rol protector en una diversidad de enfermedades, siendo la actividad física, recomendada para todo tipo de personas (Evans, 2002).

Hoy en día existe una abundante y contundente evidencia que demuestra los beneficios de la actividad física en la población adulta mayor. Se ha demostrado, por ejemplo, que enlentece los cambios fisiológicos que perjudican la capacidad de realizar ejercicio, optimiza los cambios acontecidos en la composición corporal relacionados con el envejecimiento, beneficia el bienestar tanto psicológico como 
cognitivo, controla las enfermedades crónicas, reduce el riesgo de discapacidad física e incrementa la longevidad (Singh et al., 2002).

\subsubsection{Inactividad física, capacidad funcional e independencia}

El funcionamiento independiente es definido como un estado caracterizado por la capacidad de realizar actividades diarias con vigor, la demostración de rasgos y capacidades que se asocian con un bajo riesgo de desarrollo prematuro de condiciones y enfermedades hipocinéticas (Bouchard et al., 2007), y la capacidad de vivir con independencia en la comunidad, recibiendo poca o ninguna ayuda de los demás (WHO, 2002).

Si bien, se conoce que la práctica sistemática de actividad física conlleva una amplia gama de beneficios en la salud de las personas, el grupo etario de adultos mayores es el menos activo físicamente de todos los grupos de la población (ACSM, 2009a). Este nivel de inactividad física acontecido a medida que avanza la edad, quizás no se deba directamente al mismo proceso de envejecimiento, sino más bien a la falta de estímulos de la masa muscular que les impediría a estas personas realizar sus actividades diarias con normalidad (Reid et at., 2008).

Cabe mencionar que existe una estrecha relación entre el estilo de vida sedentario, con la presencia de eventualidades que pueden generar debilidad y discapacidad en la vejez (U.S. Department of Health and Human Services, 1996). Es así como en octogenarios y nonagenarios, el paso de la capacidad a la incapacidad física, no solo se relaciona con una patología en particular, sino además con el grado de inactividad física de estas personas (Di Pietro, 1996; Morey et al., 2008).

La pérdida de la condición física, va generando que paulatinamente actividades básicas como caminar, sentarse y ponerse de pie, subir escaleras, 
cargar artículos o bolsas con alimento, entre otras, se conviertan en actividades de elevado requerimiento funcional, acercándose a sus niveles de capacidad máxima. Por lo señalado anteriormente, un envejecimiento poco activo, disminuye la autonomía e independencia, la calidad de vida y la esperanza de vida saludable en estas personas (WHO, 2002).

La capacidad funcional, involucra la capacidad respiratoria, la fuerza muscular y el rendimiento cardiovascular, cualidades que aumentan durante la infancia, llegando a su máximo en los primeros años de la edad adulta y que posteriormente van declinando con los años (Kalache y Kickbusch, 1997).

Pero esta disminución en la capacidad funcional, puede llegar a ser muy abrupta si no se entregan los estímulos idóneos para que los sistemas orgánicos puedan mantener, o bien potenciar, el desarrollo de la capacidad funcional. Dentro de estos estímulos influye fuertemente el estilo de vida que lleve la persona (tabaco, alcohol, drogas, tipo de alimentación y nivel de actividad física, entre otros), por lo tanto, no sería ilógico llegar a pensar en una discapacidad temprana considerando lo anteriormente mencionado en una sociedad tan inactiva como la actual (Esquema 6).

Este fenómeno podría ser revertido si se tomaran las medidas necesarias y de manera oportuna, tanto a nivel individual como a nivel de la salud pública (WHO, 2002). En esta misma línea, la relación entre un estilo de vida inactivo y la perdida de la capacidad funcional esta demostrada en una gran cantidad de estudios longitudinales (Stuck et al., 1999). Por ejemplo, se ha señalado que los ancianos que caminan más de 1.609 metros a la semana, tienen menos probabilidad de limitación funcional, lo que sin duda mejora la independencia de estas personas (Miller et al., 2000). 


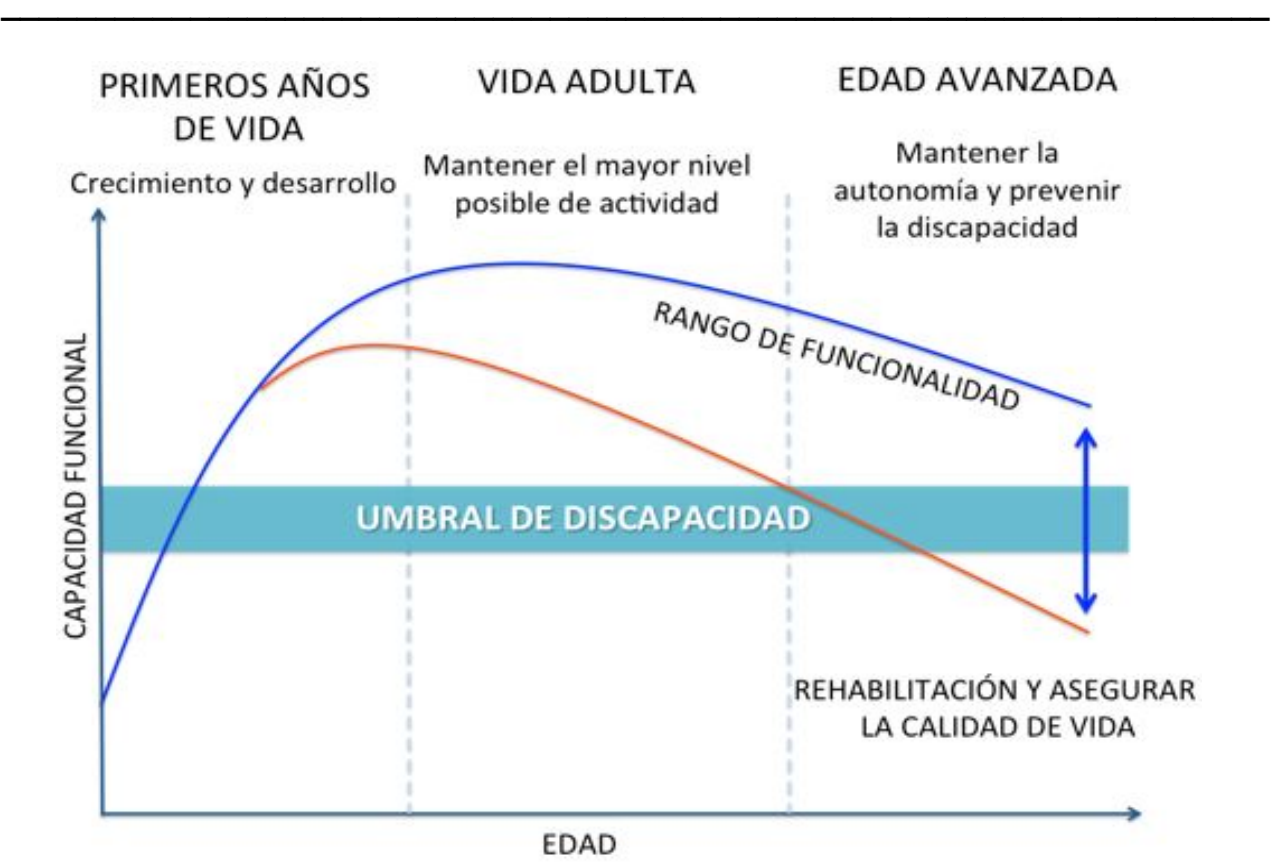

Esquema 6. Estrategia global para un envejecimiento saludable. Extraido de WHO, 2002.

\subsubsection{Senior Fitness Test}

Identificar tempranamente las variaciones en los parámetros físicos es fundamental para generar correcciones en el estilo de vida, o bien, promover la participación en un programa de entrenamiento físico, ya sea para prevenir ó para reducir el deterioro funcional. Los efectos negativos sobre la capacidad funcional podrían limitar la realización de actividades tan básicas como caminar y subir escaleras, y pueden además elevar el riesgo de caídas y discapacidad física (Jones y Rikli, 2002). 
Mantener o tratar de reducir la pérdida funcional en los ancianos, tratando de conservar ciertos parámetros físicos, son fundamentales para resguardar tanto su integridad física como para mantener su nivel de independencia (Tabla 3).

\begin{tabular}{ccc}
\hline Parámetros físicos & Función & Actividad objetivo \\
\hline $\begin{array}{c}\text { Fuerza y resistencia } \\
\text { muscular }\end{array}$ & Caminar & Cuidado personal \\
Resistencia aeróbica & Subir escaleras & Ir de compras \\
Flexibilidad & Levantarse de una silla & Tareas del hogar \\
$\begin{array}{c}\text { Capacidad motora } \\
\text { Potencia }\end{array}$ & $\begin{array}{c}\text { Levantar y alcanzar } \\
\text { objetos }\end{array}$ & Tareas en el jardín \\
$\begin{array}{c}\text { Velocidad/Agilidad } \\
\text { Balance }\end{array}$ & Flexionarse & Deportes \\
Composición corporal & Trotar /Correr & Viajar \\
\hline Deterioro físico & Limitación funcional & $\begin{array}{c}\text { Reducida } \\
\text { capacidad/discapacidad }\end{array}$ \\
\hline
\end{tabular}

Tabla 3. Cuadro que asocia los parámetros físico-fisiológicos necesarios con la función y las actividades diarias. Extraido de Jones y Rikli, 2002.

El Senior Fitness Test es una batería de pruebas que tienen como finalidad evaluar la capacidad física funcional en ancianos (Tabla 4). Esta batería creada por Rikli y Jones en el 2001 tiene ciertos criterios que benefician su aplicación en comparación a otros test para evaluar las cualidades físicas en la población mayor. Tiene fiabilidad y validez científica, es fácil y posible de aplicar y representa los principales componentes de la condición física funcional asociados a la movilidad. Tiene además, aceptable test-retest, refleja los cambios debidos a la edad y al nivel 
de condición física. Es capaz de valorar el rendimiento en una escala continua, así todos los participantes tienen alguna puntuación. Además es fácil de administrar y puntuar. Requiere poco espacio y material y es segura de realizar sin previo informe médico para la mayoría de las personas (Garatachea, 2007).

Aunque el SFT es fácil y sencillo de aplicar, esto no confiere que se deban considerar todos los resguardos pertinentes a la hora de evaluar a los ancianos. De esta manera seguir el protocolo estandarizado propuesto por las autoras de esta batería, garantizaría su fiabilidad.

\section{Test}

Objetivo

- Test sentarse y levantarse de la silla durante 30 segundos

- Flexiones de codo con peso

- Sentado alcanzar pie extendido

- Alcanzar las manos tras la espalda

- Ida y vuelta

- Test de 6 minutos paseo

- Evaluar la fuerza del tren inferior

- Evaluar la fuerza del tren superior

- Valorar la flexibilidad del tren inferior

- Valorar la flexibilidad del tren superior

- Valorar el equilibrio dinámico y la agilidad

- Valorar la resistencia aeróbica

Tabla 4. Objetivo de cada una de las pruebas de la batería SFT.

A pesar de que el SFT es seguro para la mayoría de las personas, incluso sin una revisión médica previa, siempre existirán algunas excepciones. Por ejemplo quedarán fuera de la evaluación las personas que se les haya desaconsejado realizar ejercicio físico, hayan tenido insuficiencia cardiaca congestiva, tengan dolores articulares, dolor de pecho, vértigos, angina durante el ejercicio o bien quienes tengan hipertensión no controlada. 
Para asegurar que cada test se realice al máximo rendimiento y se cumplan todas las medidas de seguridad, es importante que se sigan una serie de instrucciones el día anterior a la evaluación.

- No realizar actividad física intensa uno o dos días antes de la valoración.

- Evitar beber alcohol en exceso el día anterior.

- Comer ligero por lo menos una hora antes de la prueba.

- Ropa ligera y calzado apropiado para realizar las pruebas.

- Informar al evaluador de cualquier circunstancia que pudiera afectar tanto al resultado de las pruebas como a su salud (dolor de cabeza, haber dormido mal, catarro, entre otros).

Para mejorar la exactitud de la evaluación, es recomendable realizar una prueba de familiarización con la finalidad de que las personas conozcan los test y puedan determinar su ritmo en cada prueba.

\subsubsection{Beneficios de una vida activa}

El envejecimiento activo se define como, "el proceso de optimizar las oportunidades de salud, participación y seguridad, con el fin de mejorar la calidad de vida a medida que las personas envejecen" (WHO, 2002).

En este contexto, el estado de salud, se define como el equilibrio entre la dimensión física, psíquica y la social de la persona (Meléndez, 2000), por tanto este estado es más bien la combinación de todas estas dimensiones y no solo el desarrollo de una de estas de manera aislada, abarcando una variada serie de parámetros, desde los más amplios como lo son la sensación subjetiva de bienestar o satisfacción por la vida, a los más concretos como lo son el estado de ánimo y el nivel de ansiedad (Bañuelos, 1996), y el nivel de actividad física (Aoyagi y Shephard, 2010). 
La práctica de actividad física ha demostrado una serie importante de beneficios en los adultos mayores, lo que ayuda a retrasar y minimizar las consecuencias negativas que conlleva el envejecimiento (Guadalupe-Grau et al., 2009; Garatachea et al., 2009; Birch et al., 2005).

Si bien existe una fuerte evidencia sobre los beneficios de la actividad física regular en este tipo de población (Singh et al., 2002), la intensidad y cantidad óptima para alcanzar estos beneficios aun siguen siendo poco claras (Aoyagi y Shephard, 2010). Esto se debe a que el tipo de actividad seleccionada, la intensidad y la duración, entre otras, afectan en mayor o en menor medida a las cualidades físicas.

El ejercicio físico, practicado de manera regular y de la forma apropiada, es la mejor herramienta disponible en la actualidad para fomentar la salud y el bienestar de la persona. Cuando se realiza de manera adecuada (lo que no es tarea fácil), los beneficios del ejercicio se producen siempre, independientemente de la edad, del estado de salud y de la condición física de la persona (Castillo, 2007).

Las investigaciones realizadas en este campo indican que además de aumentar la capacidad muscular, el ejercicio físico o el aumento de la actividad física pueden ayudar a mejorar la resistencia aeróbica, el equilibrio, la movilidad articular, la flexibilidad, agilidad, velocidad al caminar y la coordinación física en general. También tienen diversos efectos favorables sobre el metabolismo, la regulación de la presión arterial y la prevención del aumento excesivo de peso. Además, hay pruebas epidemiológicas de que el ejercicio vigoroso practicado de manera regular está relacionado con un menor riesgo de enfermedades cardiovasculares, diabetes, osteoporosis y algunas formas de cáncer (WHO, 1998) (Esquema 7). 


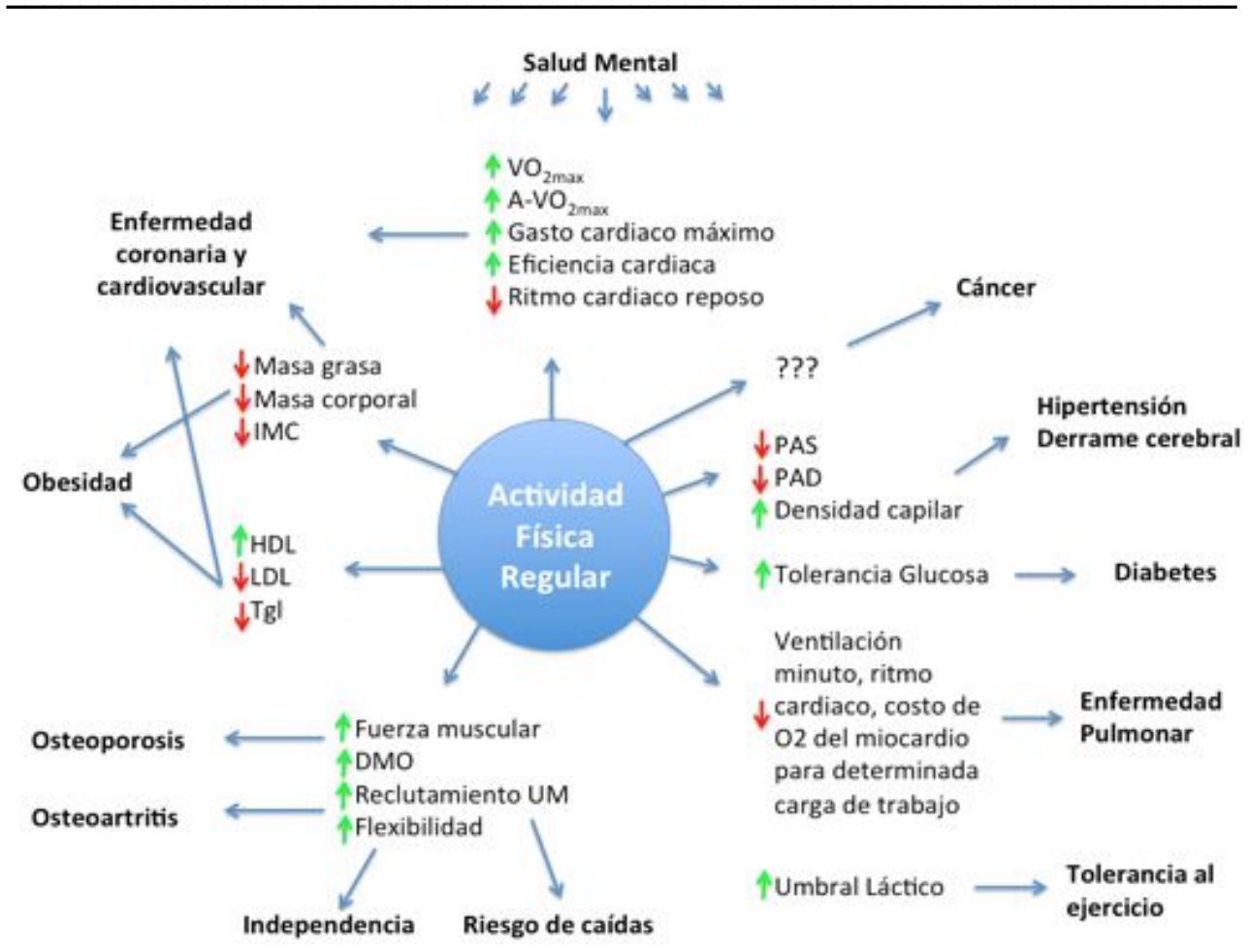

Esquema 7. Beneficios de la actividad física regular. Extraido de Birch et al., 2005.

\subsubsection{Recomendaciones de actividad física en la población de adultos mayores}

Las recomendaciones de actividad física para la población adulta mayor, son divididas entre las actividades de carácter aeróbicas y las actividades orientadas a mejorar la salud muscular y ósea (Nelson, et al., 2007) (Esquemas 8 y 9). Para su diseño y desarrollo, de estas actividades deben considerarse el estado biológico de los ancianos (Carbonell et al., 2009). 


\section{Antecedentes}

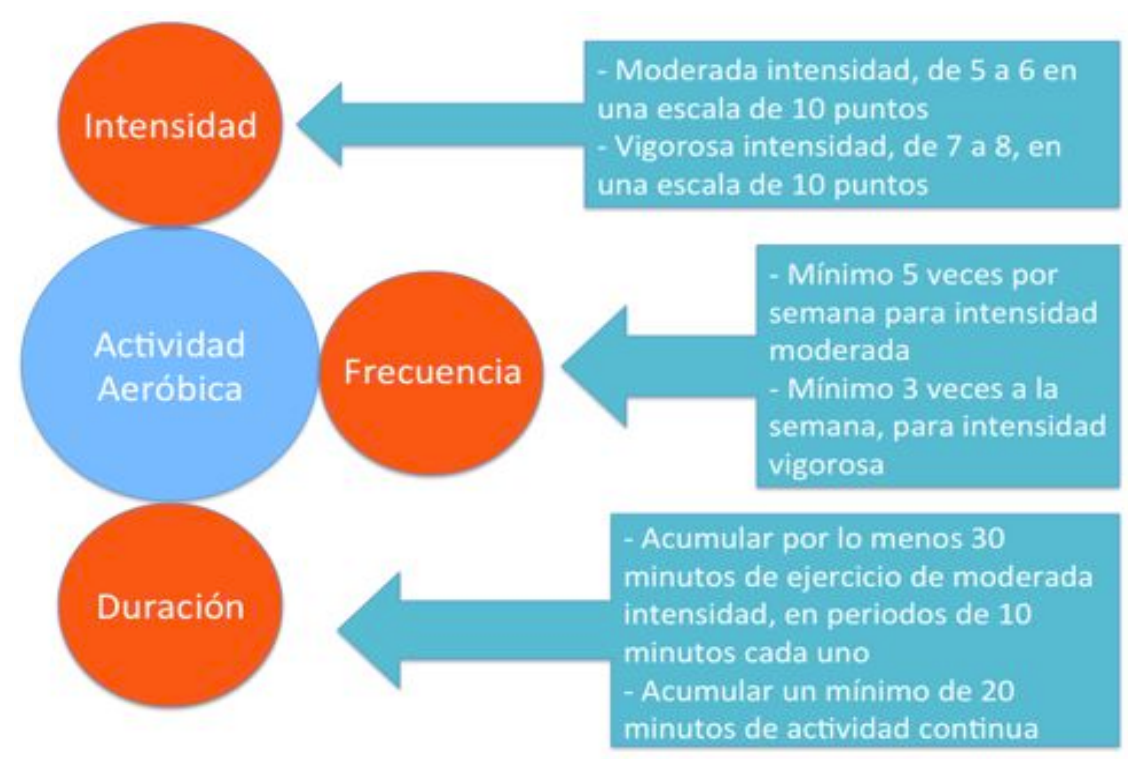

Esquema 8. Recomendaciones de actividad física aeróbica en la población adulta mayor. Adaptado de Nelson et al., 2007.

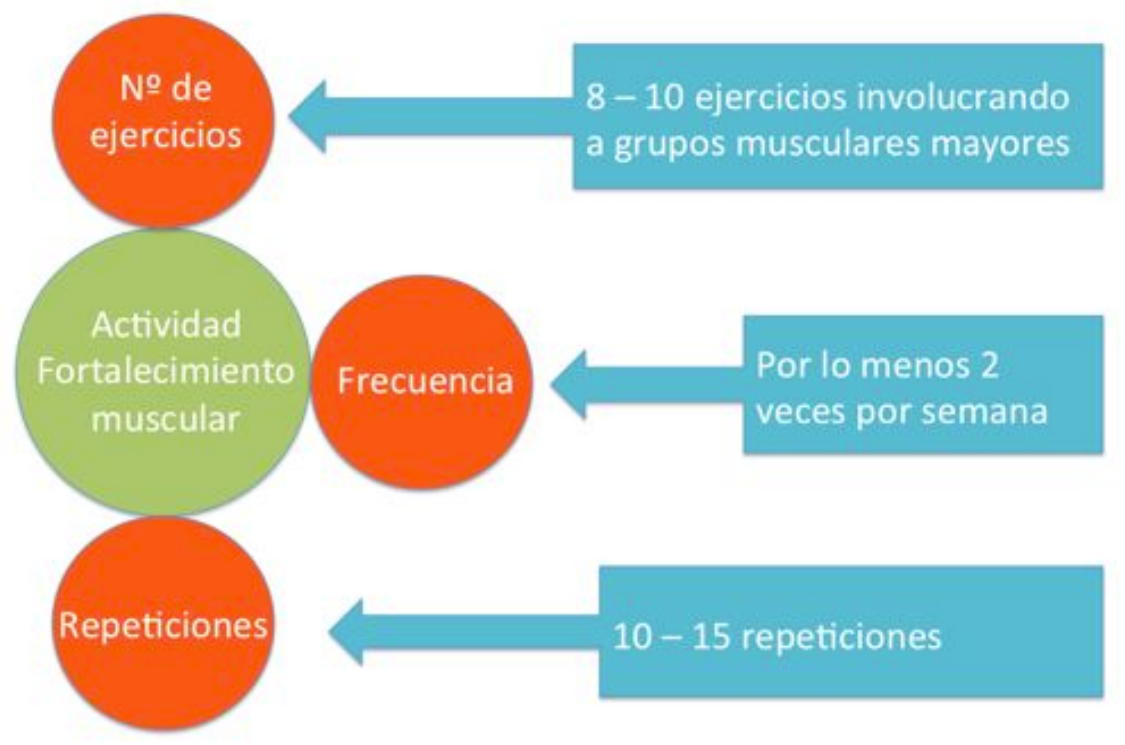

Esquema 9. Recomendaciones de actividad de fortalecimiento muscular en la población adulta mayor. Adaptado de Nelson et al., 2007. 
En 1995, la U.S. Centres for Disease Control and Prevention (CDC) y la American College of Sports Medicine (ACSM) entregaron recomendaciones sobre la dosificación de ejercicio físico con el fin de generar mejoras en el estado de salud de la población (Pate, et al., 1995). En las recomendaciones actuales a diferencia de las de 1995, se aprecia un notable énfasis en la contribución de las actividades de intensidad vigorosa y la inclusión de actividades para la ganancia de fuerza muscular y salud ósea (Oja et al., 2010).

\subsubsection{Tipos de ejercicio físico}

Un plan de entrenamiento, posee elementos básicos necesarios para la correcta prescripción de una sesión de entrenamiento. Dentro de estos elementos se encuentran, el tipo de ejercicio a utilizar, el volumen (duración, distancia o numero de repeticiones), la intensidad (carga o velocidad de ejecución), la frecuencia (número de sesiones diarias, semanales, mensuales), la densidad (trabajo por tiempo de pausa) y la progresión del ejercicio de entrenamiento (Weineck, 2005); adaptando cada uno de estos elementos a las necesidades y objetivos de cada persona.

Respecto a los tipos de ejercicios utilizados durante la sesión, estos dependerán de los objetivos planteados, de la condición física del sujeto, de la especificidad del entrenamiento, de la cualidad o cualidades físicas a desarrollar, entre otras. En la población adulta mayor se deben considerar además otras variables como su nivel de debilidad muscular, operaciones, enfermedades, problemas articulares, entre otras. Es por esto que las actividades de bajo impacto son las más recomendadas en esta población, como por ejemplo caminar, ciclismo o bicicleta estática, máquinas elípticas, Tai Chi, bailar, entre otras. Claro que si la persona no tiene grandes limitaciones, podría realizar otras actividades como por 
ejemplo, jogging, ejercicios con pesos libres o máquinas, esquí, step, aerobics, remo, entre otras.

Todos estos tipos de ejercicios aplicados en el entrenamiento pueden ser utilizados con la finalidad de mejorar las diversas cualidades físicas relacionadas con la salud en la población adulta mayor. Aumentar la fuerza y resistencia muscular, la resistencia cardiovascular, la flexibilidad y mejorar la composición corporal son fundamentales a la hora de elevar la calidad de vida y de prevenir la progresión o desarrollo de enfermedades (ACSM, 2009a).

\subsubsection{Ejercicio Aeróbico}

El ejercicio aeróbico ha sido el más estudiado en esta área, en comparación a otras modalidades de entrenamiento. Así, diversos estudios epidemiológicos han asociado el ejercicio aeróbico a una mejora en el perfil de los factores de riesgo cardiovascular, una mayor movilidad y capacidad para llevar a cabo las funciones diarias de cada persona, menor tasa de fracturas y mayor densidad mineral ósea, mejores habilidades cognitivas y un menor grado de depresión (Márquez et al., 2006). Entonces la implantación de programas de actividad física con la finalidad de generar protección frente a las limitaciones funcionales acontecidas con el proceso natural de envejecimiento, sería una herramienta efectiva para reducir las enfermedades de nuestra población (Wheat et al., 1996).

\subsubsection{Ejercicio de Resistencia}

El ejercicio de resistencia es una estrategia frecuentemente utilizada, que ha recibido gran atención en investigaciones recientes. El entrenamiento de resistencia progresivo es el tipo de entrenamiento de fuerza más utilizado. Existe amplia evidencia que indica que este tipo de trabajo es efectivo para incrementar la fuerza 
en los adultos mayores (Latham et al., 2003; Steib et al., 2010), incluso en ancianos débiles y de muy avanzada edad (Fiatarone et al., 1994; Seynnes et al., 2004).

Los beneficios del ejercicio de resistencia en los ancianos son variados, entre estos, mejora la fuerza y potencia muscular (Portegijs et al., 2008), incrementa el volumen muscular (ACSM, 2009a), mejora aspectos funcionales como subir escaleras, levantarse de una silla y velocidad de marcha (Steib et al., 2010). De hecho, las personas que participan regularmente en programas de ejercicio aeróbico o de sobrecarga tienen menos probabilidad de desarrollar obesidad, perfiles lipídicos anormales, enfermedad arteriocoronaria, diabetes tipo II y sarcopenia (Booth et al., 2000), siendo en cierta medida, muchos factores perjudiciales del envejecimiento sobre la función musculo-esquelético, mitigados por el entrenamiento de resistencia (Reeves et al., 2006).

\subsection{EJERCICIO VIBRATORIO}

Las vibraciones no son ajenas a nuestra vida diaria, podemos apreciarlas en los diversos medios de transporte, en el mundo laboral y en el deporte, entre otros. Se ha propuesto la exposición a breves periodos de vibración de cuerpo completo, como un método alternativo de intervención no farmacológico, relacionado con mejoras en el sistema músculo-esquelético, principalmente en el incremento de la fuerza de las extremidades inferiores y de la parte baja de la espalda. Se ha demostrado también grandes beneficios a nivel hormonal y neuromuscular, lo que sugiere su eficacia como herramienta terapéutica, de prevención de la sarcopenia y posiblemente de la osteoporosis sobre todo en adultos mayores, personas con movilidad reducida y personas con fuerza muscular disminuida (por ejemplo, pacientes de edad avanzada o personas enfermas) (Santin-Medeiros y Garatachea, 2010). No obstante, son necesarias más investigaciones en esta área para sugerir 
una metodología más segura de intervención en los diferentes tipos de poblaciones (Cardinale y Pope, 2003; Cardinale y Wakeling, 2005; Cardinale y Rittweger, 2006).

El trabajo vibratorio esta siendo cada vez más utilizado, convirtiéndose en una herramienta útil tanto en el deporte como en centros de rehabilitación (Verschueren et al., 2004; Bogaerts et al., 2009). El uso de la plataforma vibratoria (Imagen 2) representa la forma más común en el ámbito del entrenamiento a través de vibraciones. El estímulo vibratorio, en el sentido físico, es una fuerza oscilatoria, donde la energía mecánica es trasmitida desde un emisor, que envía la vibración (plataforma), hasta un receptor, que recibe el efecto en un punto en particular (por ejemplo, tendón), el cuerpo completo, o bien solo una parte de este (por ejemplo, una pierna) (Rittweger, 2010).

Griffin (1996), definieron los distintos tipos de ondas vibratorias: sinusoidal, multisinusoidal, transitoria, choque, estacionaria aleatoria y no estacionaria aleatoria. La mayoría de las vibraciones utilizadas para el ejercicio de vibraciones son de tipo sinusoidal (Garatachea y González-Gallego, 2010), lo que supone una transición cíclica entre contracciones musculares excéntricas y concéntricas (Rittweger, 2010) (Esquema 10). 


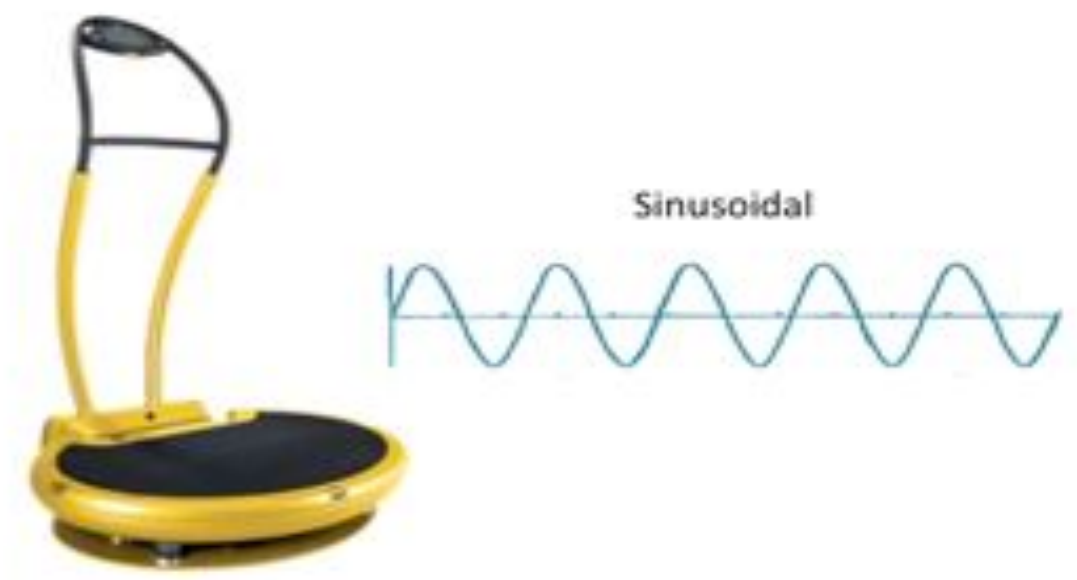

Imagen 2. Plataforma de vibración utilizada en este estudio, modelo Fitvibe Excel. (Fitvibe, GymnaUniphy NV, Bilzen, Bélgica) y tipo de onda vibratoria producida.

Desde el punto de vista mecánico, la vibración de la plataforma constituye un estímulo para el cuerpo humano. Existen básicamente dos tipos de plataformas vibratorias: las que vibran en una dirección predominantemente vertical (plataforma vertical), y las plataformas que vibran a través de la rotación de un eje horizontal (plataforma horizontal u oscilante) (Abercromby et al., 2007). En el presente estudio se ha empleado la plataforma que genera la vibración de forma vertical. 


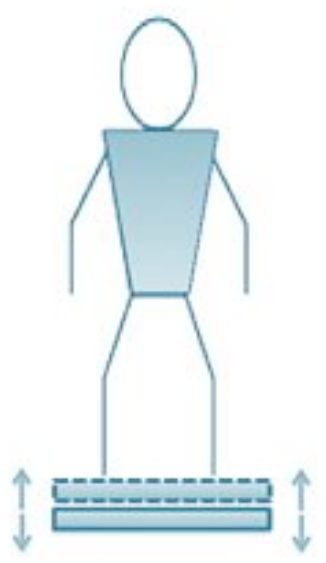

Plataforma:

Estimulo:
Vertical

Sincrónico

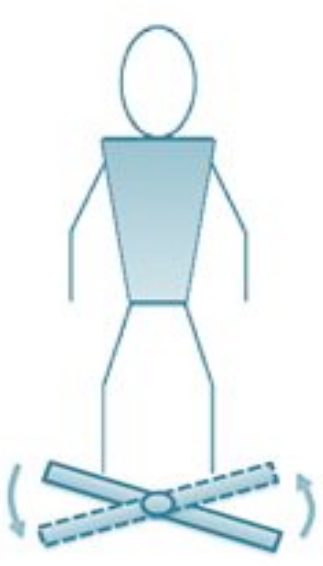

Oscilante

Alterno

Esquema 10. Tipos de plataformas vibratorias y tipo de transferencia del estimulo.

La transferencia de energía al cuerpo de la persona, depende del tipo de plataforma utilizada. Así, las plataformas de tipo oscilantes reciben la energía de manera alternada, primero un pie y luego el otro, por lo que este tipo de plataforma introduce un componente giratorio en la columna lumbar. Las de tipo verticales reciben la energía en los dos pies a la vez y de forma sincrónica, por lo cual, tanto la contracción como la relajación de las piernas se producen al mismo tiempo, dirigiendo la aceleración hacia el tronco de forma lineal (Rittweger, 2010).

\subsubsection{Variables que influyen en las vibraciones}

Las variables que influyen en la vibración son clasificadas en extrínsecas (aquellas independientes del cuerpo humano, como por ejemplo frecuencia, duración o amplitud, entre otras) y variables intrínsecas (aquellas dependientes del cuerpo 
humano, como por ejemplo peso corporal, posición y orientación del cuerpo, edad sexo o nivel de condición física, entre otras) (Fajardo y Ferliú, 2004) (Esquema 11).

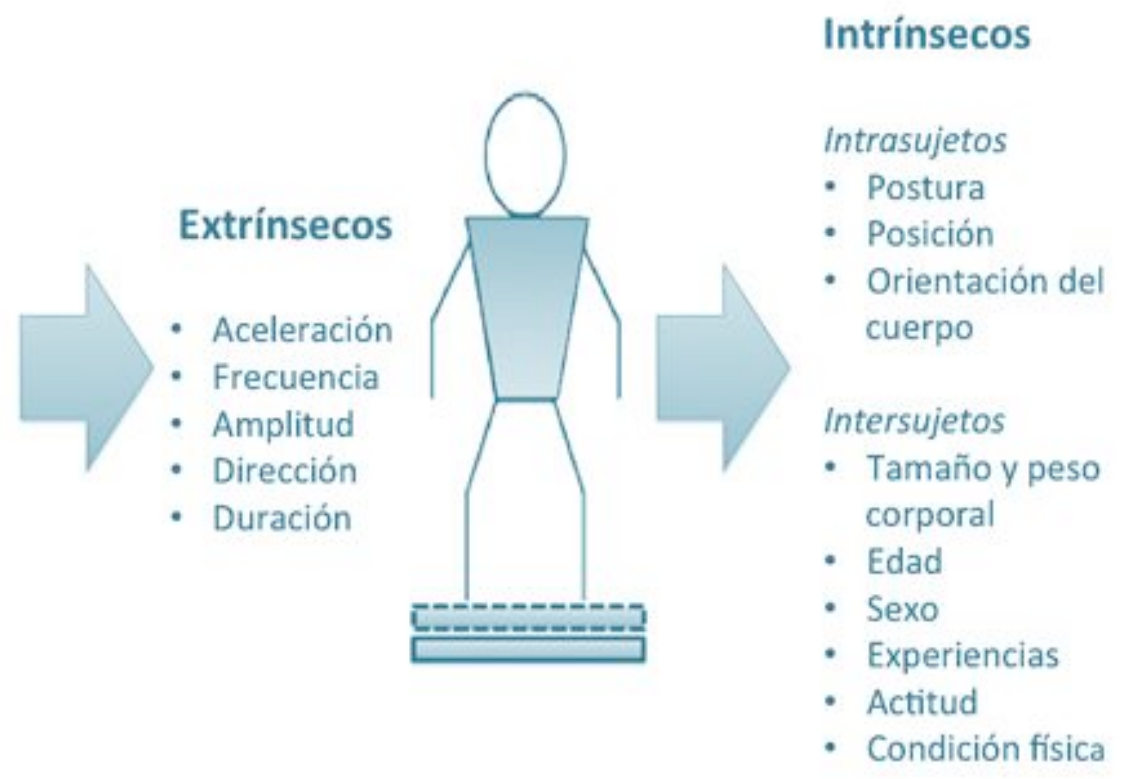

Esquema 11. Tipo de variables que influyen en el ejercicio sobre plataforma de vibraciones.

Según Totosy de Zepetnek et al., (2009), los factores más influyentes y que definen las respuestas del sistema músculo-esquelético cuando se trabaja con plataformas vibratorias son seis:

- La dirección de la vibración (vertical u horizontal). Las tres direcciones principales del espacio a las que la vibración se aplica corresponden a los ejes antero-posterior $(\mathrm{x})$, lateral $(\mathrm{y})$ y vertical $(\mathrm{z})$.

- La frecuencia de vibración. Número de ciclos de movimiento sinusoidal por segundo expresados mediante la unidad $\mathrm{Hz}$. 
- La amplitud de la vibración. Es el desplazamiento que se realiza en cada ciclo de movimiento sinusoidal, expresado en $\mathrm{mm}$.

- La aceleración (en unidades gravitacionales, $\mathrm{m} / \mathrm{s}^{2}$ ). Es la unidad con la que se expresa la vibración.

- El tiempo de exposición a la vibración. La mayoría de estudios se centran en duraciones entre 4 y 20 minutos.

- La posición tomada sobre la plataforma. Postura corporal, posición y orientación del cuerpo (sentado, de pie, recostado, etc.).

\subsubsection{Cuantificación de la carga de trabajo}

Una de las maneras más utilizadas de cuantificar la carga de entrenamiento de la plataforma vibratoria es mediante la variable: "aceleración" (Esquema 12). De esta manera podemos definir la carga de trabajo mediante la interacción de la frecuencia que varía generalmente entre 15 y $60 \mathrm{~Hz}$, y la amplitud que varía entre 1 y $10 \mathrm{~mm}$. Por tanto, la aceleración generada puede llegar a los $15 \mathrm{~g}$ ( $1 \mathrm{~g}=$ fuerza de gravedad o $9,8 \mathrm{~m} / \mathrm{s}^{2}$ ), demostrando la gran variedad de combinaciones en el diseño de los protocolos (Santin-Medeiros y Garatachea, 2010).

\section{A: amplitud (m) / (1/ frecuencia $(\mathrm{Hz}))^{2}$}

Siendo: A, la aceleración en $\mathrm{m} / \mathrm{s}^{2}$, la amplitud expresada en metros y la frecuencia en $\mathrm{Hz}$. 


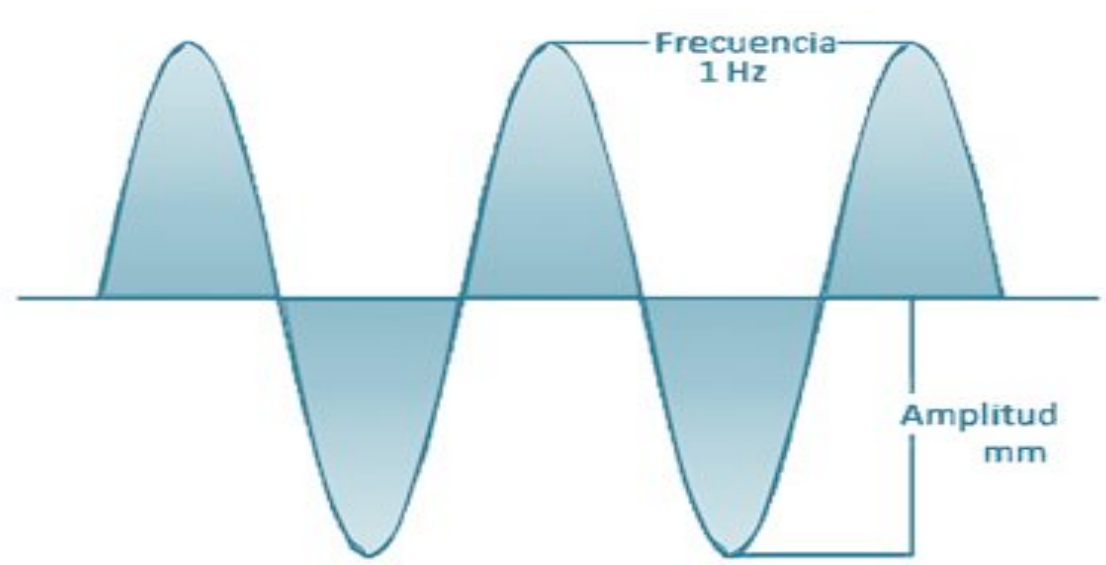

Esquema 12. Parámetros que definen la aceleración: frecuencia y amplitud.

\subsubsection{Beneficios del EVCC en la población adulta mayor}

A pesar de su reciente inclusión en el mercado, la utilización de los ejercicios vibratorios han descrito una diversidad de resultados interesantes en relación a su utilización como parte de una terapia física (Rittweger et al., 2002) o de un entrenamiento deportivo (Bosco et al., 1998; Mester et al., 1999; Martí et al., 2003), aunque cabe señalar que, la gran mayoría de estos artículos han sido aplicados en poblaciones de jóvenes y adultos. En general estos estudios reflejan ciertos beneficios como por ejemplo:

- Aumento de la fuerza en un corto espacio de tiempo.

- Mejora de la flexibilidad, movilidad y equilibrio.

- Reducción o eliminación del dolor.

- Entrenamiento del sistema neuromuscular.

- Mejora de la circulación sanguínea en las extremidades del cuerpo.

- Reconstrucción del hueso. 
En función de cómo se aplique el estímulo vibratorio (considerando las variables intrínsecas o extrínsecas mencionadas anteriormente), éste puede producir un u otro efecto sobre el organismo. Un pequeño resumen de las tres revisiones que han concluido los beneficios tanto agudos como crónicos del uso de las plataformas de vibraciones son presentadas en la siguiente tabla 5.

\begin{tabular}{ccc}
\hline Referencia & Revisión & Conclusión \\
\hline $\begin{array}{c}\text { Luo et al., } \\
2005\end{array}$ & $\begin{array}{c}\text { Catorce publicaciones (ocho } \\
\text { de efecto agudo, cinco de } \\
\text { efecto residual y tres de } \\
\text { efectos crónicos) }\end{array}$ & $\begin{array}{c}\text { "el entrenamiento vibratorio podria } \\
\text { tener efectos positivos agudos y } \\
\text { crónicos en el rendimiento } \\
\text { neuromuscular y la formación } \\
\text { muscular" }\end{array}$ \\
\hline $\begin{array}{c}\text { Jordan et al., } \\
2005\end{array}$ & $\begin{array}{c}\text { Catorce estudios (siete de } \\
\text { efectos agudos y siete de } \\
\text { efectos crónicos) }\end{array}$ & $\begin{array}{c}\text { "el entrenamiento de vibraciones } \\
\text { puede servir como una herramienta } \\
\text { para desarrollar la habilidad de fuerza } \\
\text { explosiva en atletas" }\end{array}$ \\
\hline $\begin{array}{c}\text { Cardinale y } \\
\text { Wakeling, } \\
2005\end{array}$ & $\begin{array}{c}\text { Veintitrés estudios (nueve } \\
\text { de efectos agudos y catorce } \\
\text { de efectos crónicos) }\end{array}$ & $\begin{array}{c}\text { "el ejercicio en plataforma de } \\
\text { vibraciones puede ser efectivo para } \\
\text { reducir el proceso de envejecimiento } \\
\text { en las estructuras músculo- } \\
\text { esqueléticas" }\end{array}$ \\
\hline
\end{tabular}

Tabla 5. Beneficios del efecto agudo y crónico del ejercicio de vibraciones.

Existen varios estudios en los últimos años que han aplicado las vibraciones a la población adulta mayor, encontrando una variedad de beneficios que potencian su estado de salud. La mayoría de los beneficios observados se centran en el nivel muscular, esquelético y neuromuscular, lo que conlleva resultados positivos sobre diversos componentes que mejoran la estabilidad, coordinación, fuerza, potencia, velocidad de marcha, amplitud de pasos y velocidad al levantarse de una silla, entre otros (Iwamoto et al., 2004; Marín y Rhea 2010; Santin-Medeiros y Garatachea, 
2010; Kaeding, 2009; Mikhael et al., 2010; Merriman y Jackson, 2009; Totosy de Zepetnek et al., 2009).

\subsubsection{Efectos a nivel neuromuscular y esquelético}

\subsubsection{Efecto a nivel neuromuscular}

Son pocos los estudios que explican cómo los estímulos vibratorios pueden generar estos efectos beneficiosos sobre el sistema neuromuscular (Cardinale y Bosco, 2003; Ronnestad, 2004). Algunos artículos explican que cuando un músculo es sometido a vibraciones, se estimulan las terminaciones primarias del huso muscular (Fibras la, aferentes) que excitan las a-motoneuronas y provocan la contracción de las unidades motoras, resultando finalmente en una contracción tónica del músculo conocida como reflejo tónico vibratorio (Santin-Medeiros y Garatachea, 2010). Además ocurre una modificación del centro gravitatorio mientras se está expuesto a las vibraciones, lo que obliga al individuo a reequilibrarse (Cardinale y Bosco, 2003). En un reciente meta-análisis de Marín y Rhea, (2010), concluyeron que el ejercicio de vibraciones presentaba un buen potencial para mejorar el rendimiento neuromuscular.

El entrenamiento de resistencia ha sido tradicionalmente utilizado para aumentar los niveles de fuerza de los ancianos y de esta manera, reducir los efectos de la sarcopenia (Hunter et al., 2004). Por esta razón, el entrenamiento de vibraciones cada día toma mayor interés, debido al aumento de fuerza que genera, y como consecuencia, por el incremento en la funcionalidad de los adultos mayores (Hunter et al., 2004; Jordan et al., 2005). Esta ganancia de fuerza se cree que deriva principalmente de las adaptaciones neuromusculares más que de la hipertrofia provocada por este tipo de entrenamiento (Rhen et al., 2007). 
Estos beneficios, observados con un EVCC pueden ayudar a revertir la pérdida de masa muscular, ayudando de esta manera a reducir los efectos metabólicos (enfermedades crónicas) y funcionales (dependencia) generados por esta variación en la composición corporal. Ganancias en la fuerza y en la hipertrofia son observados mayormente en sujetos con una baja tasa de fuerza y de masa muscular al comienzo de un programa de intervención con vibraciones (Kaeding, 2009).

\subsubsection{Efecto a nivel esquelético}

El ejercicio vibratorio es una nueva herramienta, que está siendo empleada y testada en diferentes áreas. Una de estas áreas son las terapias para prevenir la osteoporosis, debido a sus beneficiosos efectos sobre la masa ósea (Roelants et al, 2004; Flieger et al., 1998; Rubin et al., 2004; Torvinen et al., 2002a; Fajardo y Ferliú, 2004; Verschueren et al., 2004).

Los posibles mecanismos involucrados en los efectos positivos sobre la masa ósea de las VCC, podrían estar relacionados con los mismos principios del ejercicio aeróbico, el cual activa los osteoblastos mientras reduce la actividad de los osteoclastos. Se hipotetiza que la estimulación mecánica recluta osteoblastos adicionales e incrementa el porcentaje de mineralización superficial, aumentando el rango de formación de hueso y disminuyendo el rango de reabsorción del mismo (Rubin y Lanyon, 1985). No obstante, está claro que la tensión, la magnitud del estímulo y la frecuencia, son factores esenciales a la hora de entrenar con vibraciones. Además este método aumenta la sensibilidad del sistema músculoesquelético por efecto del estímulo mecánico, siendo ésta una de varias posibles vías para influenciar la masa ósea y su estructura (Liu et al., 2011). 


\subsubsection{Beneficios relacionados con la independencia}

El entrenamiento de vibraciones ha demostrado grandes beneficios sobre las cualidades físicas, lo que podría retrasar o bien disminuir los efectos de la dependencia de la población adulto mayor.

El entrenamiento de vibraciones ejerce diversos efectos sobre el organismo, además de los efectos mencionados anteriormente sobre la musculatura y el hueso, podemos describir otros beneficios, como en el equilibrio (Bruyere et al., 2005), en la fuerza de las piernas (Delecluse et al., 2003; Issurin et al., 1994; Issurin y Tenenbaum, 1999; Torvinen et al., 2002a), en el rendimiento muscular (Cardinale y Bosco, 2003), en la terapia de dolores de espalda (Rittweger et al., 2002) y por supuesto en la mejora de la calidad de vida y salud general (Bosco et al., 2000; Delecluse et al., 2003; Kerschan-Schindl et al., 2001; Rittweger et al., 2002; Torvinen et al., 2002a; Torvinen et al., 2002b).

Como se mencionó anteriormente, si consideramos que al menos el $80 \%$ de los sujetos mayores de 80 años han sufrido por lo menos una caída al año (Armstrong y Wallace, 1994), y que más del $90 \%$ de las fracturas de cadera se producen como consecuencia de estas caídas (Runge et al., 2000), se hace necesario buscar una forma de prevenir la perdida de las cualidades relacionadas con la marcha y el equilibrio, que elevan considerablemente el riesgo de dependencia de los ancianos.

En la literatura se han documentado diversos beneficios asociados con la mejora de la capacidad de realizar las actividades diarias de los ancianos, por ejemplo en la habilidad de caminar, equilibrio corporal y capacidad motora (Bruyere et a., 2005). También se han observado mejoras en el test de levantarse de una silla (Runge et al., 2000), aumento en la longitud del paso, tiempo máximo mantenido sobre una pierna (Iwamoto et al., 2004), aumento en la potencia muscular (Russo et 
al., 2003), en la fuerza y movilidad (Ress et a., 2007) y DMO (Gusi et al., 2006).

Por tanto se puede concluir, considerando los artículos revisados sobre el entrenamiento de vibraciones, que este método es beneficioso para una diversidad de parámetros asociados con la salud de las personas mayores, discapacitadas 0 con una condición física disminuida, siendo una herramienta que podría generar gran impacto debido principalmente a su fácil utilización y poco tiempo empleado por sesión.

\subsubsection{Efectos del EVCC sobre marcadores de inflamación}

Aunque es conocida la asociación entre la inflamación crónica de bajo grado con la inactividad física, además de la relación entre IL-6 y TNF- $\alpha$ como predictores de muerte en ancianos mayores de 80 años (Bruunsgaard et al., 2003), y la relación entre los niveles de fuerza y los de inflamación en personas mayores (Cesari et al., 2004), también lo es, el efecto antiinflamatorio del ejercicio (Abramson y Vaccarino, 2002; Petersen y Pedersen, 2005; Vassilakopoulos et al., 2003; Beavers et al., 2010). Al respecto, tanto el ejercicio aeróbico (Mattusch et al., 2000) como el de resistencia (Ogawa et al., 2010; Prestes et al., 2009; Calle y Fernández, 2010) han demostrado ayudar disminuir los niveles de inflamación en este tipo de población.

Los ancianos que realizan actividad física han demostrado bajos contenidos de IL-6 (Reuben et al., 2003; Bruunsgaard et al., 2003; Cesari et al., 2004; Colbert et al., 2004), proteína C reactiva (Reuben et al., 2003; Stauffer et al., 2004; Cesari et al., 2004; Colbert et al., 2004), TNF-a (Bruunsgaard et al., 2003; Colbert et al., 2004) y un incremento en IL-10 (Jankord y Jemiolo, 2004). Esta última citoquina se relaciona con una disminución en la mortalidad cardiovascular (Van den Biggelaar et al., 2004). Los sujetos con mayor nivel de actividad física muestran entre un 20 y un $60 \%$ menos de mediadores de inflamación que los sedentarios (Bruunsgaard, 2005). 
Actualmente existe poca evidencia científica que relacione los efectos sobre los contenidos de inflamación en el organismo tras una sesión o un programa de entrenamiento de vibraciones, y es nula la evidencia al respecto en la población anciana. Solo tres artículos tratan el tema de las vibraciones y su relación con algunos factores de inflamación. Broadbent et al., (2010), aplicaron las vibraciones en zonas localizadas (terapia de vibración), y Dina et al., (2010) sometieron a las patas traseras de ratas a sesiones de vibraciones en un agitador de laboratorio con la finalidad de estudiar las variables relacionadas con el dolor músculo-esquelético crónico. Solo uno de ellos fue aplicado sobre una plataforma de vibración (Edge et al., 2009), en el cual utilizaron las vibraciones como terapia para aminorar los efectos sobre el dolor tardío tras un entrenamiento aeróbico cuesta abajo, demostrando una disminución en los niveles de IL-6 post entrenamiento, no obstante, no se observaron cambios en los niveles en la proteína $C$ reactiva.

Debido a la escasez de información al respecto, se hace necesario estudiar los posibles efectos sobre los marcadores de inflamación que podría provocar el entrenamiento de vibraciones, tanto después de una sesión (efecto agudo), como también, después de un programa de entrenamiento (efecto crónico). Esta nueva área de investigación podría beneficiar a muchas personas, especialmente a las de mayor edad, con enfermedades crónicas y con problemas de movilidad, que podrían disminuir sus contenidos de inflamación sistémica, previniendo una serie de consecuencias que podrían afectar su salud e independencia.

\subsubsection{Recomendaciones generales para el entrenamiento vibratorio}

En el año 2003, Cardinale y Pope, exponen que sometiendo al cuerpo a frecuencias de vibraciones moderadas $(25-40 \mathrm{~Hz})$, amplitudes pequeñas $(2-10$ $\mathrm{mm}$ ) y tiempos de exposición cortos (inferiores a 30 minutos con intermitencias) se podrían conseguir adaptaciones válidas para el ámbito del entrenamiento deportivo, 
de la condición física, de la rehabilitación y de la geriatría.

Posteriormente, Luo et al., (2005) ponen de manifiesto que estos beneficios se consiguen en un rango de frecuencias entre 30 y $50 \mathrm{~Hz}$, describiendo esta zona como la más eficaz para activar la musculatura.

Más específicamente, un interesante estudio de Mester et al., (2006) generó algunas recomendaciones a partir de las conclusiones de su artículo, para el uso adecuado de las VCC, tratando de prevenir cualquier tipo de efecto negativo sobre el organismo y maximizando así los beneficios tanto para la salud como para el deporte:

- Las frecuencias de vibración no deben ser inferiores a $20 \mathrm{~Hz}$.

- La transmisión de vibraciones a la cabeza deben minimizarse. Debiendo evitarse la máxima extensión de rodillas durante la exposición.

- Las amplitudes bajas (1 - $2 \mathrm{~mm}$ ) deben usarse para el EVCC a nivel recreativo o como punto de inicio en deportes de elite.

- La duración de cada repetición debe ser muy corta (entre 20 y 60 segundos), especialmente cuando se trabaje con sobrecarga adicional.

- EI EVCC debería controlarse estrictamente en pacientes con coronariopatías o hipertensión.

\subsubsection{Contraindicaciones, indicaciones, ventajas y desventajas}

\section{Contraindicaciones}

Entre las principales contraindicaciones descritas para el ejercicio de vibraciones, destacan los problemas vasculares o cardiacos, prótesis en la cadera o 
rodilla, hernias, discopatías o espondilosis, presencia de heridas, diabetes severa, portar un marcapasos, nuevas inflamaciones, epilepsia, haber sufrido una fractura ósea reciente, embarazo, lesiones agudas de la columna vertebral y extremidades inferiores, trombosis y urolitiasis aguda, trastornos en la retina y glóbulo ocular.

Indicaciones

Este método esta siendo utilizado tanto por el área del entrenamiento deportivo como en el tratamiento de distintas patologías. Centrándonos en las indicaciones relacionadas con la salud podríamos destacar los aspectos neurológicos, la esclerosis lateral amiotrófica, esclerosis múltiple, síndrome de fatiga crónica y paresias. En las condiciones musculares, se recomienda en fibromialgia, atrofia muscular y acortamiento del músculo. En el hueso y cartílago se utiliza para ayudar en reumatismo y osteoporosis. Finalmente, en los problemas circulatorios, se emplea en lesiones por esfuerzos repetitivos, distrofia postraumática y edema.

\section{Desventajas}

El conocimiento científico es insuficiente respecto al efecto del ejercicio vibratorio en diversas poblaciones (grupo de edad, género, patología, entre otras). Además, tampoco es bien conocida la relación dosis/respuesta óptima para obtener los beneficios previamente descritos, así como los posibles efectos secundarios que podría provocar una determinada frecuencia y/o amplitud sobre el sistema neuromuscular y óseo, en el equilibrio, entre otros (Rittweger et al., 2002; Bosco et al., 1999; Mester et al., 1999; Martí et al., 2003).

No existe un criterio claro para seleccionar la aceleración o magnitud del estímulo vibratorio, ya que no existen pautas contrastadas en la actualidad que definan como diseñar un programa de ejercicios sobre una plataforma vibratoria 
(Rittweger, 2010; Merriman y Jackson, 2009). Además aún no hay claridad en cuan grande debe ser la carga, cuanto tiempo y cuan intensa debe ser esta, así como la frecuencia y la amplitud que debería ser adoptada, y cuanto debería durar el programa de entrenamiento. Todo esto tiene como finalidad generar la mayor cantidad de beneficios sin ningún tipo de perjuicio físico (Mester et al., 2006).

Por último, el precio del equipamiento certificado es bastante alto. Lo que implica destinar una buena cantidad de dinero para tener una de estas máquinas en casa, o bien, pertenecer a alguno de los centros deportivos o de rehabilitación que las ofrece dentro de las actividades destinadas para sus usuarios.

\section{Ventajas}

Un programa de entrenamiento vibratorio se puede acondicionar a diferentes niveles de resistencia, permitiendo así, trabajar objetivos distintos (Rittweger, 2010). El ejercicio vibratorio permite entrenar el sistema neuromuscular y esquelético, permitiendo mejoras en términos de fuerza y de tonicidad muscular, así también en la densidad del hueso (Rubin et al., 2004; Verschueren et al., 2004) en un espacio de tiempo considerablemente más corto (Cardinale y Wakeling, 2005) en comparación con otros métodos, siendo ésta una de sus mayores ventajas. Y además, su utilización es extremamente sencilla. 
3. Metodología 


\subsection{DISEÑO EXPERIMENTAL}

El estudio fue aprobado por el Comité de Ética de la Universidad de León. Tanto el periodo de familiarización como el periodo de evaluación de las cualidades físicas, se llevaron a cabo en la sala de musculación de la Facultad de Ciencias de la Actividad Física y del Deporte de la Universidad de León. Los diversos protocolos de biología molecular se desarrollaron en el Instituto Universitario de Biomedicina (IBIOMED) de la misma universidad. Respecto al entrenamiento de vibraciones, éste se desarrolló en la residencia para ancianos Virgen del Camino, ubicada en la ciudad de León.

El estudio estuvo dividido en cuatro fases. Periodo de familiarización, periodo de evaluación inicial, periodo de entrenamiento y periodo de evaluación final (Esquema 13).

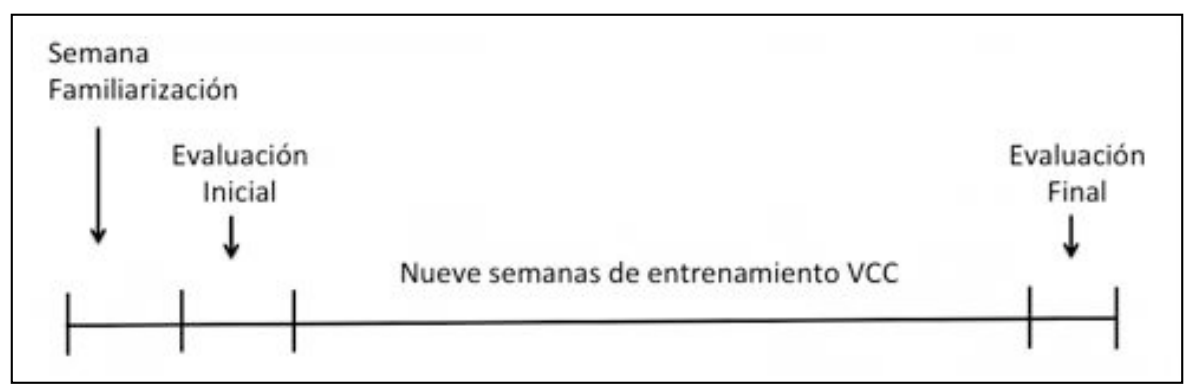

Esquema 13. Plan de trabajo.

La semana de familiarización comenzó tras una selección exhaustiva de los participante, llevada a cabo por el médico de la residencia, y tras la obtención del consentimiento de participación por parte de los ancianos. Durante este periodo se realizaron dos visitas a la sala de musculación de la Facultad de Ciencias de la 
Actividad Física de la Universidad de León, en donde se les enseñó a cada anciano a utilizar las máquinas que serían empleadas tanto durante el periodo de evaluaciones físicas, como también durante el periodo de entrenamiento. Además, durante esa misma semana, se realizaron dos sesiones más en la Residencia con la finalidad de familiarizarse con las 6 pruebas que componen el SFT.

\subsection{SUJETOS}

Para la selección de los participantes del estudio, se consideró que todos fueran ancianos e institucionalizados, y además que todos vivieran en la misma residencia. De esta manera se regularizaron diversos criterios, entre los cuales encontramos principalmente el tipo de alimentación y el horario de cada una de las comidas del día, siendo el desayuno a las $8: 30 \mathrm{~h}$, la comida a las $13: 00 \mathrm{~h}$ y la cena a las 19:00h.

De un total de 82 ancianos que viven en la Residencia Virgen del Camino, 36 ancianos pasaron los criterios de inclusión y exclusión (ver contraindicaciones p. 52), y recibieron la aprobación médica para participar en el programa de entrenamiento. A los 36 ancianos se les invitó a una sesión de presentación del programa de entrenamiento, explicándoles tanto los objetivos como los beneficios para su salud de esta modalidad de entrenamiento. Aceptaron participar 14 ancianos (6 mujeres y 8 hombres), a los que se les informó de los objetivos y procedimientos de la investigación, obteniendo su consentimiento informado por escrito (Anexo 1).

Por razones ajenas al programa de entrenamiento, 2 ancianos dejaron de participar en el programa, y 2 ancianos no cumplieron el mínimo de asistencia propuesta para este estudio, establecida en 18 sesiones equivalentes al $70 \%$. Finalmente, fueron considerados para los análisis solo los 10 ancianos que culminaron el programa de entrenamiento de vibraciones (Esquema 14). Se 
incluyeron tanto a hombres como a mujeres en el mismo grupo. Tras comprobar que no existían diferencias significativas entre los grupos.

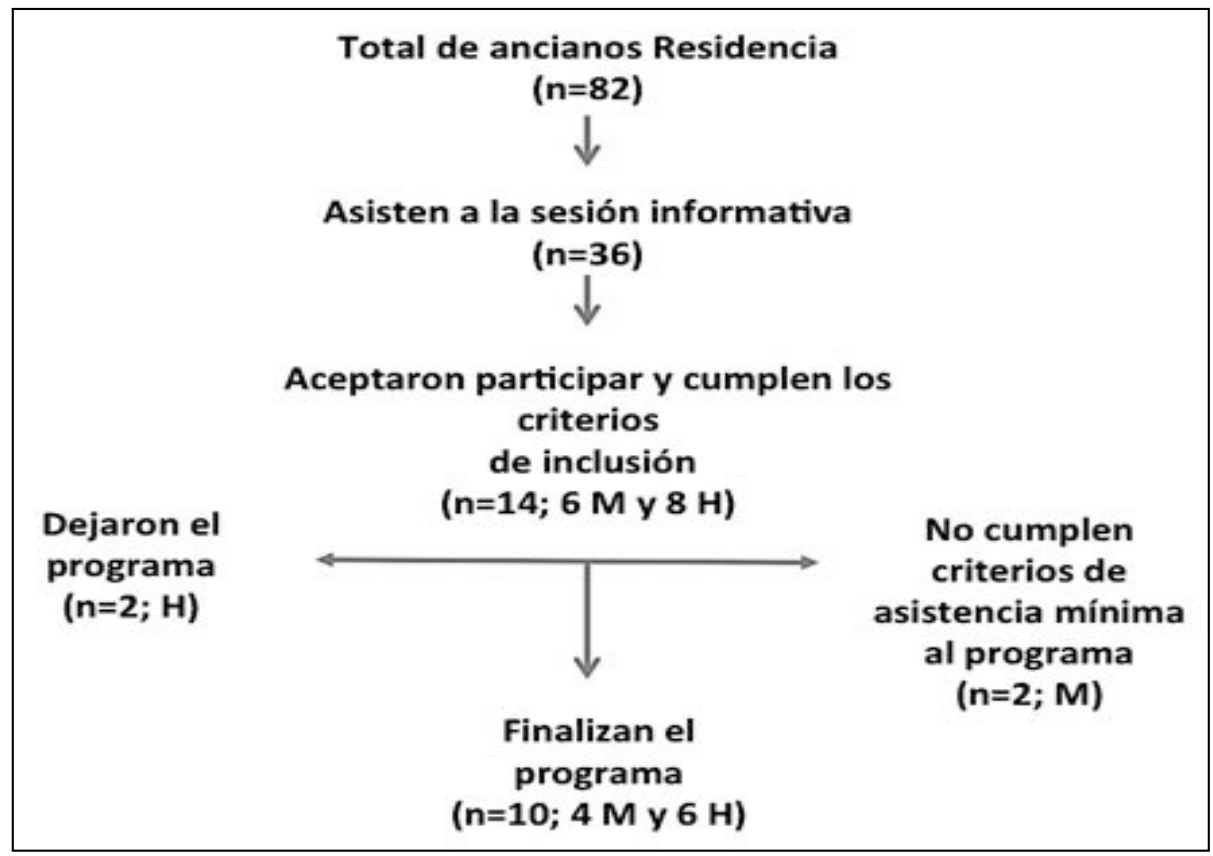

Esquema 14. Selección y exclusión de los participantes. M: mujer; H: hombre.

También en el presente estudio participaron 8 jóvenes (todos varones), con la finalidad de conocer los valores de referencia de las variables de este estudio en un grupo de personas con sus capacidades funcionales en plenitud. De esta manera se puede conocer si, tras la realización del programa de entrenamiento de vibraciones, los valores en las diversas variables se acercan a los valores de los jóvenes. Nunca ha sido la intención comparar ambos grupos. Tanto las características de los ancianos como de los jóvenes son presentadas en la tabla 6 . 


\begin{tabular}{lcc}
\hline Variable & Ancianos & Jóvenes \\
\hline Edad (años) & $81,1 \pm 1,2$ & $26,9 \pm 1,3$ \\
Estatura $(\mathrm{m})$ & $1,58 \pm 0,0$ & $1,80 \pm 0,0$ \\
Peso $(\mathrm{kg})$ & $67,3 \pm 3,6$ & $83,2 \pm 4,7$ \\
IMC $\left(\mathrm{kg} / \mathrm{m}^{2}\right)$ & $27,4 \pm 1,6$ & $25,4 \pm 0,8$ \\
MME $(\%)$ & $22,8 \pm 1,1$ & $39,2 \pm 2,2$ \\
Grasa $(\%)$ & $25 \pm 3,1$ & $14,7 \pm 1,6$ \\
RCC & $1,02 \pm 0,0$ & $0,85 \pm 0,0$ \\
Colesterol $(\mathrm{mg} / \mathrm{dL})$ & $197 \pm 7,7$ & $159,9 \pm 11,7$ \\
Colesterol-HDL $(\mathrm{mg} / \mathrm{dL})$ & $55,7 \pm 5,4$ & $44,24 \pm 2,2$ \\
Triglicéridos $(\mathrm{mg} / \mathrm{dL})$ & $91 \pm 10,2$ & $106,8 \pm 8,5$ \\
Creatinina $(\mathrm{mg} / \mathrm{dL})$ & $0,87 \pm 0,0$ & $0,97 \pm 0,0$ \\
Glucosa $(\mathrm{mg} / \mathrm{dL})$ & $106,1 \pm 9,4$ & $94,5 \pm 2,1$ \\
Urea $(\mathrm{mg} / \mathrm{dL})$ & $38,1 \pm 2,7$ & $26,9 \pm 3,6$ \\
\hline
\end{tabular}

Tabla 6. Características generales de los ancianos y los jóvenes. IMC: Índice de Masa Corporal; MME: Masa Muscular Esquelética; RCC: Relación Cintura Cadera. Valores medios \pm E.E.M. 


\subsection{ENTRENAMIENTO}

El periodo de entrenamiento consistió en 9 semanas de trabajo continuado, desde el mes de octubre al mes de diciembre. Cada sujeto entrenaba 3 veces por semana (lunes, miércoles y viernes), dejando siempre un día de descanso entre sesión. El horario de entrenamiento se estableció entre las 10:00 a 13:00 horas.

\subsubsection{Ejercicio de tipo estático y dinámico}

Durante el programa de entrenamiento se utilizaron 2 tipos de ejercicios, estáticos y dinámicos. Los estáticos son ejercicios que se caracterizan por mantener una posición deseada y no generar ningún tipo de movimiento durante el tiempo de exposición a las vibraciones. Se puede también seleccionar alguna extremidad y someterla al estímulo, pudiendo estar la persona situada fuera de la plataforma, sin necesidad de que el cuerpo este por completo sobre ella. En cambio los ejercicios de tipo dinámico, implican un rango de movimiento dado, por ejemplo, cuando se realiza el ejercicio de sentadilla, los ancianos deben subir y bajar lentamente durante el periodo de tiempo que estén sobre la plataforma (Imagen 3).

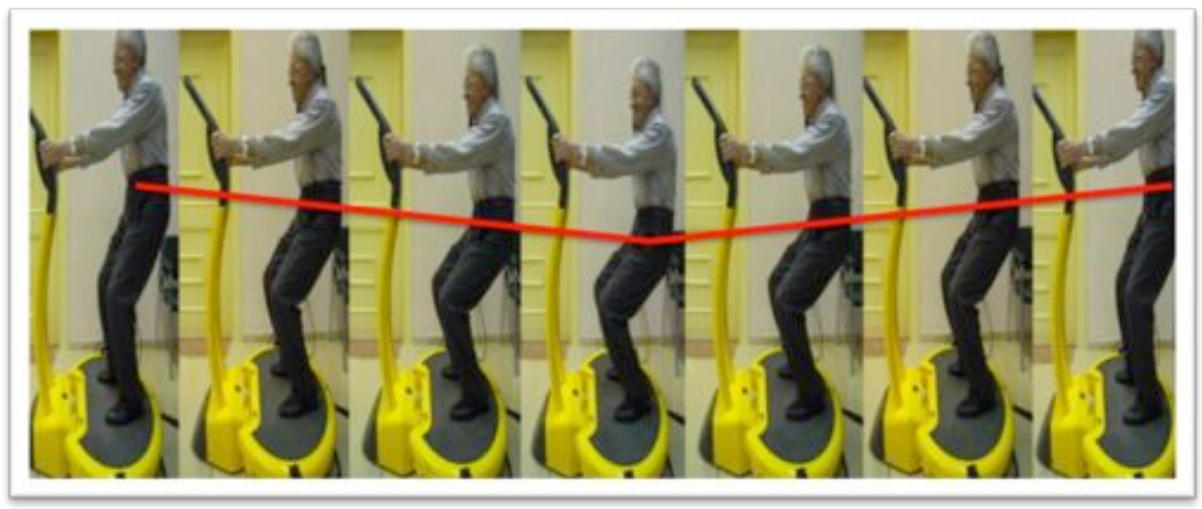

Imagen 3. Tipo de ejercicio dinámico (Sentadilla). 
Los ejercicios realizados durante las primeras dos semanas, fueron de tipo estático. Mientras que las 7 semanas posteriores se utilizaron tanto ejercicios de tipo dinámico como estático (Tabla 7; Imagenes 4 y 5).

Primeras 2 semanas

A: Sentado en una silla con ambos pies sobre la plataforma (Estático).

B: Sentado en una silla y de puntillas (Estático).

C: De pie fuera de la plataforma y con una pierna sobre ella (alternado) (Estático).

D: De pie fuera de la plataforma, tomando las correas y ejerciendo fuerza de bíceps (Estático).

E: De pie fuera de la plataforma, tomando las correas y ejercicio de fuerza de hombros (Estático).

F: De pie fuera de la plataforma, separado 1 metro, ejerciendo fuerza con las correas por el costado del cuerpo y hacia atrás (Estático).

\section{Siguientes 7 semanas}

\section{G: Sentadilla $\left(120^{\circ}-130^{\circ}\right)$} (Dinámico).

H: Sentadilla profunda $\left(90^{\circ}\right)$, (Dinámico).

I: Sentadilla amplia (Dinámico)

J: Ejericio de gemelos, puntillas (Estático).

K: Bíceps con correa, con o sin pierna sobre plataforma (Estático).

L: Ejericio de hombros con correa, con o sin pierna sobre plataforma (Estático).

Tabla 7. Descripción de los ejercicios utilizados durante las 9 semanas de entrenamiento. 


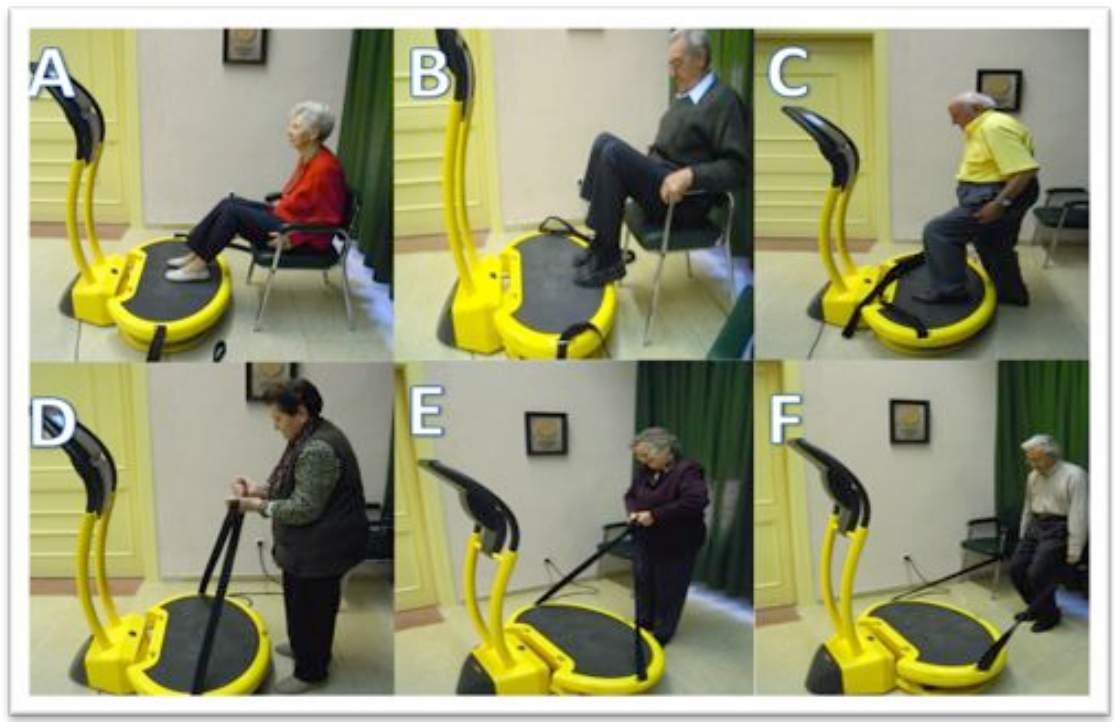

Imagen 4. Ejercicios de tipo estático utilizados las primeras dos semanas.

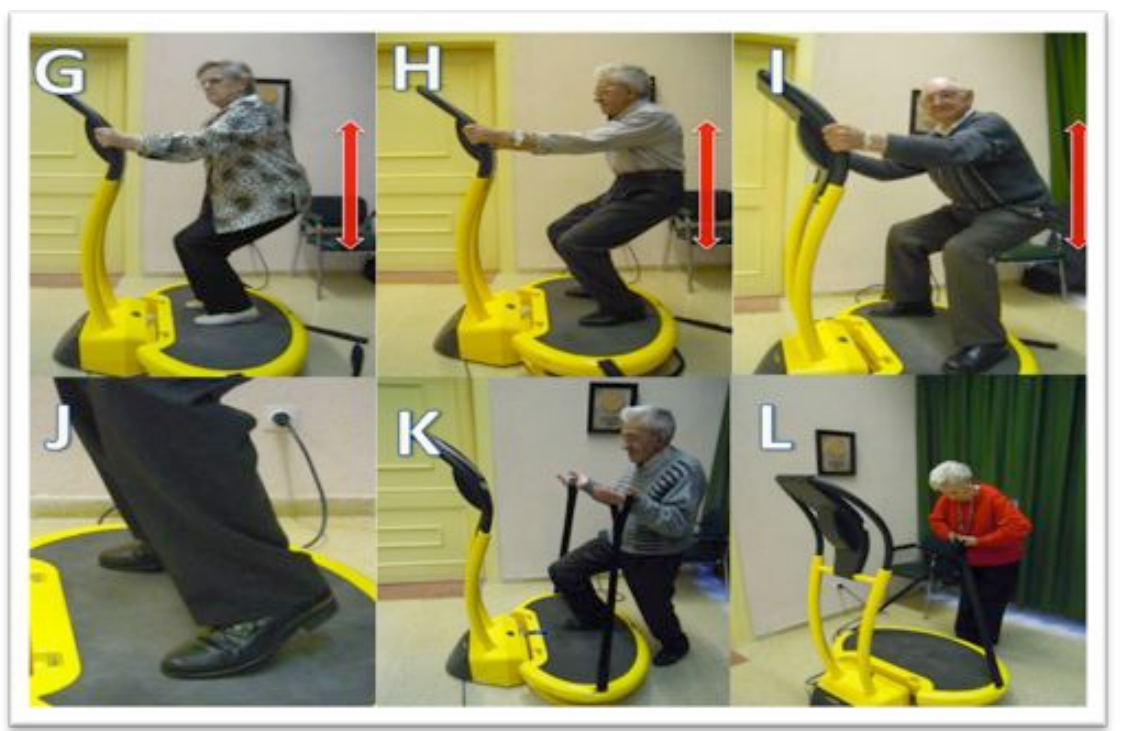

Imagen 5. Ejercicios de tipo dinámico y estático utilizados las siguientes siete semanas. 
A continuación se detalla el orden, las series y los ejercicios realizados en el programa de EVCC (Tabla 8).

\begin{tabular}{cccccccc}
\hline \multirow{2}{*}{ 2 Semanas } & A & B & C & D & E & F & Mod \\
\cline { 2 - 7 } & 2 & 1 & 2 & 1 & 1 & 1 & E \\
& 1 & 1 & 2 & 2 & 1 & 1 & E \\
\hline \multirow{7}{*}{ 7 semanas } & G & H & I & J & K & L & Mod \\
\cline { 2 - 7 } & 2 & 2 & 1 & 1 & 2 & & E-D \\
& 1 & 1 & 2 & 2 & 2 & & E-D \\
& 1 & 1 & 2 & 2 & 2 & 1 & E-D \\
& 1 & 2 & 2 & 2 & 2 & & E-D \\
& 2 & 1 & 2 & 2 & 2 & 1 & E-D \\
& 2 & 2 & 1 & 2 & 2 & 1 & E-D \\
& 1 & 2 & 2 & 2 & 2 & & E-D \\
\hline
\end{tabular}

Tabla 8. Detalle del número de series por cada ejercicio realizados durante las 9 semanas de EVCC. Mod: Modalidad; E: estático; D: dinámico. Nota: Ejercicios A, B, C, D, E, F, G, H, I, J, K y L (ver imagen p. 63).

Cabe señalar que muchos de los ancianos presentaron problemas de equilibrio durante los ejercicios con correas sobre la plataforma, por lo que se les sugirió realizar los ejercicios fuera de ésta y con una pierna sobre la máquina, luego se alternaba a la pierna sin ejercitar.

El protocolo de ejercicio consistió en una carga ascendente de entrenamiento, aumentando la frecuencia y manteniendo estable la amplitud en $2 \mathrm{~mm}$. El periodo de pausa entre ejercicio se mantuvo en 3 minutos. Se comenzó con dos semanas de 
iniciación con una carga de entrenamiento de 1,8 $\left(\mathrm{m} / \mathrm{s}^{2}\right)$ (30 segundos por $30 \mathrm{~Hz}$ de frecuencia) con 8 ejercicios de tipo estático, durante este periodo nunca se subieron por completo a la máquina.

Cada dos semanas la carga de entrenamiento aumentaba gradualmente (media $0,75 \mathrm{~m} / \mathrm{s}^{2}$ ), la frecuencia $(5 \mathrm{~Hz}$ ) y el tiempo por ejercicio (10 segundos). Se mantuvieron los 8 ejercicios iniciales durante las 4 primeras semanas. Las semanas número 5 y 6 aumentaron a 9 ejercicios, y las semanas 7 y 8 aumentaron a 10 ejercicios. Solo durante la novena semana, se disminuyó la carga en $0,85\left(\mathrm{~m} / \mathrm{s}^{2}\right)$ con el objetivo de no generar un efecto agudo que pudiese afectar los valores de los marcadores de inflamación a nivel sanguíneo. Durante esta última semana se realizaron 9 ejercicios, con una frecuencia de $40 \mathrm{~Hz}$ y con una duración por ejercicio de 50 segundos (Tabla 9).

\begin{tabular}{ccccccccc}
\hline Sem & $\begin{array}{c}\text { Ejerc } \\
\mathrm{n}^{\circ}\end{array}$ & Mod & $\begin{array}{c}\text { Ejerc } \\
(\mathrm{seg})\end{array}$ & $\begin{array}{c}\text { Frec } \\
(\mathrm{Hz})\end{array}$ & $\begin{array}{c}\text { Ampl } \\
(\mathrm{mm})\end{array}$ & $\begin{array}{c}\text { Pausa } \\
(\mathrm{min})\end{array}$ & $\begin{array}{c}\text { Tiempo } \\
\text { Vibr }\end{array}$ & $\begin{array}{c}\text { Intens } \\
\left(\mathrm{m} / \mathrm{s}^{2}\right)\end{array}$ \\
\hline $1^{\mathrm{a}}$ & 8 & $\mathrm{E}$ & 30 & 30 & 2 & 3 & $04: 00$ & 1,8 \\
$2^{\mathrm{a}}$ & 8 & $\mathrm{E}$ & 30 & 30 & 2 & 3 & $04: 00$ & 1,8 \\
$3^{\mathrm{a}}$ & 8 & $\mathrm{D}$ & 40 & 35 & 2 & 3 & $05: 20$ & 2,45 \\
$4^{\mathrm{a}}$ & 8 & $\mathrm{D}$ & 40 & 35 & 2 & 3 & $05: 20$ & 2,45 \\
$5^{\mathrm{a}}$ & 9 & $\mathrm{D}$ & 50 & 40 & 2 & 3 & $07: 30$ & 3,2 \\
$6^{\mathrm{a}}$ & 9 & $\mathrm{D}$ & 50 & 40 & 2 & 3 & $07: 30$ & 3,2 \\
$7^{\mathrm{a}}$ & 10 & $\mathrm{D}$ & 60 & 45 & 2 & 3 & $10: 00$ & 4,05 \\
$8^{\mathrm{a}}$ & 10 & $\mathrm{D}$ & 60 & 45 & 2 & 3 & $10: 00$ & 4,05 \\
$9^{\mathrm{a}}$ & 9 & $\mathrm{D}$ & 50 & 40 & 2 & 3 & $07: 30$ & 3,2 \\
\hline
\end{tabular}

Tabla 9. Planificación de la carga de entrenamiento durante las 9 semanas. Sem: semana; $\mathrm{n}^{\circ}$ : número; Mod: modalidad; Ejer: ejercicio; Frec: frecuencia; Ampl: amplitud; Pausa: entre ejercicio; Intens: intensidad. 


\subsection{MEDICIÓN Y EVALUACIÓN}

\subsubsection{Evaluación inicial y final}

En este estudio se midieron diversas variables, con la finalidad de conocer las características físicas básicas de cada sujeto, y además, para determinar los efectos del entrenamiento de vibraciones sobre la inflamación y las cualidades físicas relacionadas con la capacidad funcional de los ancianos.

Tanto antes como después de las 9 semanas de entrenamiento se evaluaron las siguientes variables:

- Peso.

- Estatura.

- Índice de Masa Corporal.

- Porcentaje de grasa.

- Relación Cintura/Cadera.

- Máxima Contracción Isométrica Voluntaria, con electromiografía de superficie del vasto lateral y vasto medial.

- Potencia del tren inferior al $20 \%, 40 \%$ y $60 \%$ de MCVI.

- Senior Fitness Test.

- Determinación de IL-1 $\beta, \mathrm{IL}-6, \mathrm{IL}-10$, TNF- $\alpha$ y proteína C reactiva por Western Blot y por RT-PCR.

\subsubsection{Antropometría}

Se evaluó la antropometría básica de cada uno de los sujetos, a través de la báscula InBody 230 (Marca Biospace, Seoul, Korea), de la cual se obtuvo el peso, el IMC, MME, el RCC y el porcentaje de grasa, por medio de bioimpedanciometría (Imagen 6). 


\section{Procedimiento}

Se solicitó a cada sujeto que el día anterior a la evaluación, no bebieran alcohol, no tomaran café, ni realizaran ejercicio físico. Además cada uno tenía que utilizar la misma indumentaria en las dos evaluaciones, tanto al iniciar como al terminar el programa de entrenamiento.

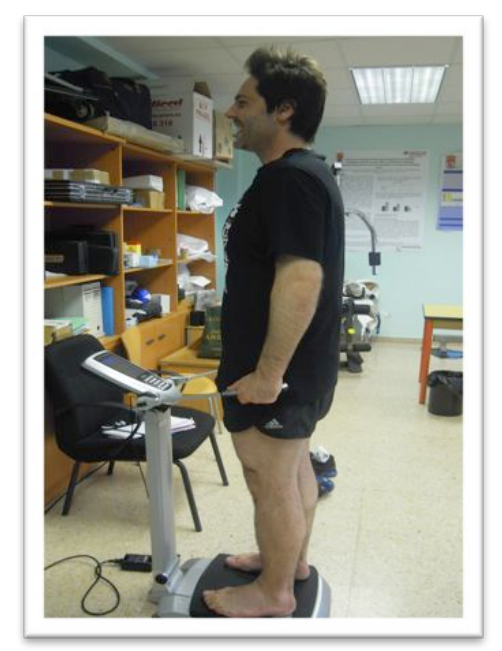

Imagen 6. Báscula InBody 230 (Marca Biospace, Seoul, Korea).

Dichos parámetros se evaluaron siempre a primera hora de la mañana, entre las 8:30 y 9:30. Los participantes se descalzaron y se situaron en el Inbody 230 lo más recto posible. La balanza fue situada sobre una superficie plana para evitar cualquier desbalance que pudiese afectar la medición. El procedimiento completo duró menos de 5 minutos. 


\subsubsection{Electromiografía de superficie}

Se realizó la EMGs en conjunto con la evaluación de la MCVI. Para esto, y previo al test de fuerza se seleccionaron las zonas de marcaje de los electrodos, en el músculo VM y en el VL. Luego se procedió a limpiar la zona, desfoliándola y humedeciéndola con alcohol, para reducir la impedancia de la piel por debajo de 5 $\mathrm{k} \Omega$ (De Luca, 1997). Posteriormente se adhirieron los electrodos (Skintact F-401, Gloucestershire, Reino Unido) a la piel para obtener los registros electromiográficos correspondientes al tren inferior (Imagen 7).

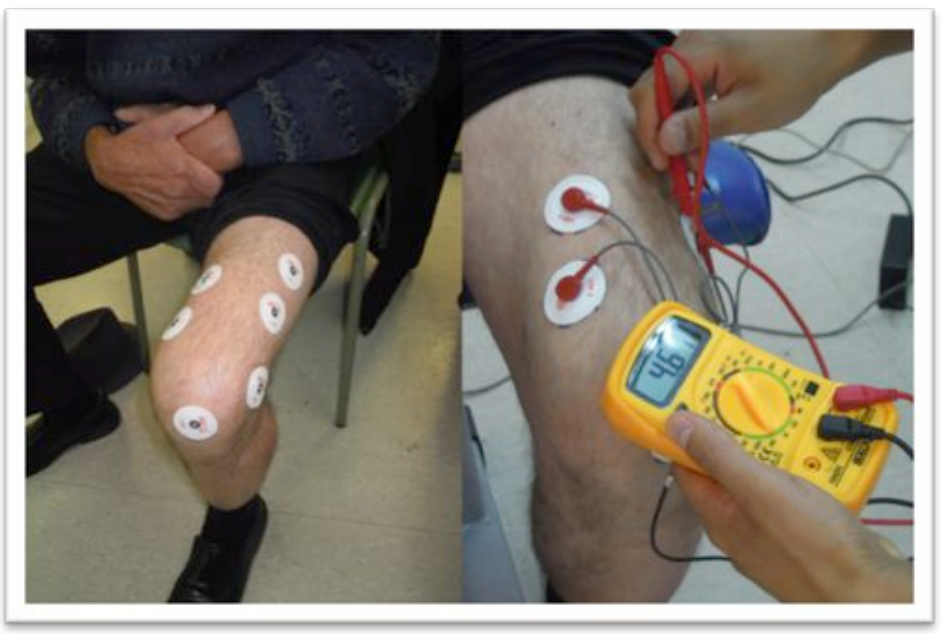

Imagen 7. Izquierda: Posición de electrodos sobre el VL y VM. Derecha: Medición de la señal menor a $5 \mathrm{k} \Omega$.

Para cada músculo se utilizaron 3 electrodos de superficie, dos de medida y uno como diferencial. Los primeros fueron colocados longitudinalmente a las fibras musculares y en la parte más prominente de cada músculo estudiado y el diferencial fue colocado en un hueso alejado de la zona. La distancia entre los electrodos fue de 2 centímetros aproximadamente (Häkkinen et al., 1998). 
Los electrodos siempre se colocaron en el mismo lugar. Para que esto fuese posible, a cada sujeto se le realizó una marca en la piel con un rotulador permanente, remarcándola y manteniéndola durante todo el periodo del programa (Häkkinen et al., 1998). Se le indicó tanto a la enfermera de la residencia, como a ellos mismos, que debían remarcar la zona por lo menos dos veces por semana (Imagen 8).

Para la EMGs del muslo durante la prueba de MCVI cada electrodo de superficie se conectó a un convertidor AD de 14-bit (ME6000 Biomonitor, Mega Electronics, Kuopio, Finlandia) con unos cables amplificadores de señal (Mega Electronics, Kuopio, Finlandia).

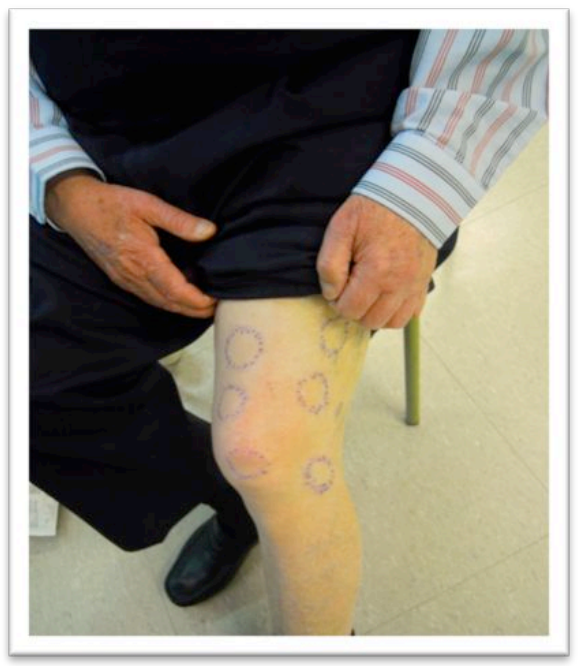

Imagen 8. Marca realizada con un rotulador permanente, la que debían remarcar dos veces por semana hasta el final del programa.

El rango de rechazo al modo común (Common Mode Rejection Ratio) fue de $110 \mathrm{~dB}$ y los datos fueron filtrados en un rango de frecuencia entre $8-500 \mathrm{~Hz}, \mathrm{y}$ almacenados con una frecuencia de muestreo de $2000 \mathrm{~Hz}$, en una tarjeta de 
memoria (compact flash, 1 Gigabyte). El análisis de los datos de EMGs se realizó con el programa específico 2.21 Megain V (Mega Electronics, Kuopio, Finlandia).

\subsubsection{Evaluación de la Fuerza y Potencia muscular}

\subsubsection{Evaluación de MCVI}

El test de MCVI del tren inferior fue realizado con una célula de carga, galga extensiométrica (Ergo meter, Globus, Italia), en una máquina de extensión de rodillas (Gervasport, Fitness Equipment, Dorsten, Alemania) con un ángulo articular aproximado de $110^{\circ}$ a $130^{\circ}$ (Imagen 9 ).

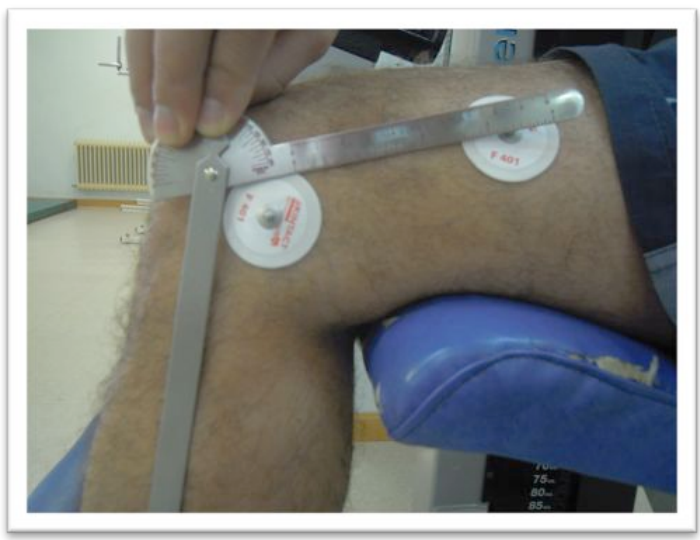

Imagen 9. Medición ángulo articular con un goniómetro.

\section{Procedimiento}

Se le solicitó a cada participante que no realizaran ejercicio el día anterior, además el test fue medido siempre a la misma hora de la mañana (entre las 9 y 11 
a.m.) para evitar variaciones en la fuerza debido a sus ciclos circadianos (Guette et al., 2005).

Posteriormente se prosiguió a mostrarles los ejercicios en la máquina de extensión de rodillas, donde se realizarían las pruebas de MCVI y de potencia muscular. Se les enseñó como debían subirse, sentarse, afirmarse, levantar las piernas, etc. También, en ese momento se apuntaba la ubicación del eje de la máquina más adecuado para el largo de sus extremidades, con la finalidad de realizar las dos evaluaciones en la misma posición articular (Imagen 10).

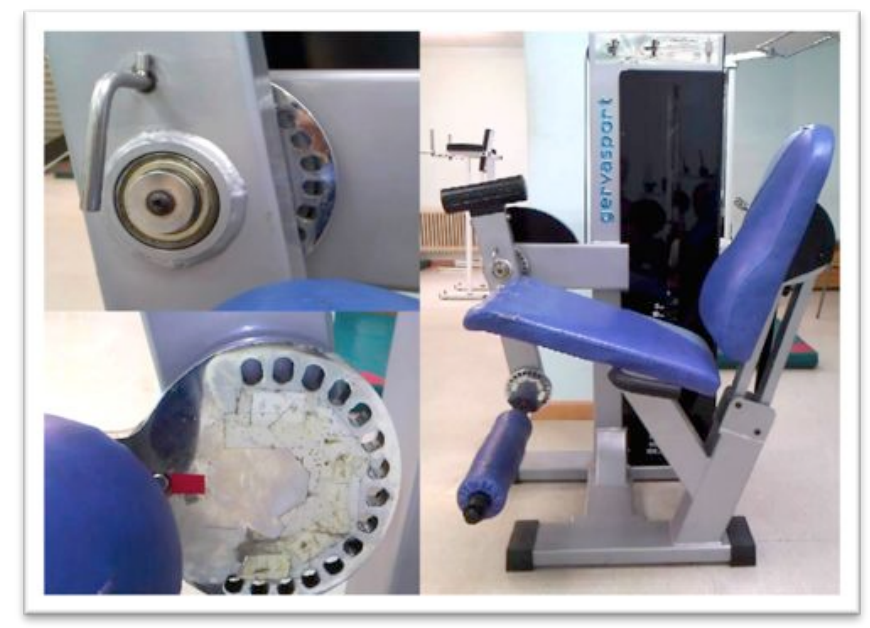

Imagen 10. Posición más idónea para cada sujeto, maquina extensión de rodillas (Gervasport, Alemania).

Antes de comenzar con el test de MCVI, tanto ancianos como jóvenes realizaron un calentamiento, consistente en caminar o trotar (ancianos y jóvenes respectivamente) ya sea dentro de la sala de musculación de manera guiada, o bien, caminando sobre un tapiz rodante (Power Jog M30, Sport Engineering Limited, 
Birmingham, Reino Unido) a una velocidad variable entre los 3 a $6 \mathrm{~km} / \mathrm{h}$, dependiendo de sus posibilidades, y durante un tiempo no menor a 5 minutos (Imagen 11).

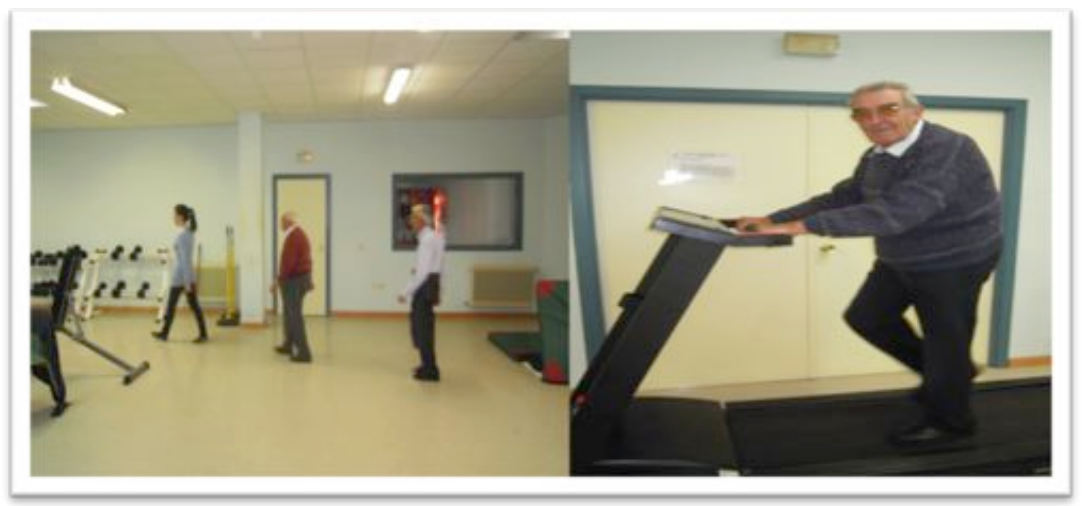

Imagen 11. Dos tipos de calentamientos. A la izquierda caminando por la sala en compañía de un guía. A la derecha calentamiento en un tapiz rodante.

Posteriormente se realizó un calentamiento en la máquina de extensión de rodillas (Imagen 12). En ambos grupos se seleccionó un peso, con el cual pudieran realizar inicialmente una serie de 10 movimientos. Posteriormente, se incrementó el peso para realizar una serie de 6 a 8 repeticiones, y finalmente una serie con 3 a 4 repeticiones. Las indicaciones para la realización de la prueba de MCVI fueron las siguientes:

- Debían mantener la espalda lo más derecha posible, sentarse cómodamente, para esto se les ubicaba el respaldo a una altura en la que ellos se sentían cómodos, dependiendo principalmente de su estatura.

- Debían afianzarse en los costados, ya sea del asiento o de los mangos laterales que posee la máquina.

- Se realizarían dos intentos, y se ejecutaría un tercero si la diferencia entre los dos primeros superaba los 5 kilogramos. 
- Tuvieron una pausa de 3 minutos entre cada intento.

- Debían hacer toda la fuerza posible durante 5 segundos.

- También se les pidió que mantuvieran las cadenas de la galga semiestiradas, para reducir cualquier tipo de "tirón" de la cadena al ejecutar el movimiento. De esta manera, se disminuía cualquier tipo de sesgo en la medición.

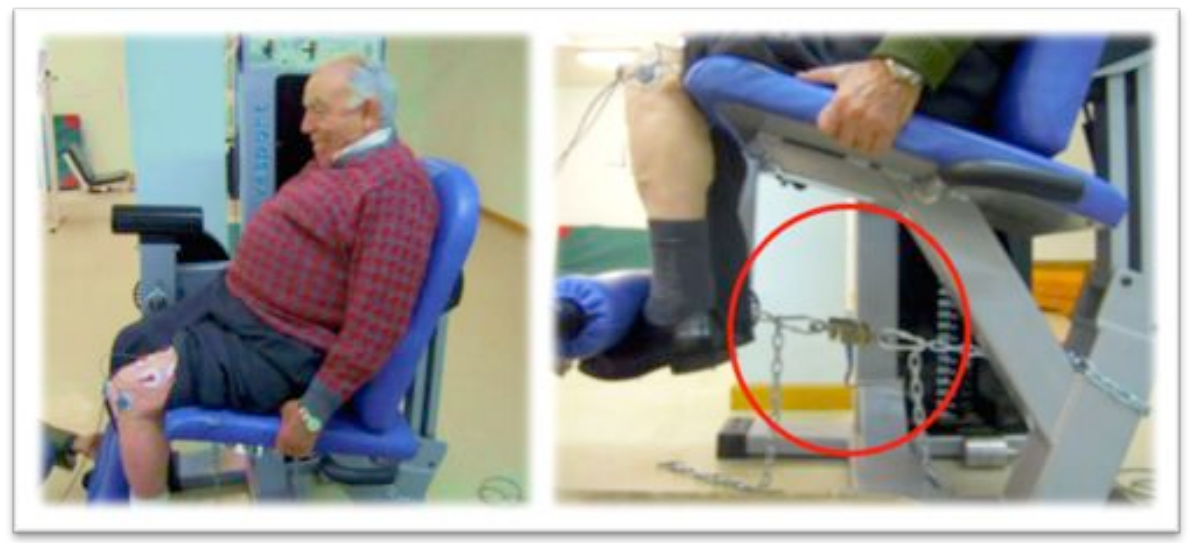

Imagen 12. Evaluación de MCVI, EMGs y galga extensiométrica (Ergometer, Globus, Italia).

Todas las evaluaciones fueron realizadas por el mismo evaluador. Una vez terminado el test, se les solicitaba que descansaran 5 minutos para comenzar con el test de potencia. Durante este tiempo, el evaluador calculaba el $20 \%, 40 \%$ y $60 \%$ de su MCVI, porcentajes a evaluar en el test de potencia.

\subsubsection{Evaluación de la Potencia Pico}

La potencia de tren inferior fue registrada por un encóder lineal rotatorio (Globus Real Power, Codogne, Italia). 


\section{Procedimiento}

Tras la realización del test MCVI, se calculó el $20 \%, 40 \%$ y $60 \%$ de su fuerza, valores utilizados para evaluar la potencia muscular del tren inferior.

El encoder fue ubicado en la parte inferior y a un costado de las placas de peso de la máquina de extensión de rodillas. El cable rotatorio quedo paralelo a las placas, y se afianzó firmemente a estas, con el fin de determinar la potencia de ejecución del movimiento.

Se le explicó a cada uno de los participantes como debían realizar el test, recalcando en la velocidad de ejecución de la prueba. El resto de las recomendaciones eran iguales al test de MCVI. Se realizaron tres extensiones a máxima velocidad para cada uno de los porcentajes $(20 \%, 40 \%$ y $60 \%$ de su MCVI). Todo fue medido en línea a través del software Real Power 3 Software Globus Evaluation Concept Version 3.11 (Globus, Italia) (Imagen 13). Si por alguna razón no se realizaba bien la prueba, se les daba 2 minutos de pausa para volver a repetir el ejercicio, señalándoles cuales eran los errores a evitar.

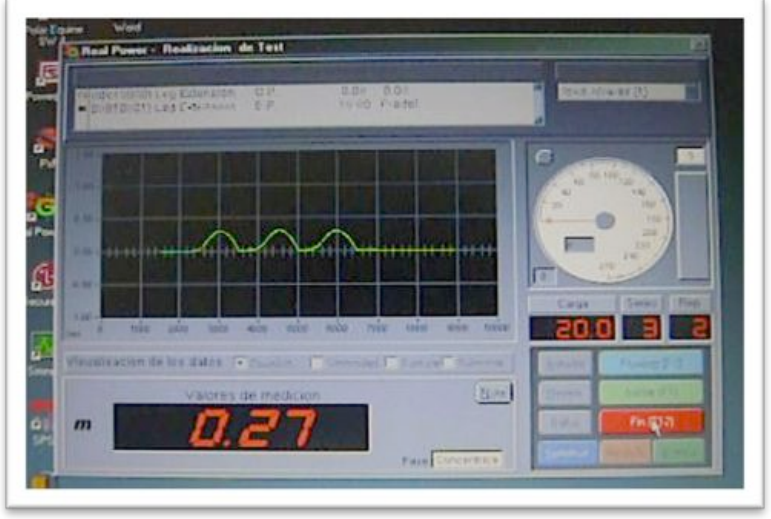

Imagen 13. Lectura en línea de la evaluación de la potencia a través del programa Real Power (Globus, Italia). 


\subsubsection{Evaluación de la Capacidad Funcional}

La capacidad funcional de los ancianos fue evaluada a través de la batería Senior Fitness Test (Rikli y Jones, 2001).

\section{Procedimiento}

Se inició con un calentamiento, comenzando con una marcha a velocidad autoseleccionada. Además, mientras caminaban los ancianos se le sumaron algunos ejercicios de activación músculo-articular, todos estos relacionados con los ejercicios que debían ejecutar posteriormente en el test. Luego, sentados en una silla, realizaban los estiramientos de las extremidades inferiores. El calentamiento duraba aproximadamente unos 10 minutos.

Antes de comenzar, el evaluador tenía disponible todo el material necesario para desarrollar las 6 pruebas del SFT, entre estos:

- Silla.

- Cronómetro.

- Mancuernas.

- Cinta métrica.

- 4 conos o similar.

- Regla métrica de $45-50 \mathrm{~cm}$.

- Rotulador.

Esta batería consta de 6 ejercicios (Imagen 14), los cuales fueron ordenados de tal manera que se minimizara la fatiga y se pudiera realizar el test de resistencia aeróbica de 6 minutos de la mejor manera al final de las pruebas. 


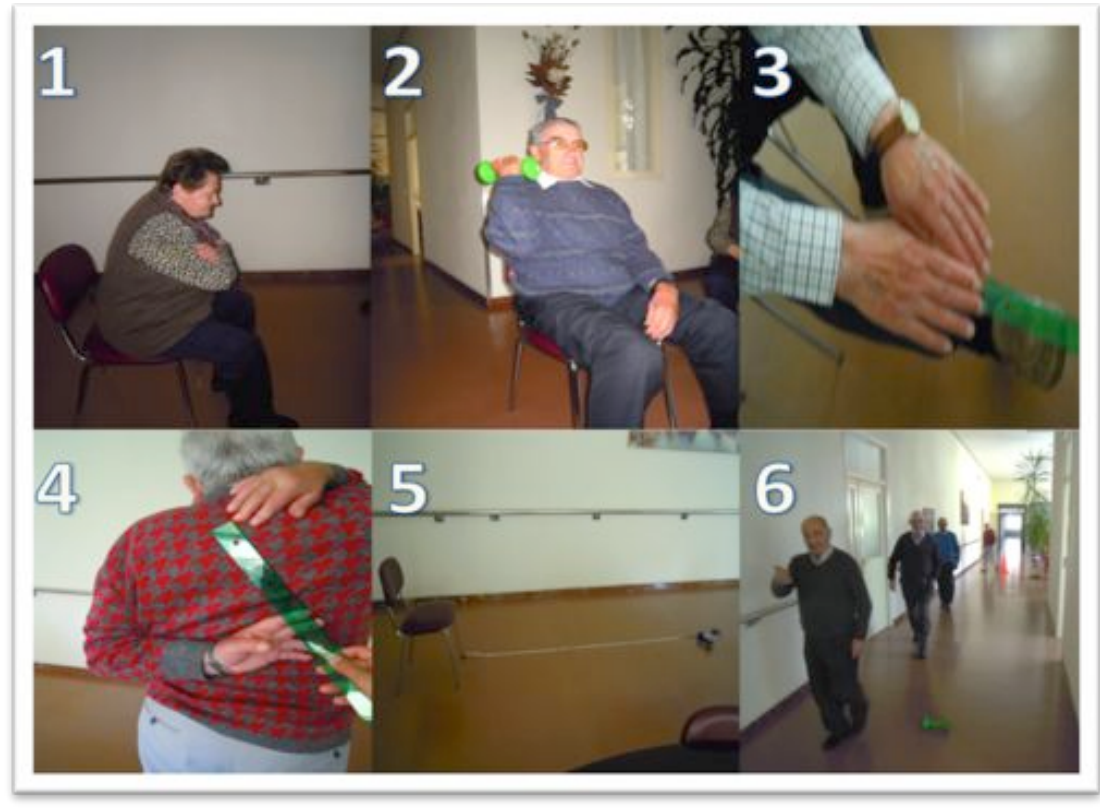

Imagen 14. Seis test evaluados en el SFT. En el anexo 2, se presentan las tablas de valoración utilizadas para evaluar el rendimiento de cada prueba de la batería SFT.

\section{1.- Test sentarse y levantarse de la silla durante $\mathbf{3 0}$ segundos}

Objetivo: Evaluar la fuerza del tren inferior.

Procedimiento: Se fijó una silla en la cual cada anciano debía sentarse y levantarse la mayor cantidad de veces posible durante 30 segundos. Todos ellos debían mantener los brazos cruzados a la altura de los hombros durante la ejecución de la prueba. Todos ellos se sentaron en la parte media de la silla.

\section{2.- Flexiones de codo con peso}

Objetivo: Evaluar la fuerza del tren superior.

Procedimiento: Se realizó esta prueba con una mancuerna de 2,2 kilos para las mujeres y de 3,6 kilos para los hombres. Se les pidió que no separaran el codo del 
costado del cuerpo. Además se les solicitó que realizaran una flexo-extensión completa la mayor cantidad de veces posible durante 30 segundos.

\section{3.- Sentado alcanzar pie extendido}

Objetivo: Valorar la flexibilidad del tren inferior.

Procedimiento: Los ancianos se sentaron en la parte de delante de la silla, debiendo estirarse todo lo posible para alcanzar la punta de su zapato. Se registraba como valor negativo cuando a estos les faltaban centímetros para alcanzar el objetivo, o bien se les apuntaba con valor positivo cuando lo sobrepasaban.

\section{4.- Alcanzar las manos tras la espalda}

Objetivo: Valorar la flexibilidad del tren superior.

Procedimiento: De pie, se les pedía que trataran de tomarse los dedos medios de ambas manos, un brazo pasaba sobre su hombro y el otro por debajo de este. Se registraba como valor negativo cuando a estos les faltaban centímetros para alcanzar el objetivo, o bien se les apuntaba con valor positivo cuando lo sobrepasaban.

\section{5.- Ida y vuelta}

Objetivo: Valorar el equilibrio dinámico y la agilidad.

Procedimiento: Se media 2,44 metros de distancia entre la silla y un cono, distancia a recorrer por los ancianos. Comenzaban sentados en la silla, con ambas manos sobre sus rodillas, debían levantarse lo más rápido posible y caminar hasta el cono y pasar por detrás de este y volver a sentarse, durante el menor tiempo posible.

\section{6.- Test de 6 minutos}

Objetivo: Valorar la resistencia aeróbica.

Procedimiento: En un pasillo se realizaron 4 marcas de 5 metros (20 metros), ubicando un cono tanto al final como al inicio de los 20 metros. Los ancianos debían 
caminar lo más rápido posible, sin correr, durante 6 minutos. Una vez terminado el tiempo, se les señalaba con un silbato y paraban en el lugar donde se encontraban, de esta manera se cuantificaba la distancia exacta recorrida durante la prueba.

\subsubsection{Obtención de las muestras sanguíneas}

Se extrajeron 3 vacutainer (Terumo Venoject, Bélgica) de $4 \mathrm{~mL}$ de sangre de cada participante tanto antes como después de las 9 semanas de entrenamiento de vibraciones. Dos vacutainer tenían EDTA como anticoagulante y el tercero heparina. Posteriormente los tres tubos se sometieron a una centrifugación a 3000 r.p.m. durante 15 minutos y siempre a una temperatura de $4^{\circ} \mathrm{C}$. Posteriormente se recogió la capa leucocitaria de los vacutainer con EDTA y el plasma del vacutainer con heparina, almacenándose $\mathrm{a}-80^{\circ} \mathrm{C}$ para su posterior análisis.

\subsubsection{Determinaciones plasmáticas}

Una muestra de $400 \mu \mathrm{L}$ de plasma con heparina obtenido tras la centrifugación de la sangre, fue utilizado para determinar la concentración de Colesterol total, Colesterol-HDL, Triglicéridos, Urea, Creatinina y Glucosa a través de un autoanalizador de parámetros bioquímicos, modelo Cobas Integra 400 (Roche Diagnostics, Suiza).

\subsubsection{Aislamiento de Leucocitos}

\section{Reactivos:}

- Tampón PBS.

- Tampón RCLB: 0,155 M ( $\left.\mathrm{NH}_{4} \mathrm{Cl}\right), 10 \mathrm{mM}\left(\mathrm{KHCO}_{3}\right)$ y 10mM (EDTA-disódico). 


\section{Procedimiento}

A $1 \mathrm{~mL}$ de capa leucocitaria se le añadió $5 \mathrm{~mL}$ de RCLB, se agitó y dejó por 30 minutos en hielo. Posteriormente se centrifugó a 2000 r.p.m por 5 minutos. Se extrajo el sobrenadante y se lavó el precipitado con PBS. Se volvió a centrifugar y se congelo el precipitado a $-80^{\circ}$ hasta el momento del análisis.

\subsubsection{Cuantificación de proteínas totales}

\section{Fundamento}

La unión de las proteínas con el reactivo de Bradford produce un cambio en el color del reactivo, y por tanto un cambio en su absorbancia. El reactivo Bradford contiene ácido fosfórico, metanol y también azul de comassie que al unirse a los residuos aminoacídicos de proteínas y en especial de arginina, cambia su máximo de absorbancia de 465 a $595 \mathrm{~nm}$.

\section{Reactivos}

- Agua Bidestilada.

- Bradford Reagent (Biorad).

- Muestra (Leucocitos).

- BSA (Bovine Seric Albumine): Para realizar la recta patrón.

\section{Procedimiento}

Se realizó una recta patrón de BSA, para posteriormente interpolar nuestras muestras de concentración desconocida. Se añadió $40 \mu \mathrm{L}$ de Bradford a cada muetra. Se leyó la absorbancia a $595 \mathrm{~nm}$ de cada microcubeta para hacer el blanco. 
Después se le añadió $2 \mu \mathrm{L}$ de muestra o patrón, según corresponda en cada microcubeta y se leyó la absorbancia a 595nm. Ésta debe haber aumentado gracias a la unión del Bradford con las proteínas que contiene la muestra y la recta patrón.

\section{Cálculos}

Los cálculos consisten en realizar una recta patrón de concentración conocida de proteínas realizada con BSA e interpolar.

\subsubsection{Cuantificación del ARNm por RT-PCR: Transcriptasa reversa $y$ Reacción en Cadena de la Polimerasa a Tiempo Real}

\section{Fundamento}

La cuantificación del ARNm de IL-1 $\beta$, IL-6, IL-10 y de TNF- $\alpha$ se realizó utilizando la técnica de RT-PCR en dos pasos: Transcripción reversa y Reacción en Cadena de la Polimerasa a Tiempo Real (RT-PCR).

\section{Método}

El ARNm de leucocitos se aisló utilizando el Kit RiboPureTM-Blood (Ambion Inc., EE.UU.) y fue cuantificado en un Nanodrop (ND-1000, Nanodrop, EE.UU.). El ADN genómico residual se eliminó tras la incubación del ARN con DNase I Rnasefree DNase (Ambion Inc. EE.UU.). El ADN complemento (ADNc) se sintetizó a partir del ARN, utilizando la enzima transcriptasa inversa del Kit High-Capacity cDNA Achive (Applied Biosystems, Reino Unido). Un control negativo (control sin transcriptasa) se desarrolló en paralelo. El ADNc se amplificó utilizando TaqMan 
Universal PCR Master Mix (Applied Biosystem, Reino Unido) en un equipo RT-PCR cuantitativa a tiempo real ABI PRISM 7000 (Applied Biosystems, Reino Unido) utilizando iniciadores específicos para el gen considerado. Las sondas TaqMan para IL-1ß (Genbank K02770.1 y HS01555410_m1), IL-6 (Genbank X04403.1 y HS00985639_m1), IL-10 (Genbank M57627.1 y HS00961622_m1), TNF- $\alpha$ (Genbank M10988.1 y Hs00174128_m1) y 18S (gen constitutivo) (Genbank X03205.1 y Hs99999901_s1) se obtuvieron comercialmente de TaqMan Assays-on-Demand Gene (Applied Biosystems, Reino Unido). Los cambios relativos en los contenidos de expresión génica se determinaron usando el método 2- $\Delta \Delta C T$ como se ha descrito previamente (Livak y Schmittgen, 2001). El número de ciclos al cual los transcriptos fueron detectables (CT) se normalizó respecto al número de ciclos para la detección del 18S, refiriéndose como $\Delta C T$.

\subsubsection{Cuantificación de proteínas por Western Blot}

\section{Fundamento:}

La determinación de proteínas se llevo a cabo a través de la técnica de Western Blot utilizando el método de Laemmli (1970).

\section{Reactivos:}

- Solución de ebullición: $\mathrm{H}_{2} \mathrm{O}$, Tris/ $\mathrm{HCl} 2 \mathrm{M}(\mathrm{pH} 6,8)$, glicerol $60 \%$, SDS $10 \%$ y pirrolina $0,5 \%$.

- Tampón de electroforesis: Tris $25 \mathrm{mM}$, glicina 0,2 M, SDS 3,5 mM pH 8,8.

- Tampón de lisis: $\mathrm{NaCl} 140 \mathrm{mM}$, EDTA 15 mM, glicerol 10\% y Tris $20 \mathrm{mM}, \mathrm{pH}$ 8.

- Tampón de transferencia: Tris $25 \mathrm{mM}$, glicina $0,2 \mathrm{M}$ y metanol $20 \%$. 
- PBS: $\mathrm{NaCl}$ 0,14 M, $\mathrm{KH}_{2} \mathrm{PO}_{4} 1,4 \mathrm{mM}, \mathrm{NaHPO}_{4} 8 \mathrm{mM}, \mathrm{KCl}$ 2,7 mM, pH 7,4

- PBS-Tween: PBS + Tween 0,05\%.

- Solución de bloqueo y de incubación de anticuerpos: 2,5 a $5 \%$ de leche en polvo desnatada diluida en PBS-Tween 0,05\%.

- Tampón de deshibridación: Tris $6,25 \mathrm{mM} \mathrm{pH} \mathrm{6,7,} \mathrm{SDS} \mathrm{2 \%} \mathrm{y} \mathrm{mercaptoetanol}$ $100 \mathrm{mM}$.

- Tampón de sonicación: sacarosa 0,25 mM, Tris $10 \mathrm{mM}$ y EDTA sódico $1 \mathrm{mM}$, $\mathrm{pH} 7,4$.

- Mezcla de inhibidores de proteasas: PMSF, aprotinina e inhibidor de tripsina.

\section{Método}

Se sonicaron los leucocitos en $150 \mu \mathrm{L}$ de tampón de sonicación (sobre hielo), al que previamente se le había añadido la mezcla de inhibidores de proteasas y fosfatasas, durante 2 ciclos de 20 segundos con 10 segundos de pausa entre ambos y con una amplitud de ciclo de $100 \%$. Tras el análisis de la concentración de proteínas medida a través del método Bradford, se tomó una cantidad de $40 \mu \mathrm{g}$ de proteína a la que se le añadió el tampón de lisis y solución de ebullición con betamercaptoetanol, y se incubó durante 2 minutos a $100^{\circ} \mathrm{C}$. Posteriormente las muestras fueron sometidas a electroforesis en varios geles de poliacrilamida al $12 \%$ en tampón de electroforesis, proceso que duró aproximadamente 100 minutos a 100 V. Finalizada la electroforesis y separadas las proteínas, los geles se transfirieron a membranas de PVDF Immobilon-P (Millipore, EE.UU.) para posteriormente permitir su exposición a los anticuerpos. La transferencia se realizó a $13 \mathrm{~V}$ durante 20 minutos. Después se incubó durante media hora en solución de bloqueo (0-5\% leche en polvo desnatada en PBS-Tween) a $37^{\circ} \mathrm{C}$. Una vez finalizado el bloqueo, las membranas se incubaron durante toda la noche con anticuerpos específicos para 
cada proteína, IL-1ß (17 kDa): Abcam; IL-6 (21 kDa): Santa Cruz Biotechnology; IL10 (37 kDa): Santa Cruz Biotechnology; TNF- $\alpha$ (17 kDa): Santa Cruz Biotechnology; proteína $C$ reactiva $(25 \mathrm{kDa})$ : Abcam. Transcurrido ese tiempo, se lavaron las membranas 5 veces durante 5 minutos cada vez, con PBS-Tween y finalmente 5 minutos solo con PBS. Posteriormente se incubó durante 1 hora y 15 minutos aproximadamente con el anticuerpo secundario antiinmunoglobulina (anti-cabra o conejo unido a HRP, dependiendo del origen del anticuerpo primario) (DAKO A/S, Glostrup, Dinamarca). Transcurrido la incubación se vuelve a realizar el mismo lavado mencionado anteriormente.

La detección de las proteínas se realizó por quimioluminiscencia utilizando el kit comercial Western Blotting Luminol Reagent (Santa Cruz Biotechnology, EE.UU.) exponiendo las membranas durante 1 minuto a la mezcla reactiva comercial. Posteriormente se introdujo en una cassette hermética junto con una película (Amersham Hyperfilm ECL, Reino Unido), durante tiempos que variaron entre los 15 segundos a los 30 minutos.

Tras el revelado y secado de la película se llevó a cabo la cuantificación de las bandas por densitometría utilizando para ello el programa Scion Image 4.02 para Windows (Scion Corporation, Frederick, EE.UU.).

Con objeto de verificar que se había cargado la misma cantidad de proteína en cada pocillo del gel, las membranas se lavaron en tampón de deshibridación durante 15 minutos y se expusieron posteriormente al anticuerpo $\beta$-Actina (42 kDa) Sigma Corporation of America, EE.UU. 


\subsection{TRATAMIENTO ESTADÍSTICO}

Las variables cuantitativas se expresan mediante el valor de su media y el error estándar de dicha media (E.E.M). Previamente al análisis comparativo, se realizó la prueba estadística Shapiro-Wilk para conocer si los datos pasan la prueba de normalidad de distribución de los datos. Posteriormente, dependiendo de este resultado se aplicó una prueba paramétrica o no paramétrica.

Se aplicó una $t$ Student para muestras pareadas y con distibución normal, o bien, la prueba de Wilcoxon para muestras pareadas sin districución normal. Para todas las pruebas se consideró un intervalo de confianza del $95 \%$, y un valor de $p<$ 0,05 como estadísticamente significativo. Para todo el tratamiento estadístico se utilizó el programa Graphpad Instat 5, versión 5.0, para MAC. 
4. Resultados 


\subsection{EFECTOS DEL EVCC SOBRE LOS COMPONENTES DE LA BATERÍA SENIOR FITNESS TEST}

El hecho de mantener las cualidades físicas necesarias para desarrollar una vida con independencia es imprescindible a medida que se avanza en edad. La batería SFT es capaz de evaluar la capacidad funcional de las personas mayores a través de 6 pruebas.

En la tabla 10 se presentan los resultados obtenidos en las diversas pruebas que componen el SFT tras el programa de EVCC, en la figura 1, se muestran los resultados categorizados en: "dentro", "sobre" o "por debajo" del rango del percentil 50. En esta figura, se observa la variación, en porcentaje, de cada uno de los sujetos del estudio tras haber culminado el programa de EVCC.

\begin{tabular}{lcccc}
\hline \multicolumn{1}{c}{ Test } & Pre & Post & $\%$ & $\boldsymbol{p}$ \\
\hline Sentarse y levantarse (rep) & $12,5 \pm 0,8$ & $14,8 \pm 0,8$ & 18,4 & * \\
Flexión de codo (rep) & $17,0 \pm 0,9$ & $20,8 \pm 0,8$ & 22,3 & * \\
Alcanzar pies (cm) & $-11,9 \pm 3,1$ & $-10,7 \pm 2,5$ & 10,1 & $\mathrm{~ns}$ \\
Alcanzar manos (cm) & $-17,5 \pm 3,0$ & $-13,8 \pm 3,4$ & 21,2 & $\mathrm{~ns}$ \\
Ir y venir y sentarse (s) & $8,3 \pm 0,4$ & $6,9 \pm 0,4$ & 16,9 & * \\
Test 6 min (m) & $426 \pm 21$ & $421 \pm 20$ & 1,2 & $\mathrm{~ns}$ \\
\hline
\end{tabular}

Tabla 10. Resultado de la Batería SFT. rep: repeticiones. Valores medios \pm E.E.M. \%: Porcentaje de variación entre el PRE y POST test. * $p<0,05$. ns: no significativo. 


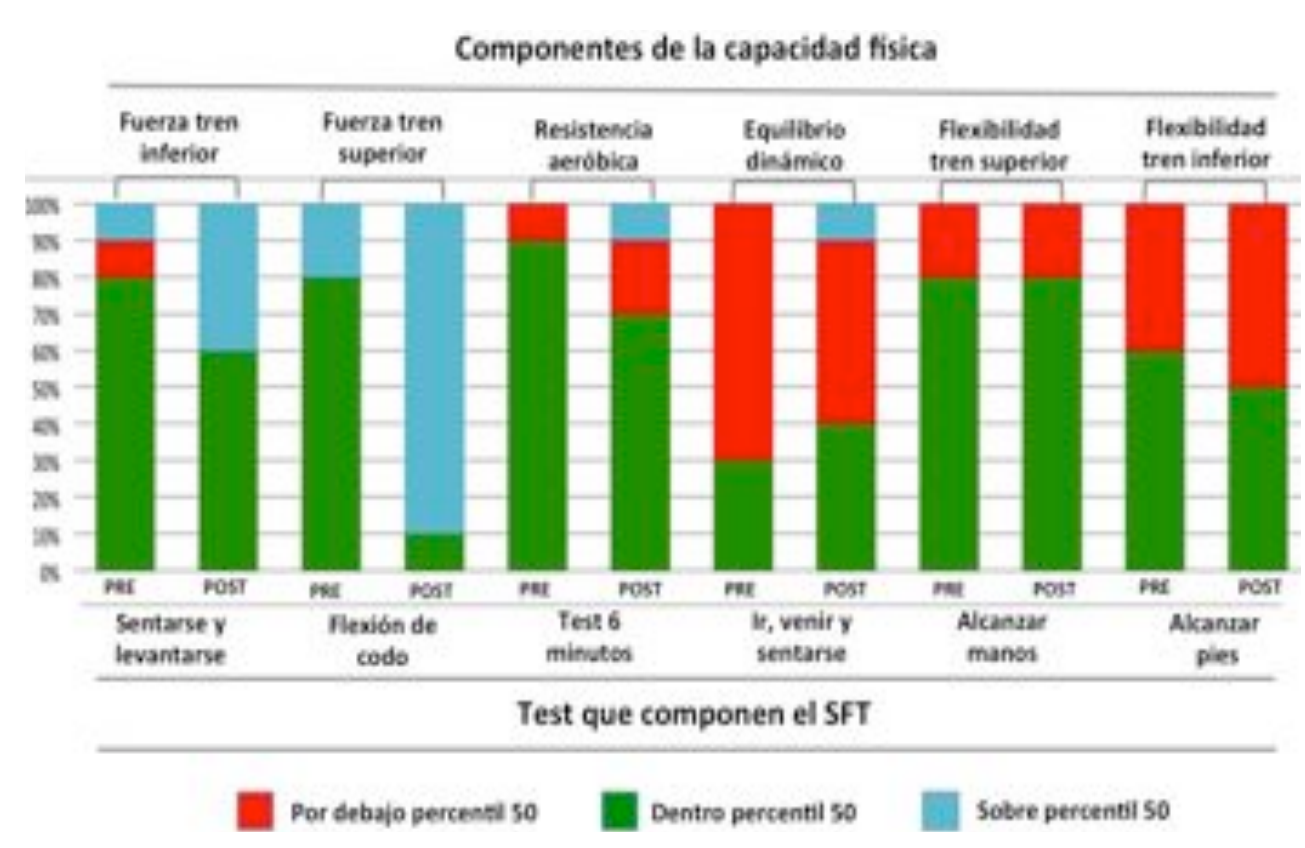

Figura 1. Variación porcentual de sujetos categorizados en: dentro, sobre o por debajo del rango del percentil 50, PRE y POST EVCC.

Se observa que en los test de, sentarse y levantarse, en la flexión de codo, en el de ir, venir y sentarse, y en el test de 6 minutos, existe una variación porcentual favorable tras el EVCC por parte de los sujetos. Demostrando de alguna manera que los ancianos mejoraron su aptitud física frente a las pruebas mencionadas. En cambio en los 2 test relacionados con la flexibilidad no se obtuvieron los mismos resultados.

A continuación, se presentan de manera más detallada los resultados obtenidos en el SFT. Siendo estos agrupados en 3 áreas, para su mejor comprensión. Estas son: fuerza del tren superior e inferior y equilibrio dinámico, flexibilidad del tren superior e inferior, y resistencia aeróbica. 


\subsubsection{Efecto del EVCC sobre la fuerza del tren superior e inferior y equilibrio} dinámico

La fuerza del tren inferior y del tren superior, así como el equilibrio dinámico en las personas mayores, son cualidades físicas relevantes a la hora de prevenir las caídas, y mantener su nivel de independencia funcional en las actividades del día a día, como por ejemplo subir escaleras, levantarse de una silla y levantar bolsas, entre otras.

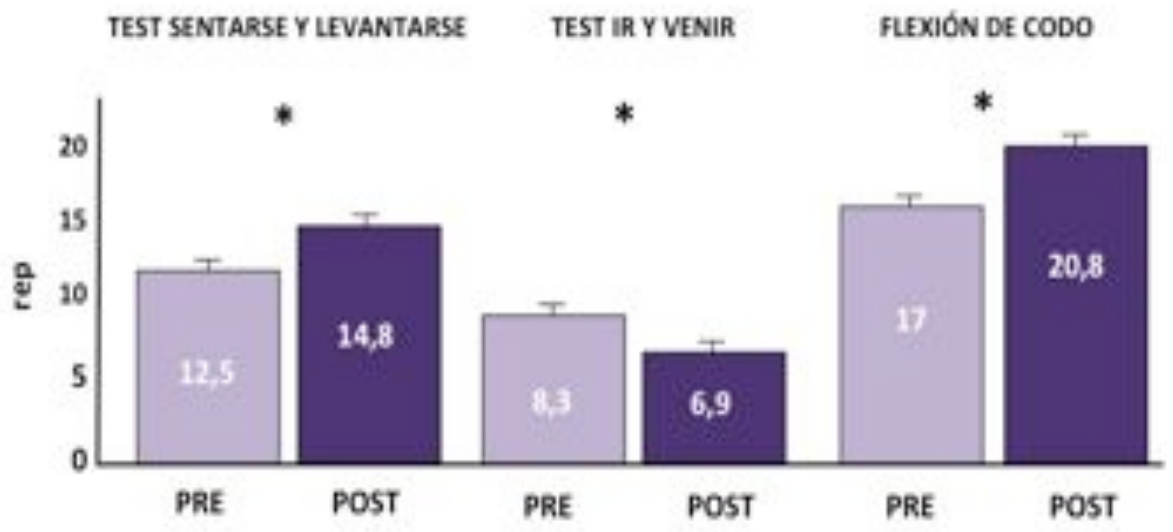

Figura 2. Resultados de la valoración del test sentarse y levantarse, test ir y venir, flexión de codo PRE y POST EVCC. Valores medios \pm E.E.M. ${ }^{*} p<0,05$.

La fuerza y la potencia muscular constituyen pilares fundamentales para la salud. En los tres test relacionados tanto con la fuerza como con la movilidad, se observan variaciones estadísticamente significativas en este estudio (Figura 2). Tanto el test "sentarse y levantarse", como el test de "ir y venir" y el test de "flexión de codo" mejoraron un $18,4 \%, 16,9 \%$ y $22,3 \%$ respectivamente. 


\subsubsection{Efecto del EVCC sobre la flexibilidad del tren superior e inferior}

La flexibilidad va disminuyendo a medida que se avanza en edad, incrementando de paso el riesgo de caídas, heridas, dolor de espalda y disminuyendo la longitud del paso, entre otros. Todos estos factores son importantes a la hora de ver reducida la movilidad física en la población de estudio.

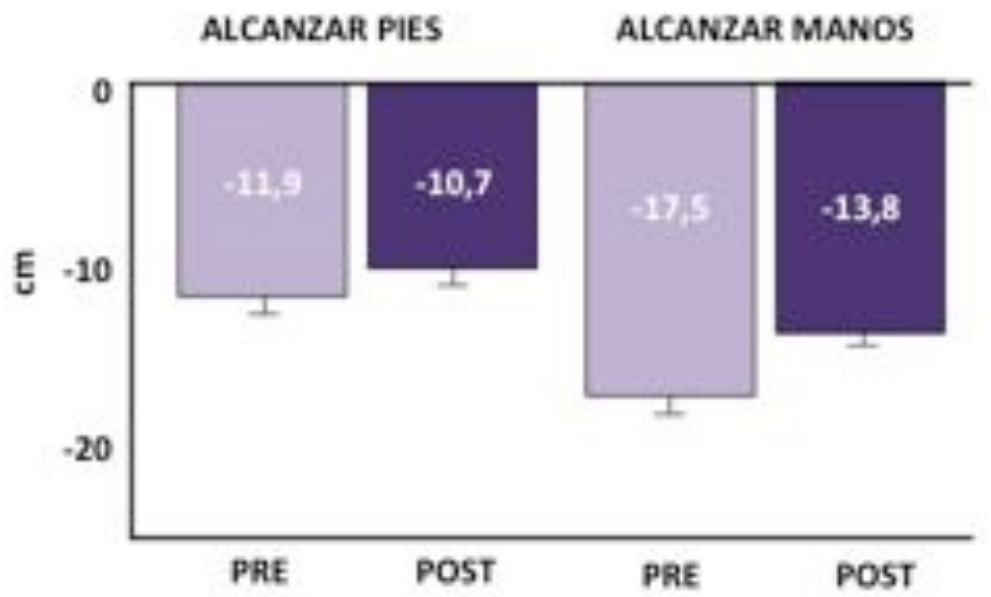

Figura 3. Resultados de la valoración del test alcanzar los pies, y alcanzar las manos PRE y POST EVCC. Valores medios \pm E.E.M. ${ }^{*} p<0,05$.

Tanto en el test "alcanzar los pies" como en el de "alcanzar las manos" no se aprecian diferencias estadísticamente significativas a pesar de que la distancia entre los dos puntos a alcanzar (mano con pie, o bien, mano con mano tras la espalda), disminuyeron en un $10,1 \%$ y un $21,2 \%$ respectivamente (Figura 3 ). 


\subsubsection{Efecto del EVCC sobre la resistencia aeróbica}

Las personas mayores que poseen un elevado nivel de resistencia aeróbica, también poseen un mayor grado de salud y ven aumentado su expectativa de vida, lo que mejora considerablemente la calidad de la misma. Es por esto que mantener o tratar de retardar la pérdida de la resistencia aeróbica es tan importante en este tipo de población.

\section{TEST 6 MINUTOS}

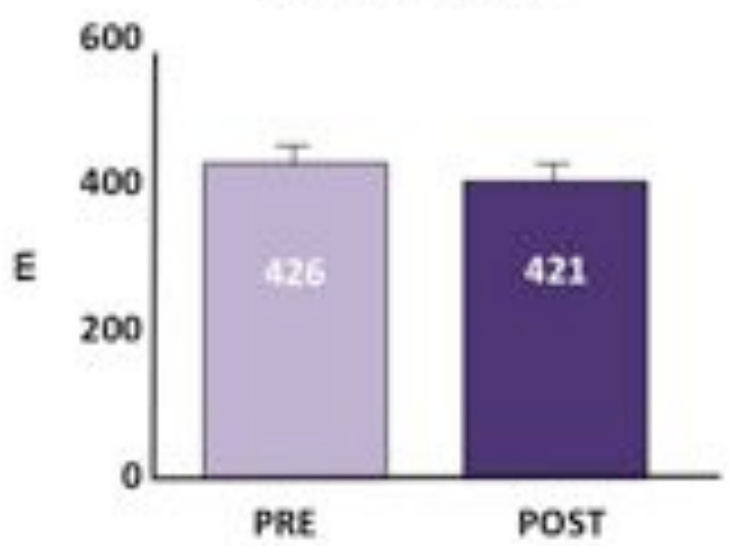

Figura 4. Resultados de la valoración del test de caminar 6 minutos PRE y POST EVCC. Valores medios \pm E.E.M.

A diferencia de lo observado en el test de flexibilidad del tren superior e inferior, en donde a pesar de no obtener diferencias estadísticas significativas, sí se observa cierta mejoría; en el test de 6 minutos se aprecia una constancia en su rendimiento medio $(1,2 \%)$, no obteniéndose una diferencia estadística entre los valores (Figura 4 ). 


\subsection{EFECTO DEL EVCC SOBRE LA EVALUACIÓN DE LA FUERZA, POTENCIA Y ACTIVIDAD ELECTROMIOGRÁFICA DEL TREN INFERIOR}

Como se mencionó anteriormente, la pérdida de la masa muscular a medida que avanza la edad es un proceso normal del organismo, que conlleva una disminución considerablemente de los niveles de fuerza y potencia muscular. Además, estos cambios hacen necesario aumentar la señal eléctrica al músculo con el fin de reclutar una mayor cantidad de fibras musculares para una acción motriz en particular. Todo lo mencionado, perjudica la capacidad muscular de los ancianos, elevando el riesgo de caídas y de perdida de su independencia, entre otros. En la siguiente tabla (11) se recogen los resultados relacionados con la fuerza, potencia y función neuromuscular.

\begin{tabular}{lcccc}
\hline \multicolumn{1}{c}{ Parámetro } & PRE & POST & $\%$ & $p$ \\
\hline MCVI (N) & $338 \pm 38$ & $390 \pm 45$ & 15,0 & * \\
Fuerza relativa (N/Kg) & $5,1 \pm 0,5$ & $5,9 \pm 0,7$ & 15,6 & * \\
Potencia Pico 20\% (W) & $30,8 \pm 4,4$ & $32,6 \pm 5,0$ & 5,8 & * \\
Potencia Pico 40\% (W) & $67,3 \pm 10,7$ & $79,2 \pm 12,9$ & 17,6 & * \\
Potencia Pico 60\% (W) & $86,9 \pm 11,5$ & $109,1 \pm 13,3$ & 25,4 & * \\
EMGs Vasto Lateral $(\mu \mathrm{V})$ & $407 \pm 46$ & $227 \pm 27$ & 44,3 & * \\
EMGs Vasto Medial $(\mu \mathrm{V})$ & $293 \pm 33$ & $222 \pm 26$ & 24,4 & *
\end{tabular}

Tabla 11. Resultado sobre la MCVI, fuerza relativa, potencia pico al $20 \%, 40 \%$ y $60 \%$ y EMGs, PRE y POST EVCC. Valores medios \pm E.E.M. \%: Porcentaje de variación. * $p<0,05$. 
4.2.1. Efecto del EVCC sobre la Máxima Contracción Voluntaria Isométrica y sobre la Fuerza Relativa

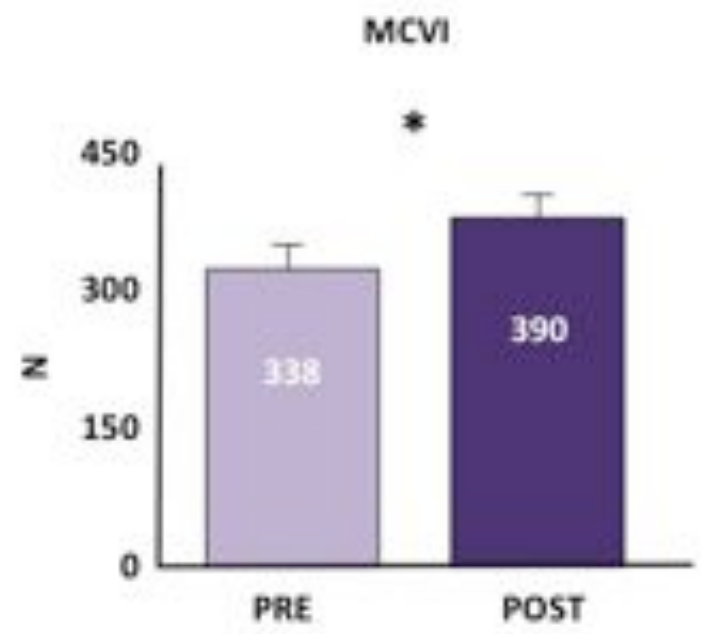

Figura 5. Resultados de la valoración de la Máxima Contracción Voluntaria Isométrica PRE y POST EVCC. Valores medios \pm E.E.M. * $p<0,05$.

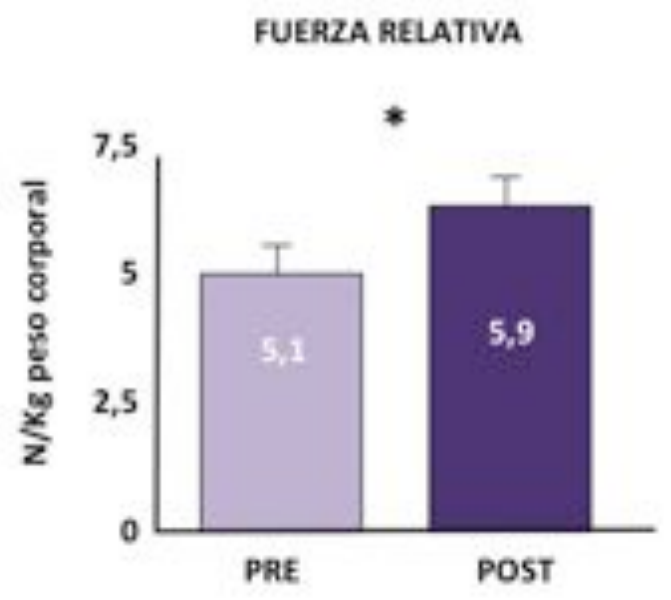

Figura 6. Resultados de la fuerza relativa PRE y POST EVCC. Valores medios \pm E.E.M. ${ }^{*} p$ $<0,05$. 
En el test de MCVI se aprecia un aumento de un 15,0\% tras el EVCC, con una diferencia estadísticamente significativa entre sus medias. Al relativizar el valor obtenido en el test de MCVI con el peso corporal total de cada individuo del estudio, podemos observar un incremento de un $15,6 \%$ en su fuerza relativa, con una diferencia estadísticamente significativa (Figura 5 y 6 ).

\subsubsection{Efecto del EVCC sobre la Potencia Pico al $20 \%, 40 \%$ y $60 \%$ de la MCVI}

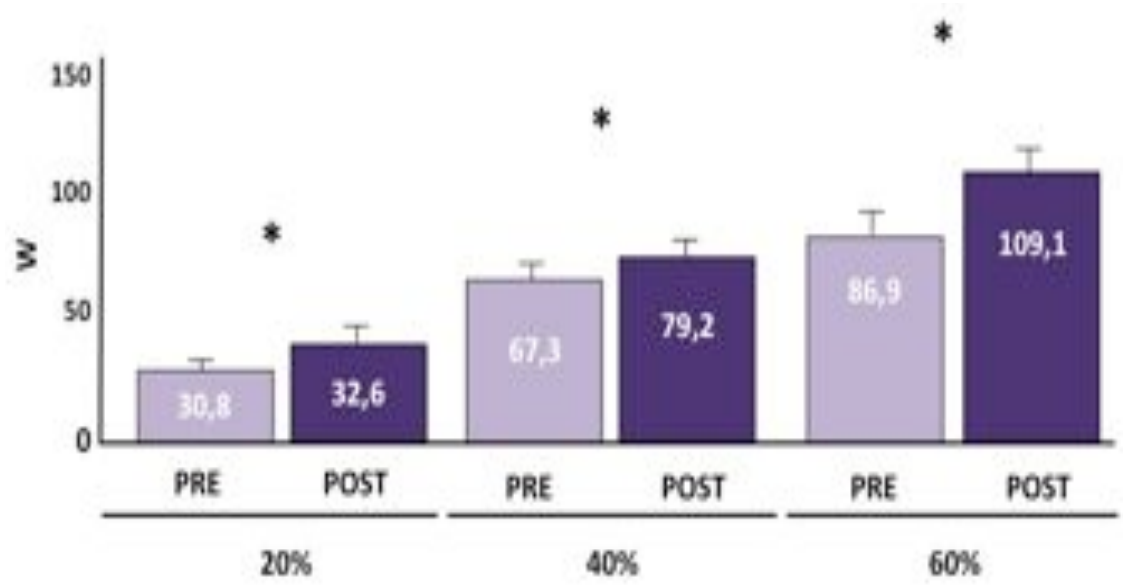

Figura 7. Resultados de la valoración de la potencia al $20 \%, 40 \%$ y $60 \%$ de la MCVI PRE y POST EVCC. Valores medios \pm E.E.M. ${ }^{*} p<0,05$.

Al igual que lo observado en la fuerza, la potencia mostró un importante incremento tras el programa de entrenamiento de vibraciones. Como se observa en la figura 7 , la potencia al $20 \%, 40 \%$ y $60 \%$ aumentó en un $5,8 \%, 17,6 \%$ y $25,4 \%$ respectivamente, todas las variaciones fueron estadísticamente significativas. 


\subsection{EFECTO DEL EVCC SOBRE LA ELECTROMIOGRAFÍA DE SUPERFICIE}

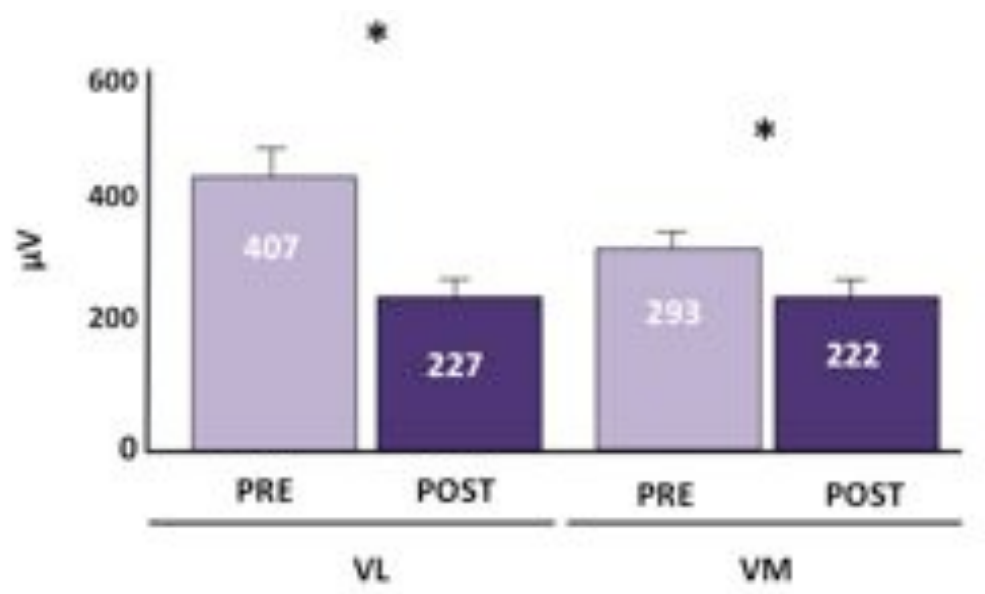

Figura 8. Resultados de la valoración del la EMGs del vasto lateral y del vasto medial PRE y POST EVCC. Valores medios \pm E.E.M. ${ }^{*} p<0,05$.

En la figura 8 se aprecia que tanto en el VL como en el VM existe una disminución estadísticamente significativa en la señal electromiografíca de los ancianos. La señal en el VL disminuyó un $44,3 \%$ y un $24,4 \%$ en el VM tras el programa de EVCC. Al casociar los valores de fuerza obtenidos tras el EVCC y estos valores de la EMGs, se podría expresar que mejoró la actividad contráctil del músculo. 


\subsection{VALORES DE MCVI Y POTENCIA DE JÓVENES Y ANCIANOS}

Con la finalidad de tener una idea de las diferencias existentes entre dos poblaciones tan diferentes como la de jóvenes y ancianos, se determinaron los valores de MCVI, Fuerza relativa, Potencia Pico al $20 \%, 40 \%$ y $60 \%$, además de la actividad electromiográfica del VL y VM en sujetos jóvenes (Tabla 12). La idea no es comparar, sino más bien tener un punto de referencia sobre un grupo de sujetos que poseen sus capacidades funcionales en plenitud y así poder determinar si el EVCC, en cierta medida, ayuda a detener o a mejorar estas variables, "acercándose" a los valores de los jóvenes.

\begin{tabular}{lc}
\hline \multicolumn{1}{c}{ Parámetro } & Valores \\
\hline MCVI $(\mathrm{N})$ & $1069 \pm 68$ \\
Fuerza relativa $(\mathrm{N} / \mathrm{kg})$ & $13,8 \pm 1,0$ \\
Potencia Pico 20\% $(\mathrm{W})$ & $199 \pm 16$ \\
Potencia Pico 40\% $(\mathrm{W})$ & $322 \pm 32$ \\
Potencia Pico 60\% $(\mathrm{W})$ & $444 \pm 34$ \\
EMGs Vasto Lateral $(\mu \mathrm{V})$ & $1111 \pm 206,0$ \\
EMGs Vasto Medial $(\mu \mathrm{V})$ & $1229 \pm 251,5$
\end{tabular}

Tabla 12. Resultado sobre la MCVI, fuerza relativa, potencia pico al $20 \%, 40 \%$ y $60 \%$ y electromiografía de superficie en jóvenes. Valores medios \pm E.E.M. 
4.5. EFECTO DEL EVCC SOBRE LOS VALORES ABSOLUTOS Y RELATIVOS DE LA FUERZA DE JÓVENES Y ANCIANOS

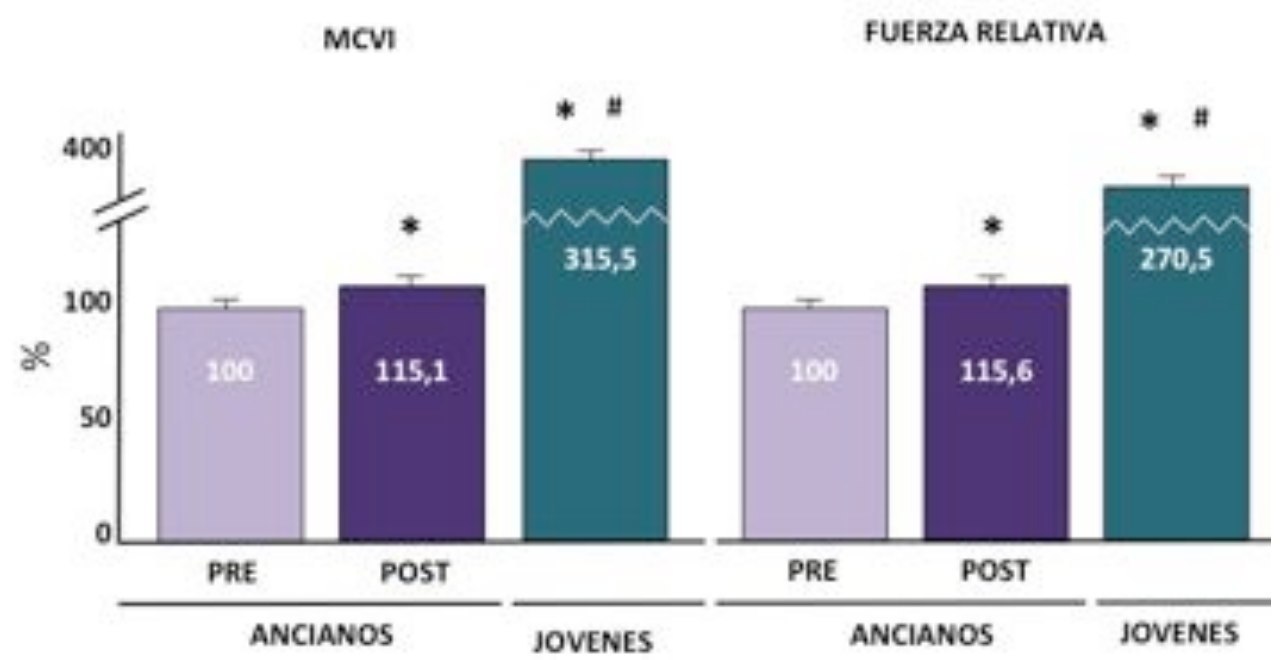

Figura 9. Comparación porcentual de la MCVI y fuerza relativa de los ancianos PRE y POST EVCC, y valores de un grupo de jóvenes. Media \pm E.E.M. * $p<0,05$ respecto al grupo PRE. \# $p<0,05$ respecto al grupo POST.

En la figura 9, se pone de manifiesto que al comparar los valores obtenidos de MCVI y de la fuerza relativa en los ancianos se obtienen dos resultados evidentes. Por un lado, las ganancias de fuerza (PRE y POST) entre los valores relativos y los valores absolutos experimenta sólo un $0,5 \%$ de variación. $Y$ por otro lado, la diferencia entre el valor POST tras el EVCC y el valor de los jóvenes es de un $274,1 \%$ en valores absolutos, mientras que con valores relativos es de un $233,8 \%$, observándose una diferencia de un 40,3\%. 
4.6. EFECTO DEL EVCC SOBRE LA POTENCIA PICO DE JÓVENES Y ANCIANOS

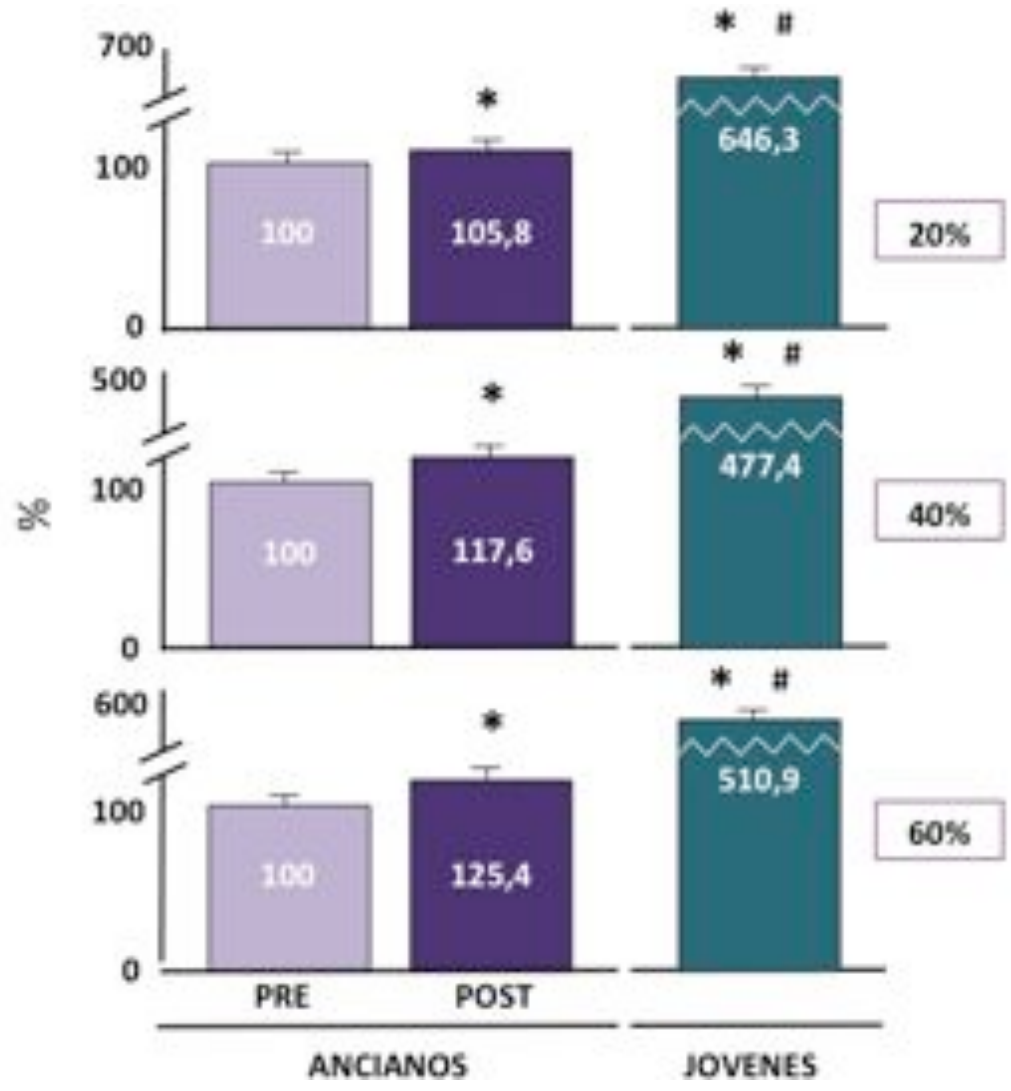

Figura 10. Comparación porcentual de la potencia pico al $20 \%, 40 \%$ y $60 \%$ de los ancianos PRE y POST EVCC y valores de un grupo de jóvenes. Media \pm E.E.M. ${ }^{*} p<0,05$ respecto al grupo PRE. \# $p<0,05$ respecto al grupo POST.

La potencia es una característica física fundamental para la salud, en especial de los ancianos. Tras el EVCC la potencia al $20 \%, 40 \%$ y al $60 \%$ mejoraron en un $5,8 \%, 17,6 \%$ y en un $25,4 \%$ respectivamente. Como se aprecia en la figura 10 , los valores referenciales de los jóvenes son sustancialmente más elevados (5 veces) 
comparado con los valores de los ancianos. Esto explica en cierta medida el gran esfuerzo que les puede significar levantarse de una silla a este colectivo.

\subsection{MARCADORES DE INFLAMACIÓN ENTRE JÓVENES Y ANCIANOS}

A medida que se envejece se van produciendo cambios tanto fisiológicos como fisiopatológicos que incrementan la inflamación a nivel sistémico. De esta manera se va deteriorando el estado de salud de las personas mayores. Tanto el entrenamiento aeróbico como el de resistencia han demostrado tener cierto efecto positivo sobre diversos marcadores de inflamación. Pero no existen estudios sobre el efecto crónico del EVCC en estos marcadores.

\subsubsection{Contenido de ARNm de diversos marcadores de inflamación}

En la siguiente tabla (13) se presentan expresados como porcentaje de cambio los contenidos de ARNm de diversas citoquinas en los diferentes grupos experimentales estudiados.

\begin{tabular}{cccccc}
\hline & \multicolumn{2}{c}{ Ancianos } & \multicolumn{2}{c}{ Jóvenes } \\
\hline ARNm & Pre & Post & $\boldsymbol{p}$ & & $\boldsymbol{p}$ \\
\hline IL-6 & 100 & $112,5 \pm 3,2$ & $\mathrm{~ns}$ & $78,7 \pm 2,0$ & $\mathrm{~ns}$ \\
IL-1 $\beta$ & 100 & $110,6 \pm 4,4$ & $\mathrm{~ns}$ & $33,2 \pm 5,8$ & $\mathrm{~ns}$ \\
TNF- $\alpha$ & 100 & $90,5 \pm 3,4$ & $\mathrm{~ns}$ & $71,3 \pm 8,0$ & $\mathrm{~ns}$ \\
IL-10 & 100 & $59,0 \pm 8,6$ & ns & $104,3 \pm 10,8$ & $\mathrm{~ns}$ \\
\hline
\end{tabular}

Tabla 13. Porcentaje de variación de las concentraciones de ARNm a través de la técnica RT-PCR, considerando los valores de los ancianos PRE EVCC como el 100\%. ns: no significativo 
A pesar de las variaciones en los contenidos de ARNm en un $12,5 \%, 10,6 \%$, $9,5 \%$ y $41 \%$ en IL- 6 , IL- $1 \beta$, TNF- $\alpha$ y IL-10 respectivamente, no se obtuvieron diferencias estadísticamente significas entre los valores PRE y POST tras el EVCC. Tampoco se observaron cambios significativos cuando el grupo de anciano se comparó con el grupo de referencia de sujetos jóvenes.

\subsubsection{Contenido proteico de diversos marcadores de inflamación}

En la tabla 14 se resumen los valores expresados como porcentaje de cambio, de los contenidos proteicos de diversas citoquinas tanto antes como después del EVCC. Además se recogen los valores de un grupo de jóvenes para las mismas citoquinas. No se obtuvieron diferencias significativas entre los tres grupos.

\begin{tabular}{cccccc}
\hline & \multicolumn{2}{c}{ Ancianos } & \multicolumn{3}{c}{ Jóvenes } \\
\hline Proteína & Pre & Post & $\boldsymbol{p}$ & & $\boldsymbol{p}$ \\
\hline PCr & $100 \pm 8$ & $84,2 \pm 11$ & $\mathrm{~ns}$ & $77,6 \pm 20$ & $\mathrm{~ns}$ \\
IL-6 & $100 \pm 13$ & $87,6 \pm 12$ & $\mathrm{~ns}$ & $127,6 \pm 15$ & $\mathrm{~ns}$ \\
IL-1 $\beta$ & $100 \pm 18$ & $100,1 \pm 12$ & $\mathrm{~ns}$ & $110,0 \pm 18,1$ & $\mathrm{~ns}$ \\
TNF- $\alpha$ & $100 \pm 12$ & $112,0 \pm 10$ & $\mathrm{~ns}$ & $139,1 \pm 21$ & $\mathrm{~ns}$ \\
IL-10 & $100 \pm 24$ & $133,4 \pm 42$ & $\mathrm{~ns}$ & $178,9 \pm 37$ & $\mathrm{~ns}$ \\
\hline
\end{tabular}

Tabla 14. Porcentaje de variación de las concentraciones de proteínas a través de la técnica Western Blot, considerando los valores de los ancianos PRE EVCC como el 100\%. PCr: proteína $\mathrm{C}$ reactiva. ns: no significativo.

Como se puede apreciar en las siguientes figuras (11 - 15), a pesar de las variaciones en las concentraciones de un $15,8 \%, 12,4 \%, 0,1 \%, 12 \%$ y $33,4 \%$ en la 
proteína C reactiva, IL-6, IL-1 $\beta$, TNF- $\alpha$ y IL-10 respectivamente, no se obtuvieron diferencias estadísticamente significativas entre los valores PRE y POST tras el EVCC en ancianos. Tampoco se obtuviero cambios significativos desde el punto de vista estadístico cuando los anteriores valores se compararon con los obtenidos en el grupo de sujetos jóvenes.

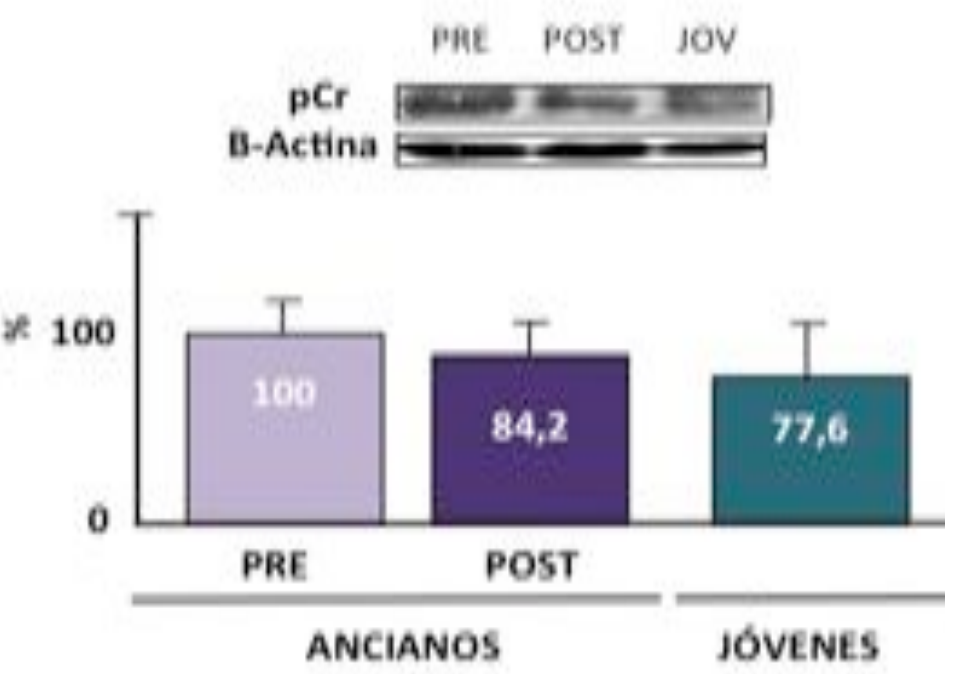

Figura 11. Cuantificación del contenido proteico de proteína $C$ reactiva obtenido de leucocitos. Valores medios \pm E.E.M. 

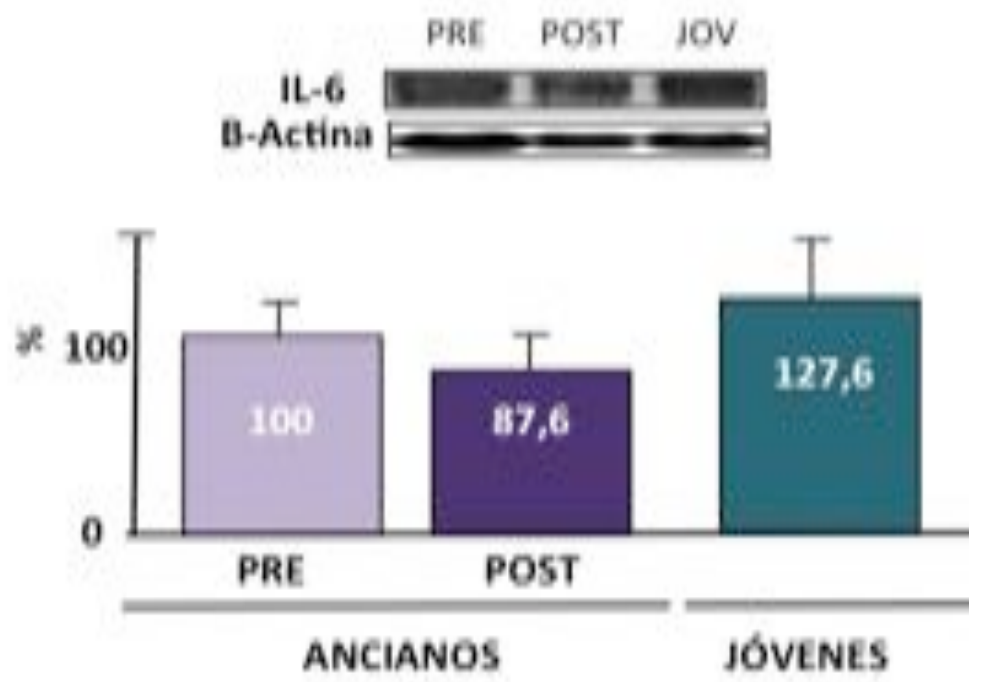

Figura 12. Cuantificación del contenido proteico de la citoquina IL-6 obtenida de leucocitos. Valores medios \pm E.E.M.
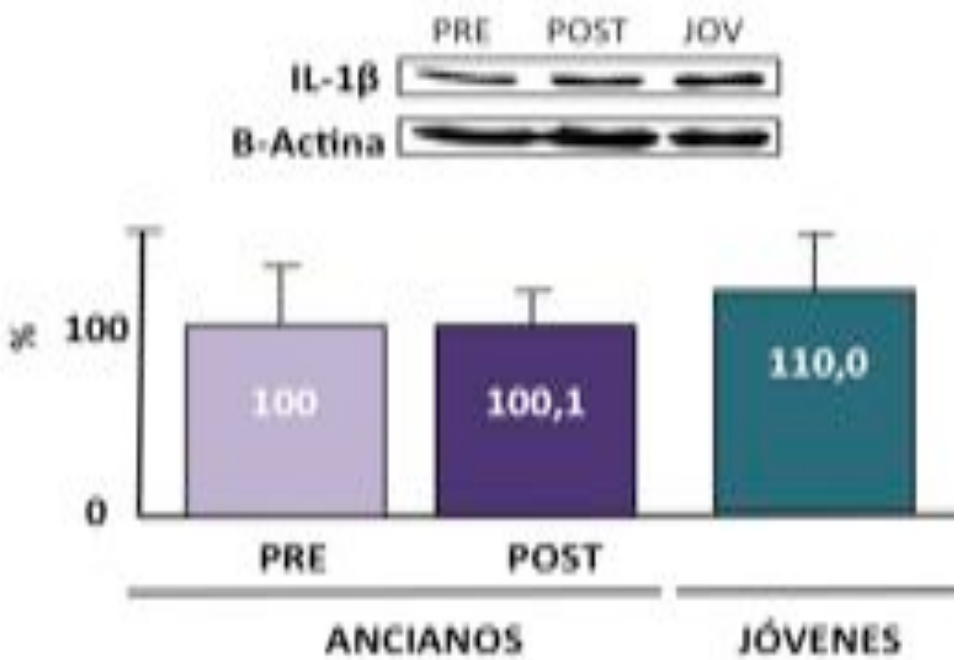

Figura 13. Cuantificación del contenido proteico de la citoquina IL-1 $\beta$ obtenida de leucocitos. Valores medios \pm E.E.M. 

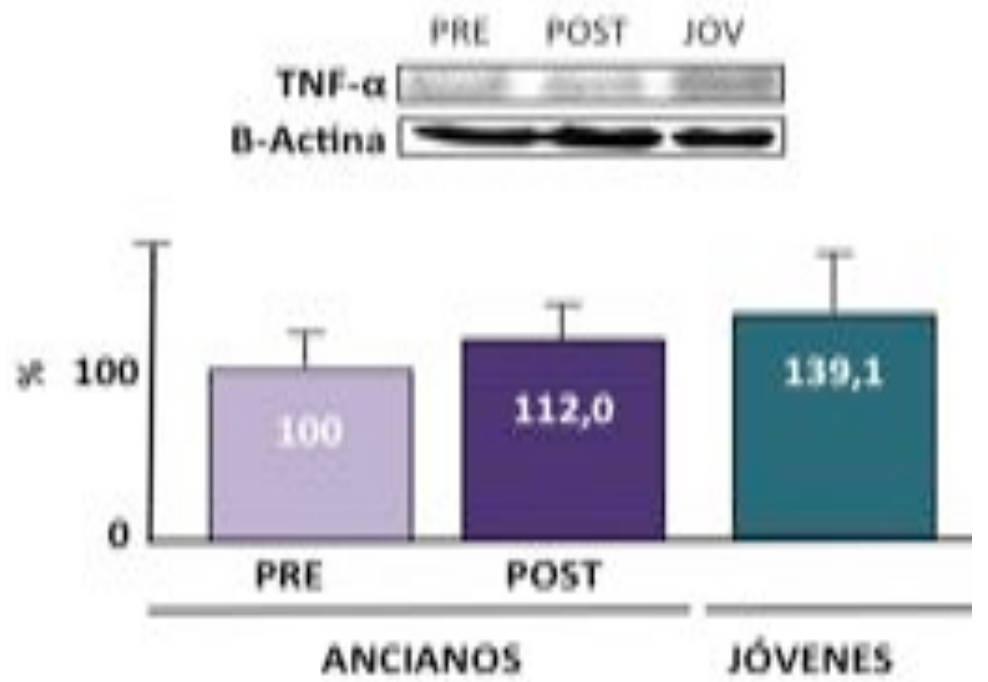

Figura 14. Cuantificación del contenido proteico de la citoquina TNF- $\alpha$ obtenida de leucocitos. Valores medios \pm E.E.M.
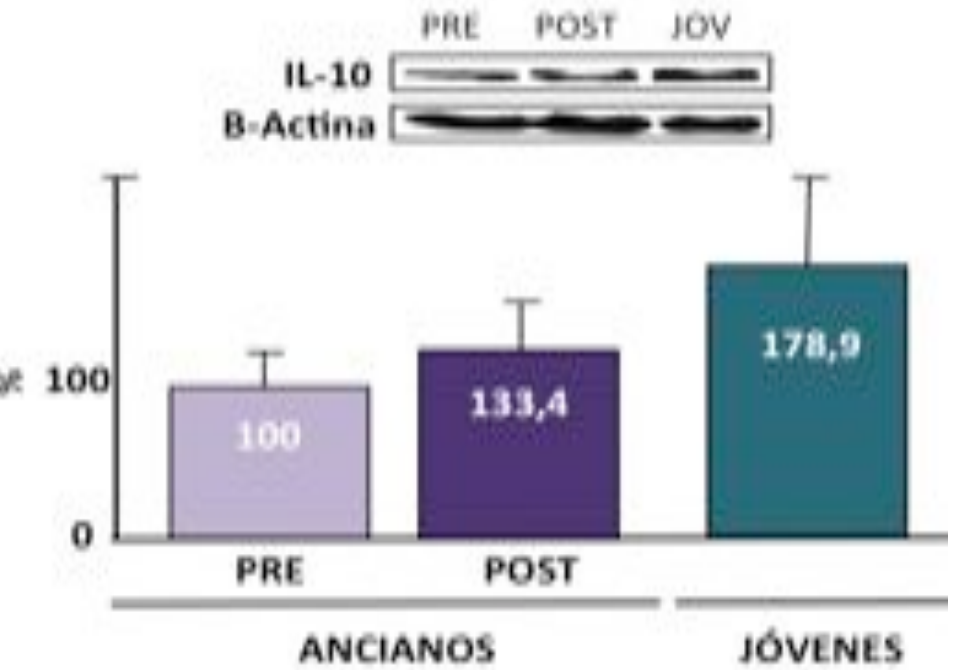

Figura 15. Cuantificación del contenido de la citoquina IL-10 obtenida de leucocitos. Valores medios \pm E.E.M. 


\section{Discusión}




\subsection{EFECTO DEL EVCC SOBRE LA CAPACIDAD FUNCIONAL DE LOS ANCIANOS}

Evaluar la condición física de los ancianos es fundamental a la hora de prevenir el deterioro funcional, o bien para promover y definir las características de un programa de entrenamiento físico que ayude a disminuir la perdida de las funciones físicas, con la finalidad de retrasar la dependencia de estas personas (Jones y Rikli, 2002).

En el presente estudio se ha podido demostrar que un programa de 9 semanas de entrenamiento de vibraciones en ancianos, puede lograr importantes modificaciones en casi todas las cualidades física evaluadas a través de la batería SFT. Esto demuestra que el entrenamiento de vibraciones parece ser tan o más eficiente que los programas "tradicionales" de entrenamiento en incrementar la fuerza de la extremidad superior; así como también, la fuerza, potencia pico, la actividad electromiográfica y el equilibrio dinámico del miembro inferior. No obstante, no se obtuvieron diferencias significativas ni en la flexibilidad ni en la resistencia aeróbica con este tipo de entrenamiento.

A continuación se discuten los resultados obtenidos de los diversos componentes de la capacidad física medidas a través del SFT. Estas seguirán siendo agrupadas en las 3 áreas mencionadas anteriormente (fuerza y equilibrio dinámico, flexibilidad, y resistencia aeróbica), con la finalidad de relacionar y discutir de manera más precisa los resultados obtenidos de este estudio con los artículos seleccionados de la literatura científica. Dentro del área de la fuerza y el equilibrio dinámico se incluye además una breve discusión sobre los resultados obtenidos en la MCVI, EMGs y evaluación de la potencia muscular. 


\subsubsection{Fuerza y equilibrio dinámico}

\subsubsection{Efectos del EVCC sobre la fuerza del tren superior}

El entrenamiento de resistencia parece tener un claro efecto sobre la fuerza del tren superior en ancianos. No obstante, tanto el tiempo de duración de los programas como la ganancia de fuerza son bastante variables y poco concluyentes. Morris y Schoo, (2004), determinaron tras un análisis de 15 artículos científicos, que la media de duración de los programas de resistencia tradicional es de 26,9 semanas y la ganancia de fuerza es de un $26,9 \%$.

Actualmente no existe en la literatura científica estudios específicos sobre el efecto del EVCC en el tren superior en la población anciana, siendo éste el primero en esta línea. Pero sí se pueden encontrar estudios de este tipo en otras poblaciones, y también los hay enfocados a otras áreas, lógicamente con otras finalidades. De todas maneras, estos estudios demuestran cambios fisiológicos positivos sobre la extremidad superior (Bosco et al., 1999; Mischi y Cardinale, 2009; Moran et al., 2007; Hazell et al., 2007; Cochrane y Hawke, 2007; Cochrane et al., 2008a; Cochrane et al., 2008b; Cochrane, 2011)

Se ha especulado que el efecto del estímulo vibratorio sería reducido en el tren superior, debido a tener que viajar a través del cuerpo, resultando en un estímulo insuficiente como para incrementar la actividad muscular de esa extremidad (Mester et al. 2003; Luo et al. 2005). No obstante, un interesante estudio de Hazell et al., (2007) realizado con jóvenes, evaluó el efecto de un entrenamiento sobre la plataforma de vibraciones en el tren superior y midió la actividad EMGs del bíceps y tríceps braquial durante la realización de dos tipos de ejercicio (dinámico y estático). Los autores concluyeron que la actividad muscular efectivamente se incrementa, en mayor medida cuando la amplitud y la frecuencia de las vibraciones son mayores, y 
cuando la posición tanto de sentadilla sobre la plataforma como del ejercicio de bíceps o tríceps es dinámico y no estático. Todos estos datos, han aclarando la incertidumbre respecto a la efectividad de la vibraciones para incrementar la actividad muscular en el tren superior.

En otro estudio con jóvenes, realizado por Marín et al., (2010), se observó que tanto la alta como la baja magnitud del estimulo vibratorio $(50 \mathrm{~Hz}, 2,51 \mathrm{~mm}$ y $30 \mathrm{~Hz}$, $1,15 \mathrm{~mm}$ respectivamente) provocan un estimulo adicional al tren superior. En esta ocasión se llevó a cabo un ejercicio de tríceps en posición sentadilla de $90^{\circ}$.

Para aclarar un poco más este tema, y poder fundamentar los resultados obtenidos en el presente estudio sobre la valoración de la fuerza del tren superior a través del test "flexión de codo" se puede hacer referencia a Marín, (2011), el cual expone que: "Aplicar un estímulo vibratorio mediante una plataforma de vibraciones genera efectos no solamente en las extremidades que están próximas al foco vibratorio, sino también en las que están alejadas".

Como se puede apreciar, en los artículos tratados hasta el momento, por un lado la mayoría de los estudios en esta área se han realizado con jóvenes, y por otro, no existe uniformidad respecto a la carga de entrenamiento que se debe utilizar para lograr los mayores beneficios de las vibraciones sobre el tren superior. Existe una gran laguna en este aspecto que se repite constantemente al tratar de comprender y protocolizar el entrenamiento de vibraciones.

En el presente estudio, se aplicaron dos ejercicios de tren superior (bíceps y hombros). Las magnitudes utilizadas en nuestro estudio concuerdan con las expuestas por Marín et al., (2010) y Hazell, (2007). La carga fue incrementada paulatinamente con objeto de ir adaptando la musculatura al estímulo vibratorio. Por esta razón, si bien al comienzo del programa se observa una carga menor de 
trabajo, después de la segunda semana de trabajo la carga comienza a aumentar, acercándose a las frecuencias utilizadas en los estudios mencionados, ciñéndonos también a un principio fundamental del entrenamiento que es el aumento progresivo de la carga (Weineck, 2005).

Con la finalidad de comparar los resultados obtenidos en este estudio, que utiliza el EVCC, con los obtenidos en otros estudios con otros métodos de trabajo, se presentan dos investigaciones. La gran ventaja y razón de por que se han seleccionado estas dos investigaciones, se debe por un lado, a que evalúan la fuerza del tren superior de igual manera que se ha hecho en este estudio, siendo dentro de los posible, una comparación valida de los resultados entre estos métodos de trabajo. Y además, ambos estudios han sido aplicados en poblaciones de adultos mayores. Incluso, la segunda investigación fue aplicada en ancianos institucionalizados, mejorando aun más la posible comparación entre estos programas de trabajo físico.

En el primero de estos artículos (Hughes et al., 2009), se investigaron los efectos de un programa de entrenamiento de "múltiples-componentes" como lo definen los autores. Este abarcaba ejercicios de flexibilidad, ejercicio aeróbico de bajo impacto, ejercicios de resistencia, con una duración por sesión de 60 minutos, 3 veces por semana, durante 10 meses. Se encontraron diferencias significativas en la fuerza del tren superior entre el grupo que realizó el programa y el control, tanto a los 5 como a los 10 meses de entrenamiento.

El otro estudio (Lobo et al., 2011), aplicó un programa de actividad física en ancianos institucionalizados. De los 4 grupos intervenidos, 2 se adhirieron a un programa de ejercicio físico, de un año de duración con 2 sesiones semanales. Uno de estos grupos entrenados efectuó un programa de ejercicio aeróbico consistente en 10 minutos de calentamiento, 20 minutos de ejercicio aeróbico o danza durante el 
primer mes, aumentando a 30 minutos el resto del año. La intensidad durante el primer mes fue de 2 a 3 en la escala del esfuerzo percibido de Borg, el resto del año se aumentó hasta situarse entre 4 a 6 .

El otro grupo entrenó la resistencia muscular, para lo cual realizó 2 series de 6 ejercicios (8 a 12 repeticiones) centrándose en el cuádriceps, la zona de isquiotibiales, tronco, brazos y pared abdominal. Las primeras dos semanas se trabajó al 45 - 50\% de 1RM, desde la tercera semana se aumentó la carga entre un $60 \%$ y $65 \%$ de 1 RM manteniéndose hasta el final del programa. Cada 4 semanas se repitió el test de 1RM para adecuar la carga.

Respecto a los resultados obtenidos sobre la fuerza del tren superior, ambos grupos de entrenamiento, tanto de resistencia muscular como de entrenamiento aeróbico, aumentaron la fuerza en un 45,5\% y $2,8 \%$ respectivamente; encontrándose una diferencia significativa solo en el primer grupo.

En nuestro estudio se observa una ganancia de un 22,3\% en la fuerza del tren superior, diferencia estadísticamente significativa al compararse con los valores iniciales de los ancianos. Al comparar estos resultados con los obtenidos en los estudios mencionados anteriormente, de entrenamiento "tradicional", podríamos expresar que el EVCC parece ser más eficiente a la hora de aumentar la fuerza del tren superior, en un espacio de tiempo apreciablemente menor.

Esto sugiere por una parte, que el EVCC podría ser una herramienta útil para mejorar la fuerza del tren superior, y por otra parte, este resultado refuerza lo expuesto por Cardinale y Wakeling, (2005), sobre la ventaja que supone el EVCC relacionado con el menor tiempo empleado en cada sesión de entrenamiento, lo que influye en la duración total del programa. Basándose en lo expuesto anteriormente por Morris y Schoo, (2004), existiría entonces una gran diferencia entre el tiempo 
empleado en este programa de EVCC, en comparación con la duración media de un programa de entrenamiento "tradicional", para obtener resultados similares a los expuestos en este estudio.

Por otro lado, a pesar de que la mayoría de los ancianos participantes de este estudio, no soportaban estar en posición de sentadilla estático ni dinámico sobre la plataforma cuando era realizado el ejercicio de bíceps, como alternativa, estos colocaron solo una pierna en la plataforma mientras la otra estaba fuera de la máquina, posición que les proporcionaba mayor estabilidad, Aun así, fue posible observar variaciones significativas en su fuerza. Esto rebate de alguna manera lo expuesto por Hezell et al., (2007), que expone que las mayores activaciones musculares en el tren superior se aprecian cuando se realiza tanto la posición sentadilla como el ejercicio de bíceps de forma dinámica.

Se puede deducir entonces, que aunque los ancianos no estén por completo sobre la plataforma, el estimulo vibratorio sería suficiente para aumentar la fuerza del tren superior. Cabe señalar también, que las diferencias entre el estudio de Hezell et al., (2007) y el presente, se deberían más bien a las poblaciones estudiadas (jóvenes y ancianos respectivamente), como también en los niveles de fuerza previos a iniciar el programa de entrenamiento. Por tanto, también es muy posible, al igual que ocurre con otros métodos de entrenamiento, una población con un nivel de fuerza menor sea más sensible al efecto de las vibraciones, como es el caso de los ancianos.

\subsubsection{Efectos del EVCC sobre la fuerza del tren inferior}

Los resultados recogidos en la literatura sobre el efecto del entrenamiento de resistencia tradicional en la extensión de rodillas en ancianos es bastante claro (Morris y Schoo, 2004). En una revisión de la literatura, estos autores encontraron 
que la media de fuerza ganada en la extensión de rodillas era de $43,1 \%$; apreciándose una amplia variación en la ganancia de fuerza entre los artículos analizados, así como también, en la duración de los programas (media de 23,4 semanas).

Al analizar los estudios en ancianos de Hughes et al., (2009) y de Lobos et al., (2011), mencionados anteriormente por utilizar métodos de entrenamientos "tradicionales", se puede señalar que también existe similitud con nuestro estudio en las pruebas de evaluación utilizadas para medir la fuerza en el tren inferior (sentarse y levantarse 5 veces, y sentarse y levantarse durante 30 segundos respectivamente). Los métodos de entrenamiento utilizados en estos estudios generan mejorías significativas en la fuerza del tren inferior. Sin embargo, cabe señalar al respecto que, el EVCC tendría un efecto mayor que el entrenamiento aeróbico, y tendría un efecto menor que el entrenamiento específico de resistencia muscular. La gran diferencia y ventaja al comparar el EVCC con estas modalidades se centra nuevamente en la duración del programa.

Estos resultados afectarían positivamente sobre las tareas básicas de los ancianos, por ejemplo en la velocidad (Bassey et al., 1988; Bassey et al., 1992; Fiatarone et al., 1990), y resistencia al caminar (McCartney et al., 1995; McCartney et al., 1996; Ades et al., 1996), en sentarse y levantarse de una silla, y subir escaleras como demuestra la literatura (Morris y Schoo, 2004).

Los efectos del EVCC sobre la fuerza muscular del tren inferior y el equilibrio dinámico, cualidades que están relacionadas con la capacidad de movilidad y agilidad, han sido puestas de manifiesto por diversos autores (Bruyere et al., 2005; Delecluse et al., 2003; Issurin et al., 1994; Issurin y Tenenbaum, 1999; Torvinen et al., 2002a). 
En relación a los resultados obtenidos en nuestro estudio en el test de sentarse y levantarse de una silla durante 30 segundos, Runge et al., en el año 2000 , encontraron un aumento significativo de un $18 \%$ en el test de sentarselevantarse de una silla 5 veces lo más rápido posible, en tan solo 2 meses de entrenamiento de vibraciones en un grupo de ancianos. En el presente estudio, se ha observado una mejoría de un $18,4 \%$ tras 9 semanas de entrenamiento.

Tanto las intensidades como la metodología utilizada en el estudio de Runge et al., (2000) son similares a las empleadas en nuestro estudio. Sin embargo, las diferencias más relevantes parecen estar en las amplitudes utilizadas, ya que en el trabajo de Runge ésta varió entre un 7 y $14 \mathrm{~mm}$ (peak to peak, rango completo de movimiento) en una plataforma oscilante, en comparación a los $2 \mathrm{~mm}$ utilizados permanentemente en nuestro estudio (plataforma vertical). Esto haría suponer que no existirían grandes diferencias sobre la fuerza del tren inferior respecto al tipo de plataforma utilizada si se aplican las cargas de entrenamiento adecuadas.

Rees et al., en el 2007, realizaron un completo estudio con EVCC, en el cual se evaluó el rendimiento muscular y la movilidad con diversos test, tales como sentarse y levantarse de una silla, tiempo de ir y volver, tiempo en caminar 5 y 10 metros, subir escaleras, y midieron la fuerza en una máquina isocinética en un grupo de ancianos. Este estudio duro 2 meses, con una frecuencia de entrenamiento de 3 veces por semana, utilizando una frecuencia de $26 \mathrm{~Hz}$ durante todo el programa, variando tanto el tiempo de exposición a las vibraciones como la amplitud (5 - $8 \mathrm{~mm}$ peak to peak). Cabe señalar que en este estudio se aplicó una metodología mixta, ejercicios estáticos durante las primeras cuatro semanas y ejercicios dinámicos en el resto del programa.

Estos investigadores hallaron mejorías tanto en la fuerza muscular como en la movilidad de los ancianos sometidos al EVCC en comparación al grupo control. 
Específicamente encontraron diferencias significativas en el test de levantarse y sentarse de una silla, levantarse y caminar 3 metros, caminar rápidamente 5 y 10 metros, y en la fuerza isocinética (extensión de rodilla).

Recientemente Machado et al., (2010) han publicado un estudio en el cual se ha utilizado un protocolo de entrenamiento de vibraciones bastante similar al aplicado en la presente memoria, en una población de ancianos no institucionalizados. En este estudio se empleo una intensidad (aceleración media) de $2,67 \pm 1,4\left(\mathrm{~m} / \mathrm{s}^{2}\right)$, mientras que en el presente estudio fue de $2,91 \pm 0,8\left(\mathrm{~m} / \mathrm{s}^{2}\right)$, no existiendo diferencias estadísticamente significativas entre las dos cargas de entrenamiento.

En el trabajo de Machado et al., (2010) se evaluó la movilidad a través del test ir y venir 3 metros, y la MCVI de la misma manera que se ha evaluado en el presente estudio. La MCVI aumentó un 38,8\% (diferencia estadísticamente significativa) y el test de ir y venir incremento un $9 \%$. En nuestro estudio se mejoró un $15,0 \%$ y un $17,4 \%$ respectivamente (ambos estadísticamente significativos).

Tras observar estos resultados, se puede deducir que hay cierta concordancia en los resultados. EI EVCC aumenta la MCVI y la movilidad de los ancianos tras un entrenamiento sobre la plataforma de vibraciones. Estos resultados también son apoyados por los obtenidos por otros autores, que a pesar de las variaciones existentes en los protocolos de EVCC empleados, de la población estudiada y de la carga utilizada, entre otros, sugieren que los efectos de las vibraciones sobre la ganancia de fuerza y equilibrio de los ancianos son bastante alentadores (Roelants et al., 2004; Verschueren et al., 2004; Bogaerts et al., 2009). 


\subsubsection{Efectos del EVCC sobre la actividad EMGs}

Está ampliamente aceptado el importante papel de los factores neurales en la ganancia de la fuerza (Gabriel et al., 2006). Con el entrenamiento de resistencia ocurren adaptaciones en el sistema neuromuscular, tanto a nivel neural como intramuscular (Kraemer et al., 1996; Sale, 1988). Estas adaptaciones generan grandes ganancias de fuerza, principalmente en los primeros meses de un entrenamiento de resistencia en ancianos (Morganti et al., 1995), caracterizado por una mayor actividad neural (Sale, 1988), y a medida que avanza el programa los niveles de ganancia de fuerza son menores (Morganti et al., 1995), y comienzan a ser más importantes los cambios a nivel intramuscular (Sale, 1988).

La EMGs es una técnica capaz de medir la actividad muscular; particularmente, detecta los cambios en el impulso de la señal a través de los electrodos. Esto se interpreta como un incremento en la conducción neuromuscular, denotando la magnitud de la respuesta eferente del sistema nervioso central para activar las fibras musculares.

En la primera fase de un programa de entrenamiento de resistencia cuyo fin es aumentar la fuerza, se observa un incremento en la amplitud de la actividad EMGs. Este aumento, evidencia la participación neural en la ganancia de la fuerza, siendo aun más notoria cuando la hipertrofia muscular no ha sido un factor relevante como resultado del entrenamiento.

En el presente estudio se aprecia una variación de un $44,3 \%$ en la señal EMGs del músculo VL y de un $24,4 \%$ en el VM. Al respecto un interesante estudio de Alkner et al., (2000), en el que se evaluó la respuesta muscular (vasto lateral, medial y recto anterior) medido a través de la EMGs, a distintas cargas de la fuerza máxima isométrica, tanto en un ejercicio de extensión de rodilla como en un ejercicio 
de prensa de piernas, concluyó que el VL parece ser el músculo más fiable para predecir la producción de fuerza. Esto estaría relacionado y podría explicar en cierta medida la ganancia de fuerza de un $15,0 \%$ tras el EVCC en el grupo de ancianos participantes en el presente estudio. También cabe señalar que hubiese sido interesante poder haber medido el nivel de hipertrofia muscular en los ancianos para contrastar valores de la EMGs y de masa muscular con el incremento en la fuerza.

Dos estudios previos (Machado et al., 2010 y Ferri et al., 2003) han evaluado, a través de la EMGs, el efecto sobre la actividad muscular tras un programa de entrenamiento de vibraciones y tradicional, respectivamente. En ambos estudios se muestra una mejoría en la actividad neuromuscular. Machado et al., (2010) pusieron de manifiesto un incremento de un $25,3 \%$ en el VM y de un $12,9 \%$ en el VL; mientras que Ferri et al., (2003), apreciaron una mejoría en la actividad del VL de un 17,3\% y $13,4 \%$ en la cuarta semana y al finalizar el estudio de 16 semanas. Cabe señalar que en ambos trabajos no se obtuvieron diferencias estadísticamente significativas, a diferencia del presente estudio.

\subsubsection{Efectos del EVCC sobre la potencia muscular}

Respecto a los resultados obtenidos sobre la potencia muscular en el presente estudio, los dos autores mencionados anteriormente (Machado et al., 2010 y Ferri et al., 2003) también analizaron el efecto sobre esta cualidad física después de un entrenamiento de vibraciones y de fuerza tradicional respectivamente.

Ferri et al., (2003) proponen que la mejoría en la potencia muscular es consecuencia, en primer lugar, del incremento de la fuerza, debido a factores musculares como por ejemplo un aumento en la coordinación muscular. Además expresan que este aumento en la potencia puede ser ocasionado también por una mejoría en el torque más que en la velocidad de contracción. 
También en este estudio se pone de manifiesto que el entrenamiento de resistencia muscular en ancianos aumenta la potencia en mayor medida que la fuerza. Esto ayudaría a estas personas a recuperar las funciones relacionadas con la locomoción, las cuales se van perdiendo durante el proceso de envejecimiento, mejorando de esta manera su calidad de vida.

Russo et al., (2003), demostraron una ganancia de un $5 \%$ en la potencia muscular en mujeres postmenopáusicas (60,7 años de edad) que participaron en un entrenamiento de vibraciones durante 6 meses, $(28 \mathrm{~Hz}$; amplitud variable, 3 series de 2 minutos por 1 minuto de descanso). No obstante cabe señalar que la evaluación de la potencia difiere con la realizada en este estudio (plataforma de contacto).

Por la razón mencionada anteriormente, respecto a la metodología de evaluación de la potencia, se hace complicado poder comparar los resultados con otros estudios. Por el contrario, Machado et al., (2010), utilizaron un programa de vibraciones y evaluaron la potencia pico al $20 \%, 40 \%$ y $60 \%$ de la MCVI de igual forma que en el presente estudio. Sin embargo, ellos no encontraron diferencias estadísticamente significativas. En nuestro estudio se obtuvo una diferencia de un $5,8 \%, 17,6 \%$ y de un $25,4 \%$ al $20 \%, 40 \%$ y $60 \%$ respectivamente de la MCVI (todos con significación estadística). También cabe señalar que si bien Machado et al., (2010), no obtuvieron diferencias significativas, el grupo control empeoró su rendimiento a estas tres cargas en comparación al grupo que realizó el EVCC, lo que confiere a este tipo de entrenamiento la característica de preservar el rendimiento muscular.

Por otro lado, también Roelants et al., (2004) concluyeron que la fuerza muscular y la velocidad de movimiento de los flexores de rodilla aumentan significativamente posterior a un EVCC en mujeres ancianas. Esto sugiere que la 
ganancia en el rendimiento muscular se debía principalmente al efecto del estímulo vibratorio. Además, ponen de manifiesto que la magnitud de los resultados obtenidos con el EVCC es similar a los observados con un entrenamiento de resistencia, método empleado generalmente con el fin de mejorar la fuerza en esta población. Por tanto, los resultados obtenidos en el presente estudio están en concordancia con los de Rehn et al, (2007), respecto a los beneficios de este tipo de entrenamiento sobre la potencia muscular.

La amplia disparidad encontrada en los resultados de la mayoría de los estudios de vibraciones, pueden ser debidas a la alta variabilidad apreciada en los protocolos de entrenamiento utilizados (Jordan et al., 2005), siendo obvia la falta de un programa estandarizado para incrementar la fuerza y la potencia muscular en los ancianos (De Vos et al., 2005).

Respecto a la magnitud de los resultados obtenidos en el presente estudio, sobre los valores de fuerza y potencia muscular obtenidos tras la realización del programa de EVCC en los ancianos, cabe señalar que, levantarse de una silla es una tarea básica y necesaria para cualquier persona, lamentablemente con el deterioro funcional acontecido durante el envejecimiento, a los ancianos les supone un esfuerzo casi por no decir máximo realizar esta actividad. En cambio a los jóvenes solo les representa valores de potencia que fluctúan entre un $50 \%$ y un $60 \%$ (Serra, 2006). Si bien, pretender alcanzar los valores de los jóvenes sería absurdo, en el presente estudio se incrementó en un $15,6 \%$ la fuerza relativa y un $25,4 \%$ la potencia muscular al $60 \%$ de su MCVI. Estos incrementos tanto en la fuerza como en la potencia son reflejados en el test levantarse de una silla en 30 segundos, donde se obtiene un incremento de un $18,4 \%$. Esto puede significar una mejoría sustancial en la ejecución de las actividades rutinarias de estas personas como es, levantarse de una silla. 


\subsubsection{Efectos del EVCC sobre el equilibrio dinámico}

Profundizando en los resultados obtenidos sobre el equilibrio dinámico, se puede observar en la literatura que tanto las investigaciones que utilizan un programa de "resistencia tradicional" como de vibraciones, demuestran efectos beneficiosos sobre la fuerza y el equilibrio que se relacionan con efectos positivos en la movilidad de los ancianos.

Al respecto, Morris y Shoo, (2004), analizaron 11 estudios sobre el efecto del entrenamiento de resistencia tanto en el equilibrio estático como dinámico. Estos observaron que los beneficios son mayores en esta última variable, no detectando un efecto tan significativo en el equilibrio estático. Concluyeron además que un programa de entrenamiento de resistencia podría ser utilizado en la práctica clínica con el fin de mejorar esta cualidad en los ancianos.

En nuestro estudio, utilizando un programa de EVCC, se obtuvo un $16,9 \%$ de mejoría en el test de equilibrio dinámico. Lobo et al., (2011), encontraron mejorías de un $22,9 \%$ para el grupo de entrenamiento aeróbico, y un 10,3\% para el grupo de entrenamiento de resistencia. Tanto los resultados del presente estudio como el de Lobo et al., fueron estadísticamente significativos. Se puede resumir, que en una muestra de personas mayores e institucionalizadas, el EVCC ejerce un efecto similar a las metodologías de entrenamientos más tradicionales.

En relación al EVCC, varios autores han demostrado sus beneficios. Por ejemplo, un estudio de Bruyere et al., (2005) demostró una influencia positiva en la habilidad de caminar, equilibrio corporal y capacidad motora, en tan solo 6 semanas de entrenamiento de vibraciones, en una población de ancianas institucionalizadas. También existe evidencia de los efectos del EVCC sobre los desequilibrios posturales (Verschueren et al., 2004), equilibrio y movilidad (Bruyere et al., 2005; 
Bautmans et al., 2005), y control postural (Bogaerts et al. 2009). En este último artículo, concluyeron que en ancianos institucionalizados el EVCC fue asociado con una reducción en la frecuencia de caídas. Todo lo expuesto anteriormente apoyaría los resultados obtenidos en nuestro estudio.

Kawanabe et al., en 2007 demostraron en su estudio con ancianos que, cuando una rutina de ejercicio tradicional es acompañada de un EVCC, es posible apreciar una diferencia más acentuada en la velocidad de caminar, la longitud del paso y en el tiempo máximo de mantenerse de pie con un solo apoyo, en comparación al grupo que no incluyó el EVCC. Todo lo anterior se consiguió en tan solo dos meses de entrenamiento.

Por otro lado, Ress et al., (2007) concluyeron que no hay diferencias en el test de ir y venir, velocidad de caminar y el test de sentarse y levantarse, cuando se realizan los mismos ejercicio sobre y fuera de la plataforma. Aunque posteriormente, este mismo autor puso de manifiesto los beneficios en el equilibrio de un programa de EVCC en la población anciana (Ress et al., 2008).

Sin embargo, no todos los ancianos tienen una capacidad funciona inicial, que les permita realizar un programa de ejercicio tradicional más un programa de EVCC como en el caso del estudio de Kawanabe et al., 2007. Así, Ress et al., (2008), exponen que el nivel basal de cada anciano es fundamental a la hora de tratar de comprender los resultados obtenidos. Así, es de esperar, que los que poseen un menor equilibrio al iniciar el programa de EVCC presenten ganancias mayores una vez finalizado este periodo. Quizás debido a esto, es que se aprecian resultados a veces tan favorables y otras veces desfavorables en relación al EVCC como es el caso de los estudios de Kawanabe et al., (2007) y de Ress et al., (2007) respectivamente. 
Una revisión de Rehn et al., (2007), sobre los efectos en el rendimiento muscular de las piernas con el entrenamiento de vibraciones, señaló al estudio de Bautmans et al., (2005) como uno de los más destacables respecto a la metodología utilizada en su investigación. Bautmans et al., (2005), indicaron que en personas mayores institucionalizadas con capacidades funcionales limitadas, solo 6 semanas de EVCC es seguro y beneficioso para mejorar su equilibrio y movilidad.

En general, se puede mencionar que la gran parte de las publicaciones recogidas hasta la fecha demuestran un efecto favorable en el equilibrio y la movilidad al utilizar un programa de EVCC (Garatachea y González-Gallego, 2010). Además, mientras menor sea la capacidad funcional de los ancianos, mayores beneficios se pueden esperar con el uso de la plataforma de vibraciones (Kaeding, 2009).

También es importante señalar el posicionamiento del ACSM (2009b) en donde se expresa que, tanto el ejercicio aeróbico como de resistencia reducen el riesgo de discapacidad, y que el ejercicio físico posee un papel terapéutico en la población mayor. Así, Morris y Schoo, (2004), exponen que hay una fuerte evidencia que los programas de entrenamiento de la fuerza en adultos mayores que viven independientes o en alguna institución, pueden mejorar sus niveles de fuerza, resistencia, tanto del tren inferior como superior. De esta manera es posible mejorar su capacidad para llevar a cabo sus actividades diarias, mejorar además su equilibrio dinámico y estático, reducir el riesgo de caídas y alejarlos de la dependencia y de esta forma mejorar su calidad de vida.

Finalmente, al tratar de valorar la importancia de los resultados obtenidos en el presente estudio con un programa de EVCC sobre la fuerza, potencia, EMGs y equilibrio dinámico de un grupo de ancianos institucionalizados, se deberían tener presente ciertos aspectos fundamentales. Aquí se exponen tres: 
Primero, según publican Clark et al., (2011), la fuerza muscular se relaciona con la función de movilidad en los adultos mayores y la producción de energía eficaz, la cual requiere de una rápida activación neuromuscular. Ya en 1991, Buchner y de Lateur, sostenían la relación existente entre el umbral de la fuerza muscular y ciertas habilidades funcionales, tales como la capacidad de subir escaleras.

Segundo, como se mencionó anteriormente, el estudio de Laukkanen et al., en 1995 señala la asociación existente entre las dificultades para moverse en interiores y al aire libre, la reducción de la velocidad al caminar, y la fuerza muscular reducida, con un mayor riesgo de muerte.

Y tercero, el riesgo de caídas es un problema importante tanto en la población adulta mayor en general, como en el $30 \%$ de los ancianos residentes que sufren caídas cada año. El equilibrio, la fuerza y la potencia muscular, son algunos de los factores de riesgo que pueden mejorar con intervenciones como por ejemplo las plataformas de vibraciones, mejorando de esta manera la estabilidad postural (Garatachea y González-Gallego, 2010).

\subsubsection{Flexibilidad}

\subsubsection{Efectos del EVCC sobre la flexibilidad del tren superior e inferior}

En el posicionamiento del ACSM se expone que la flexibilidad y el rango de movimiento decrece a medida que se avanza en edad, lo que incrementa el riesgo de caídas, heridas y dolor de espalda, entre otros (ACSM, 2009b). Además de la disminución del rango articular (Schultz, 1992), se puede apreciar la disminución de la longitud del paso, la disminución en la extensión de tobillo y de la rotación pélvica, 
siendo todos estos factores importantes a la hora de ver reducida la movilidad física de estas personas (WHO, 1998).

Morris y Schoo, (2004) al analizar la literatura, deducen que el entrenamiento de resistencia muscular no demuestra efectos importantes sobre la flexibilidad del tren inferior. Además, se ha encontrado una alta variabilidad en los resultados, desde una disminución de un $2 \%$ en la flexibilidad, hasta una mejoría de un $6,1 \%$ (Adams et al., 2001).

El estudio de Hughes et al., (2009), que empleó un programa de entrenamiento de múltiples-componentes, y que evaluó la flexibilidad del tren superior de la misma manera que en nuestro estudio, no encontró diferencias significativas en esta cualidad.

No obstante, Lobo et al., (2011) obtuvieron que la flexibilidad del tren inferior, mejoró significativamente tanto en los grupos de entrenamiento aeróbico como de resistencia, $21,5 \%$ y $50 \%$ respectivamente. En cuanto a la flexibilidad del tren superior, solo se observó una diferencia significativa en el grupo de entrenamiento de resistencia $(22,8 \%)$.

Analizando la literatura, se ha comprobado que desde el año 2006 hasta la fecha se han publicado varios artículos que demuestran los efectos positivos del EVCC sobre la flexibilidad. No obstante, estos estudios han sido aplicados principalmente en jóvenes.

Al observar los resultados y conclusiones de estos artículos, queda claro que el EVCC ayuda a mejorar la flexibilidad y a mantener su efecto en el tiempo (Feland et al., 2010; Van den Tillaar, 2006). El estudio de Feland et al., en el 2010 demostró que el entrenamiento de la flexibilidad (isquiotibiales) sobre una plataforma de 
vibraciones fue más efectiva (estadísticamente) que sin ella. Además, después de tres semanas, los jóvenes que no realizaron ejercicios de flexibilidad sobre la plataforma volvieron a sus valores basales, mientras que los que utilizaron las vibraciones eran aun un $11 \%$ más flexibles.

Van den Tillaar, (2006) evaluó también en jóvenes el efecto de un EVCC como complemento al entrenamiento de flexibilidad tradicional. Con tan solo tres sesiones semanales durante un mes, se obtuvo un $16 \%$ de mejoría de la flexibilidad en los isquiotibiales en el grupo que sumó el EVCC, en comparación con el grupo de entrenamiento tradicional.

Apoyando lo expuesto por Feland et al., (2010) y Van den Tillaar, (2006), otro estudio, también realizado en jóvenes, demostró que el EVCC es efectivo para mejorar la flexibilidad de la espalda baja y de los isquiotibiales (Di Giminiani et al., 2010).

Respecto al efecto agudo del EVCC sobre la flexibilidad, un estudio en jóvenes, demostró que la flexibilidad aumentó por lo menos durante los 15 minutos posteriores al entrenamiento, a pesar de las variaciones del protocolo tanto en la amplitud como en la frecuencia (Gerodimos et al., 2010). En esta misma línea, un estudio de Jacobs y Burns en el 2009, puso de manifiesto que con tan solo 6 minutos de exposición a las vibraciones de cuerpo completo se pueden encontrar mejorías significativas en la flexibilidad.

Por otro lado, la investigación llevada a cabo por Cochrane et al., (2009), se centró en el efecto agudo de las vibraciones en el complejo de alargamiento tendónmúsculo en sujetos sanos, sobre una plataforma de vibraciones de tipo vertical, concluyendo que con 15 segundos a $6 \mathrm{~Hz}$ se produce un marcado alargamiento en el músculo gastrocnemio en comparación al mismo ejercicio (sentadilla) sin vibraciones. Anteriormente Cochrane y Stannard (2005), ya habian observado una 
mejoría en la flexibilidad de un grupo de jugadoras de hockey, señalando que el EVCC potencia el reflejo de estiramiento.

En lo estrictamente relacionado con el EVCC en ancianos, se han observado mejorías en la longitud del paso tras un programa de EVCC (Iwamoto et al., 2004; Kawanabe et al., en el 2007). Sin embargo, estos cambios al parecer, están relacionados más bien con el incremento de la fuerza en los músculos involucrados con la marcha que con una mejoría en la flexibilidad.

También, varias de las posiciones que se adoptan sobre la plataforma, requieren por parte de los ancianos, un cierto esfuerzo para incrementar el rango articular, lo que alargaría los músculos extensores principalmente de las extremidades inferiores (Runge et al., 2000), ayudando en cierta medida a incrementar su flexibilidad.

Hasta la fecha no existen investigaciones que estudien directamente el efecto de un programa de vibraciones sobre la flexibilidad en ancianos. Solo existe un artículo de revisión que menciona los posibles beneficios del EVCC sobre la flexibilidad en la población anciana (Piatin et al., 2009).

En el presente estudio, se aprecian diferencias favorables en la flexibilidad del tren superior $(21,2 \%)$ y del tren inferior $(10,1 \%)$ con un programa de EVCC, pero no se encontraron diferencias significativas entre los valores basales y los posteriores al programa de EVCC.

Basándose en las últimas publicaciones sobre el tema, todo haría pensar que existe cierta relación entre el EVCC y el incremento de la flexibilidad (Cochrane y Stannard, 2005; Van den Tillaar, 2006; Cochrane et al., 2009; Feland et al., 2010; Di 
Giminiani et al., 2010; Gerodimos et al., 2010) apoyando de esta manera los resultados obtenidos en nuestro estudio.

\subsubsection{Resistencia aeróbica}

\subsubsection{Efectos del EVCC sobre la resistencia aeróbica}

El entrenamiento de resistencia muscular no demuestra efectos importantes sobre la capacidad aeróbica en ancianos (Morris y Schoo, 2004). Pero estos mismos autores expresan que una extremidad inferior más fuerte podría ser capaz de generar mayor fuerza de propulsión y generar energía más eficiente, incrementando la velocidad de caminar. La relación entre la fuerza muscular y la velocidad de caminar, podría ser mayor en ancianos con un nivel de fuerza disminuido al iniciar un programa de entrenamiento (Bassey et al., 1988; Bassey et al., 1992; Fiatarone et al., 1990). Cabe destacar al respecto que, en diversos estudios estos cambios observados sobre la velocidad de caminar, no han sido visibles en la caminata a velocidad autoseleccionada.

En el estudio de Lobo et al., (2011), se valoró la capacidad aeróbica a través del test de 2 minutos de la batería SFT, un test optativo al de 6 minutos aplicado en nuestro estudio. En dicho trabajo, encontraron una mejoría significativa tanto para el grupo de entrenamiento aeróbico como para el de resistencia $(9,2 \%$ y $4,3 \%$ respectivamente). Estos resultados difieren de los obtenidos en el presente estudio.

Puede ser que los resultados obtenidos en el test de 2 minutos evaluado por Lobo et al., (2011), esten más relacionados con el fortalecimiento de la musculatura involucrada en la marcha y con un incremento en el equilibrio dinámico más que con un aumento en la capacidad aeróbica. 
Apoyando esta idea, Iwamoto et al., (2004), encontraron mejoras significativas en la longitud del paso, máximo momento extensor de la rodilla y máximo tiempo mantenido sobre una pierna, tras un periodo de entrenamiento que incluía trabajo de fuerza, equilibrio y vibraciones durante tres meses. Estos resultados lograron mejorar la capacidad ambulatoria de los ancianos.

Por otro lado, y en línea con los resultados obtenidos en el presente estudio, Hughes et al., (2009), utilizando un programa de entrenamiento de múltiplescomponentes, evaluaron la resistencia aeróbica con el mismo test utilizado en nuestro estudio (caminar 6 minutos), y no encontraron diferencias significativas entre el grupo que realizó el programa y el grupo control.

Respecto a las recomendaciones presentadas por Nelson, et al., en el 2007 para mejorar la resistencia aeróbica en los adultos mayores (Esquema 8; p. 37), estos autores sugieren, acumular al menos 30 minutos al día de ejercicio, en tandas de al menos 10 minutos de duración, con una intensidad moderada (5 a 6 en una escala de 10 puntos), 5 veces a la semana. $O$ bien, se puede realizar un mínimo de 20 minutos de actividad continua, por lo menos 3 veces a la semana, con una intensidad vigorosa ( 7 a 8 en una escala de 10 puntos). Como es posible apreciar, un EVCC, debido a sus características, no se ajustaría a estas recomendaciones.

Por otra parte, los cambios cardiovasculares acontecidos, tanto durante como al final de un programa de EVCC, son mínimos en comparación a los cambios apreciados a nivel muscular (local). Por esta razón se promueve el uso de este método en personas con problemas al corazón, debido principalmente a su bajo nivel de estrés cardiovascular (Garatachea y González-Gallego, 2010).

Esto no quiere decir que el EVCC no posea efecto alguno sobre el sistema cardiovascular, de hecho varios artículos han ayudado a dilucidar los efectos 
fisiológicos del EVCC tanto en jóvenes como en ancianos, aportándonos valiosa información al respecto (Cochrane et al., 2008a; Cocrhane et al., 2010; Cochrane, 2011).

De hecho, se ha descrito que el $\mathrm{VO}_{2 \text { máx }}$ se incrementa al realizar un ejercicio sobre la plataforma de vibraciones, y más aun cuando se aumenta la carga ( $20 \%$ y $40 \%$ del peso corporal) en ancianos. Se estima que el $\mathrm{VO}_{2}$ durante un EVCC podría

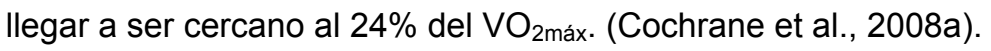

En resumen, con un EVCC se produce un bajo estrés cardiovascular y no se cumplirian las recomendaciones mínimas de actividad física para el desarrollo de la capacidad aeróbica (Nelson et al., 2007), siendo el $\mathrm{VO}_{2}$ inferior al 40\%, mínimo recomendado para mejorar la capacidad aeróbica en ancianos (Evans, 2002). Todas estas variables mencionadas anteriormente, no generarían el estímulo suficiente para producir cambios importantes a nivel fisiológico que se traduzcan en un aumento de la capacidad aeróbica en los ancianos con este tipo de entrenamiento, apoyando, en cierta manera, los resultados obtenidos en el test de 6 minutos tras el programa de EVCC observado en el presente estudio. No obstante es apresurado señalar que no tenga efecto alguno, puesto que la falta de estudios sobre esta área en ancianos es considerable (Garatachea y González-Gallego, 2010).

Para finalizar, se puede expresar que los efectos fisiológicos del EVCC son complejos, y hasta el momento no hay unanimidad absoluta al respecto (Cochrane et al., 2008a; Cocrhane et al., 2010; Cochrane, 2011). Por tanto, al analizar los resultados de los estudios sobre el EVCC en ancianos, se podría señalar que los cambios acontecidos como resultado de un programa de EVCC se aprecian más bien a nivel local que a nivel sistémico. 
Una de las ventajas más apreciables de este método de entrenamiento, radicaría en el corto periodo de tiempo necesario para observar cambios en la fuerza del tren inferior y superior, potencia muscular, flexibilidad y equilibrio dinámico. Todos estos resultados concuerdan con los obtenidos en este estudio, lo que apoyaría lo expuesto por Cardinale y Wakeling, (2005), sobre los efectos similares del EVCC al entrenamiento aeróbico y de resistencia tradicional (Lobo et al., 2011).

Por tanto, se podría decir que el EVCC es una buena manera de iniciar un programa de fortalecimiento en personas con déficit de movilidad, fuerza y equilibrio, entre otros, y también una buena herramienta de complemento en cualquier tipo de programa de entrenamiento con el fin de mejorar la capacidad física y la calidad de vida de los ancianos, a pesar de que con este método no se cumplan las recomendaciones mínimas de actividad física para esta población (Nelson et al., 2007).

Finalmente, volver a destacar las grandes limitaciones que se pueden apreciar en la literatura respecto a la escasez de estudios en ancianos y la gran variedad de combinaciones en el diseño de protocolos de entrenamiento (SantinMedeiros y Garatachea, 2010). Es por esto, que profundizar y generar mayor conocimiento sobre esta área se hace tan necesario. Además es importante sugerir una metodología más segura de intervención para llegar a utilizar el EVCC como una modalidad terapéutica y de prevención en las diferentes poblaciones de la sociedad, especialmente en las más vulnerables, como es el caso de la tercera edad (Cardinale y Pope, 2003; Cardinale y Wakeling, 2005; Cardinale y Rittweger, 2006; Garatachea y González-Gallego, 2010). 


\subsection{EFECTO DEL EVCC SOBRE LA INFLAMACIÓN}

Las citoquinas juegan un papel fundamental en la iniciación de la respuesta inflamatoria (Calle y Fernández, 2010). Además, tanto el entrenamiento aeróbico como el de resistencia han demostrado aminorar los niveles de inflamación sistémica tras un programa de ejercicio en la población adulta mayor (Mattusch et al., 2000; Ogawa et al., 2010; Prestes et al., 2009; Calle y Fernández, 2010).

El efecto de las citoquinas sobre el ejercicio aeróbico está mucho más documentado que su efecto sobre el ejercicio de resistencia (Calle y Fernández, 2010). Por el contrario, la información sobre la utilización de un EVCC y de sus efectos sobre la inflamación es limitada o casi nula. Hasta la fecha, solo un articulo (Edge et al., 2009) ha estudiado el efecto agudo de las vibraciones sobre los contenidos de IL-6 y proteína $C$ reactiva. Sin embargo, ningún artículo ha indagado el efecto crónico de un EVCC sobre la inflamación sistémica en ningún grupo poblacional.

A la hora de poder discutir los resultados obtenidos en el presente estudio, hay que tener en consideración ciertos puntos. Uno de estos hace mención a las diferencias existentes entre la respuesta aguda y la respuesta crónica del ejercicio sobre la concentración de citoquinas. El efecto agudo se ve modulado principalmente por las demandas energéticas y el daño muscular, mientras que el efecto crónico, depende más de los cambios acontecidos a nivel de la composición corporal, metabolismo y la función de órganos (Lehman et al., 1997). Esta es una de las razones por las que el ejercicio practicado regularmente parece disminuir la respuesta inflamatoria y promover la antiinflamatoria (Walsh et al., 2011).

Otro punto a considerar es que, si bien es conocido que ocurre un incremento en la concentración de citoquinas y de proteína $C$ reactiva según avanza la edad 
(Bruunsgaard, 2002; Rohde et al., 1999), y que tanto el entrenamiento físico como la pérdida de peso juegan un importante papel tanto en el control como en la disminución de las citoquinas proinflamatorias (Stewart et al., 2007), no existe una claridad absoluta al respecto. De hecho, algunos estudios han demostrado que los programas de ejercicio no influyen sobre ciertos marcadores de inflamación (Hammett et al., 2004; Marcell et al., 2005; Nassis et al., 2005).

Otro punto importante a considerar es que, las concentraciones plasmáticas de ciertas citoquinas dependen de diversos factores como por ejemplo, la intensidad y duración del ejercicio, tipo de contracción y cantidad de grupos musculares involucrados, el modo de ejercicio empleado, tiempo de pausa entres series, nivel de condición física, estado de salud y daño muscular generado, entre otros. Todos los factores anteriormente expuestos pueden estar implicados en las diferencias en el comportamiento de las citoquinas, bien durante, o bien después de un entrenamiento aeróbico o de resistencia muscular (Calle y Fernández, 2010). Respecto a este último punto, también se pueden observar variaciones en las concentraciones dependiendo de cuanto tiempo haya transcurrido tras la última sesión de ejercicio (Hirose et al., 2004; Petersen y Pedersen, 2005; Miles, 2008; Ploeger et al., 2009). Además, muchas veces la elevación de una citoquina a nivel intracelular no se reflejará de igual manera a nivel plasmático (Bruunsgaard et al., 2004; Buford et al., 2009). Es por esta razón que se hace tan complicado poder generalizar los resultados de los estudio en esta área y poder establecer un comportamiento de las citoquinas pro y antiinflamatorias con un tipo de ejercicio en particular (Bruunsgaard, 2005).

En el presente estudio se determinaron las concentraciones de ARNm de las citoquinas proinflamatorias IL-1 $\beta$ y TNF- $\alpha$, de la antiinflamatoria IL-10, y de IL-6 que dependiendo de su comportamiento pleiotrópico relacionado con TNF- $\alpha$ influye sobre la función pro o antiinflamatoria en el organismo (Bruunsgaard, 2005; Hirose et 
al., 2004).

Respecto al efecto crónico del EVCC, como resultado del presente estudio, se ha observado una disminución en las concentraciones del ARNm de IL-6 y TNF- $\alpha$, y en la concentración proteica de la proteína $C$ reactiva. Se observa además, un incremento en el ARNm de IL-1 $\beta$ y IL-10. A simple vista se puede apreciar una disminución en las citoquinas proinflamatorias, a excepción de la IL-1 $\beta$ que muestra un leve incremento; y se observa un aumento en la citoquina antiinflamatoria (IL-10). Lamentablemente, todos los valores expuestos no obtuvieron una variación estadísticamente significativa tras compararlos con sus valores basales.

Para una mejor compresión de los resultados obtenidos en este estudio, se hace necesario asociar y entender el EVCC como una modalidad más cercana al entrenamiento de resistencia que al entrenamiento de tipo aeróbico, ya sea por sus características metabólicas o por sus efectos a nivel muscular. De este modo se pueden analizar los resultados de una manera más apropiada. Por tanto, ciñéndonos a lo anteriormente planteado, es que se asociarán los resultados obtenidos en el presente estudio a los resultados del efecto crónico de un entrenamiento de resistencia muscular en la población adulta mayor.

TNF- $\alpha$ es una citoqina que se relaciona con una serie de condiciones fisiopatológicas, como insulino resistencia (Koopman et al., 2005; Sigal et al., 2006), hipertensión (Kelly et al., 2004), síndrome metabólico (Phillips, 2007) y aterosclerosis (Krook et al., 2007). Además presenta una relación inversa con la masa muscular y la fuerza en los ancianos, entre otros. Según Calle y Fernández, (2010) TNF-a es la principal citoquina relacionada con los niveles de inflamación sistémica del organismo, mediando la síntesis de IL-6, proteína C reactiva, IL-10, entre otras proteínas con funciones pro o antiinflamatorias. Por tanto, una concentración elevada de TNF- $\alpha$ posee una fuerte asociación con la mortalidad cardiovascular en 
ancianos (Van den Biggelaar et al., 2004).

En relación a los valores basales de TNF- $\alpha$ entre los jóvenes y los ancianos de este estudio, una interesante investigación de Stewart et al., (2007) demostró que los jóvenes tienen valores más elevados de TNF- $\alpha$ que los ancianos, e incluso esta elevación se mantiene posterior a la intervención de un programa de entrenamiento combinado (aeróbico y de resistencia). Esto apoyaría lo observado en nuestro estudio, tras medir la concentración proteica de TNF- $\alpha$. En este mismo estudio (Stewart et al., 2007), no se observaron diferencias en IL-6, IL-1 $\beta$, mientras que los valores de proteína $C$ reactiva solo disminuyeron significativamente tras el programa combinado de entrenamiento en los jóvenes y ancianos con una menor condición física $\left(\mathrm{VO}_{2 m a ́ x}\right)$. Estos autores exponen que las razones de la mayor elevación de TNF- $\alpha$ en jóvenes que en ancianos no ha sido bien estudiada y que necesita de mayor profundización. Respecto al efecto del entrenamiento de resistencia, un estudio de Levinger et al., (2009) que consistió en 10 semanas de entrenamiento de resistencia en hombres y mujeres de mediana edad, no encontró una disminución en los contenidos de TNF- $\alpha$. En cambio Olson et al., (2007), si apreciaron una disminución en los valores de dicha citoquina. La diferencia entre sus resultados al parecer radica en que, en este último estudio, la duración del programa de entrenamiento fue de un año. Esto de alguna manera hace suponer que el tiempo de duración de los programas juega un importante papel en el efecto sobre los valores basales de esta citoquina.

Una revisión sobre la efectividad del entrenamiento de resistencia en los niveles de TNF- $\alpha$ concluye que no hay una aparente respuesta de esta citoquina con este tipo de entrenamiento (De Salles et al., 2010).

Años atrás se pensaba exclusivamente en el papel proinflamatorio que posee IL-6. Pero actualmente se conoce que esta citoquina posee un papel fundamental 
como mediador de la inflamación en el organismo. Específicamente por su relación con la producción de citoquinas tanto pro como antiinflamatorias (Calle y Fernández., 2010). La secreción de IL-6 por los miocitos parece tener una función antiinflamatoria, en oposición a la secreción crónica generada en las células adiposas (Mathur y Pedersen, 2008; Petersen y Pedersen, 2005; Brandt y Pedersen, 2010).

Para una mejor comprensión, se debe diferenciar entre los contenidos agudos de IL-6 (y también de TNF- $\alpha$ ) y los crónicos en respuesta al ejercicio, ya que la elevación de IL-6 junto con TNF- $\alpha$, tanto durante como en las horas posteriores al ejercicio, está relacionada con la estimulación de la lipólisis y la reposición de glucógeno, como vía de regulación energética. Sin embargo, solo IL-6 ha demostrado estimular la oxidación de lípidos (Brandt y Pedersen, 2010). Además esta elevación post ejercicio de IL-6 esta relacionada con las vías de señalización de la hipertrofia muscular a través de la estimulación de las células satélites (Serrano et al., 2008). Esta información ayuda en cierta forma a aclarar los contenidos elevados de estas citoquinas aparecidos en muchos artículos al respecto. De esta manera se diferencia el efecto de IL-6 como regulador energético, y su efecto sobre la inflamación crónica derivada de las células adiposas así como también de la infiltración de las células del sistema inmune en este tejido.

El estudio de Buford et al., (2009), midió las concentraciones de IL-6, IL-1ß, IL10 y TNF- $\alpha$ inmediatamente después de una sesión de ejercicio de resistencia al $80 \%$ de 1 RM en mujeres desentrenadas (54 años de media). En este estudio no encontraron cambios significativos en las concentraciones de estas citoquinas a nivel plasmático. No obstante, sí se apreció un incremento en el ARNm de IL-6, IL$1 \beta$ y TNF- $\alpha$ a nivel muscular.

Respecto al efecto del entrenamiento de resistencia sobre esta citoquina, el 
estudio mencionado anteriormente de Levinger et al., (2009) no apreció una disminución en IL-6 tras un programa de 10 semanas de entrenamiento de resistencia. A su vez, el estudio de Olson et al., (2007) de un año de duración, tampoco observaron variaciones significativas en sus valores basales.

IL-1 $\beta$ forma parte del sistema inmune innato que regula funciones del sistema inmune adaptativo (Arend, 2002). Esta citoquina ha demostrado generalmente no incrementarse después de un entrenamiento aeróbico, mientras que posterior a una sesión de resistencia, o bien se mantiene o se incrementa levemente (Calle y Fernández, 2010).

El estudio de Levinger et al., (2009) demostró una disminución en los niveles de IL-1 $\beta$ tras un programa de 10 semanas de entrenamiento de resistencia. Según Izquierdo et al., (2009), el efecto del entrenamiento de resistencia podría elevar IL1 ra que bloquearía la acción fisiológica de IL-1ß.

Por otro lado, un incremento en la expresión y síntesis por parte del las células hepáticas de la proteína $\mathrm{C}$ reactiva se ha demostrado con el aumento conjunto de IL6 y de TNF- $\alpha$. Aunque al parecer la producción en el tejido vascular (síntesis local) tiene una función más relevante en el desarrollo de la aterosclerosis (Stewart et al., 2007).

Sobre las concentraciones de proteína $\mathrm{C}$ reactiva con el entrenamiento aeróbico, no hay una tendencia clara, debido a que algunos artículos muestran que no existen cambios importantes con este tipo de entrenamiento (Kelley y Kelley, 2006; Stewart et al., 2007). Sin embargo, hay otros en el cual si se puede apreciar una disminución significativa respecto a sus valores basales (Martins et al., 2010).

El entrenamiento de resistencia a largo plazo podría influir sobre los valores 
basales de proteína C reactiva (Stewart et al., 2007; De Salles et al., 2010). Así es el caso del estudio de Levinger et al., (2009) que demostró una disminución en los niveles de proteína $C$ reactiva tras un programa de 10 semanas de entrenamiento de resistencia. Según Calle y Fernández., (2010), esta disminución en los valores de proteína $C$ reactiva podrían estar relacionados con la reducción en el porcentaje de masa grasa o en la disminución del perímetro de cintura de los sujetos, efecto que se aprecia usualmente con este tipo de entrenamiento. De hecho, se ha demostrado que valores inferiores de proteína $C$ reactiva están asociados con la ganancia de fuerza y con la pérdida de masa grasa (Martins et al., 2010).

De Salles et al., (2010), en su revisión pone de manifiesto que existe suficiente apoyo científico para pensar que la proteína C reactiva disminuye con el entrenamiento de resistencia. Adicionalmente se señala que mujeres, personas obesas y ancianos son los mayores beneficiados con este tipo de programas. Este hecho confirma, de alguna manera, lo observado en los valores de esta proteína medida en nuestro estudio.

Por último, las concentraciones de IL-10 pueden ser inducidas por IL-6 como respuesta al ejercicio (Petersen y Pedersen, 2005). Se ha demostrado que la liberación de IL- 6 a nivel de las células musculares, estimula la síntesis de IL-10 (Brandt y Pedersen, 2010), inhibiendo además la síntesis de IL-1 $\beta$ y de TNF- $\alpha$ (Mathur y Pedersen, 2008).

Un incremento en IL-10 ha sido demostrado después de un ejercicio excéntrico del flexor del codo (Hirose et al., 2004). Al parecer, la intensidad del ejercicio tiene un fuerte efecto sobre los niveles de IL-10 (Izquierdo et al., 2009). Según estos mismos autores, esto se debería a que la alta intensidad eleva el estrés hormonal e IL-6, promoviendo de esta forma un incremento en IL-10 para controlar la inflamación. Esto podría explicar de alguna manera las altas concentraciones de IL- 
10 observadas en los jóvenes en comparación a los ancianos.

Para concluir, cabe recordar que, los contenidos de citoquinas apreciados tanto después de una sesión aguda de ejercicio como después un programa de entrenamiento, son altamente influenciables por factores como la intensidad del ejercicio, tiempo de duración, pausa entre series, duración del programa, condición física del sujeto, entre otras, dificultando su análisis.

\subsection{PUNTOS IMPORTANTES A CONSIDERAR}

Tras la revisión de la literatura es importante señalar algunos puntos que pudieron afectar el análisis de los resultados obtenidos en el presente estudio, así como también, mencionar posibles carencias de esta investigación que no debieran repetirse para mejorar la calidad de las futuras investigaciones en esta área. He aquí los más relevantes:

- Procurar contar con un grupo control.

- Contar con un número mayor de ancianos antes de iniciar el programa debido a la alta posibilidad de que no completen el estudio.

- Medir componentes como masa magra, masa grasa, etc. con una técnica más precisa.

- Evaluar la EMGs en otros grupos musculares.

- Medir la MCVI en otros grupos musculares.

- Establecer una uniformidad (minutos, horas, días) en el momento de extracción de muestras posterior a una sesión o programa de entrenamiento.

- Según lo expuesto en la literatura se necesita un programa de mayor duración para observar variaciones en marcadores de inflamación.

- Evaluar los niveles de actividad física.

- Evaluar mejorías a nivel psico-social. 
6. Conclusiones 


\section{Conclusión primera}

El EVCC parece ser una herramienta eficaz para incrementar máxima contracción voluntaria isométrica y la potencia muscular del tren inferior, posiblemente debido al efecto del estímulo vibratorio sobre la actividad neuromuscular observada en el presente estudio.

\section{Conclusión segunda}

Un programa de EVCC es capaz de mejorar tanto la flexibilidad y la fuerza de ambas extremidades, como el equilibrio dinámico, componentes importantes en la capacidad funcional de los ancianos. Estos resultados positivos podrían ser consecuencia de los efectos beneficiosos del estímulo vibratorio sobre la función muscular.

\section{Conclusión tercera}

Tras el EVCC no se observa un aumento en la resistencia aeróbica en los ancianos. Esto podría deberse a que tanto las características del entrenamiento vibratorio como posiblemente los niveles de $\mathrm{VO}_{2}$ alcanzados no lograrían las recomendaciones mínimas para el desarrollo de dicha cualidad.

\section{Conclusión cuarta}

El entrenamiento de vibraciones de cuerpo completo utilizado no provoca alteraciones significativas en los diferentes marcadores de inflamación analizados, lo que sugiere que dicho programa de actividad física no exacerba la inflamación sistémica asociada con la edad y, por tanto, podría prescribirse de forma segura en una población anciana. 
Carlos Cristi Montero

\section{Conclusión final}

Aunque un programa de 9 semanas de EVCC no mejora significativamente la resistencia aeróbica y la inflamación en ancianos institucionalizados, se ha podido constatar que mejora ligeramente la flexibilidad y aumenta significativamente los valores de rendimiento muscular, como fuerza, potencia, equilibrio dinámico y activación neuromuscular. Estas cualidades podrían ayudar a alejar a los adultos mayores de la dependencia funcional, mejorando de esta manera su expectativa y su calidad de vida. Además es importante señalar que todo esto se consigue en un periodo de tiempo considerablemente menor en comparación con otros métodos utilizados tradicionalmente. 


\section{Bibliografía}


Abercromby, A. F., Amonette, W. E., Layne, C. S., McFarlin, B. K., Hinman, M. R., \& Paloski, W. H. (2007). Vibration exposure and biodynamic responses during wholebody vibration training. Medicine and Science in Sports and Exercise, 39, 1794-1800.

Abramson, J. L., \& Vaccarino, V. (2002). Relationship between physical activity and inflammation among apparently healthy middle-aged and older US adults. Archives of Internal Medicine, 162, 1286-1292.

Adams, K. J., Swank, A. M., Berning, J. M., Sevene-Adams, P. G., Barnard, K. L., \& Shimp-Bowerman, J. (2001). Progressive strength training in sedentary, older african american women. Medicine and Science in Sports and Exercise, 33, 1567-1576.

Ades, P. A., Ballor, D. L., Ashikaga, T., Utton, J. L., \& Nair, K. S. (1996). Weight training improves walking endurance in healthy elderly persons. Annals of Internal Medicine, $124,568-572$.

Alkner, B. A., Tesch, P. A., \& Berg, H. E. (2000). Quadriceps EMG/force relationship in knee extension and leg press. Medicine and Science in Sports and Exercise, 32, 459463

American College of Sports Medicine. ACSM. (2009a). ACSM's guidelines for exercise testing and prescription (Ed. Octava). Philadelphia: Wolters Kluwer/Lippincott Williams and Wilkins. pp. 380

American College of Sports Medicine. ACSM. (2009b). American college of sports medicine position stand. progression models in resistance training for healthy adults. Medicine and Science in Sports and Exercise, 41, 687-708.

Amiridis, I. G., Hatzitaki, V., \& Arabatzi, F. (2003). Age-induced modifications of static postural control in humans. Neuroscience Letters, 350, 137-140.

Andreyeva, T., Michaud, P. C., \& Van Soest, A. (2007). Obesity and health in europeans aged 50 years and older. Public Health, 121, 497-509.

Aoyagi, Y., \& Shephard, R. J. (2010). Habitual physical activity and health in the elderly: The nakanojo study. Geriatrics and Gerontology International, 10, S236-S243.

Aranceta Bartrina, J., Serra-Majem, L., Foz-Sala, M., \& Moreno-Esteban, B. (2005) Grupo colaborativo SEEDO. Prevalencia de obesidad en españa. Medicina Clínica, 125, 460-466

Araújo, C. G. S. (2008). Flexibility assessment: Normative values for flexitest from 5 to 91 years of age. Arquivos Brasileiros de Cardiologia, 90, 280-287. 
Arend, W. P. (2002). The balance between IL-1 and IL-1Ra in disease. Cytokine and Growth Factor Reviews, 13, 323-340.

Armstrong, A. L., \& Wallace, W. A. (1994). The epidemiology of hip fractures and methods of prevention. Acta Orthopaedica Bélgica, 60, 85-101.

Baloh, R. W., Ying, S. H., \& Jacobson, K. M. (2003). A longitudinal study of gait and balance dysfunction in normal older people. Archives of Neurology, 60, 835-839.

Bañuelos, S. (1996). La actividad física orientada hacia la salud. Madrid: Biblioteca Nueva. pp. 302.

Bassey, E. J., Bendall, M. J., \& Pearson, M. (1988). Muscle strength in the triceps surae and objectively measured customary walking activity in men and women over 65 years of age. Clinical Science, 74, 85-89.

Bassey, E. J., Fiatarone, M. A., O'Neill, E. F., Kelly, M., Evans, W. J., \& Lipsitz, L. A. (1992). Leg extensor power and functional performance in very old men and women. Clinical Science, 82, 321-327.

Bastone Ade, C., \& Jacob Filho, W. (2004). Effect of an exercise program on functional performance of institutionalized elderly. Journal of Rehabilitation Research and Development, 41, 659-668.

Bautmans, I., Van Hees, E., Lemper, J. C., \& Mets, T. (2005). The feasibility of whole body vibration in institutionalised elderly persons and its influence on muscle performance, balance and mobility: A randomised controlled trial [ISRCTN62535013]. BMC Geriatrics, 22, 5-17.

Beavers, K. M., Brinkley, T. E., \& Nicklas, B. J. (2010). Effect of exercise training on chronic inflammation. International Journal of Clinical Chemistry, 411, 785-793.

Beenakker, K. G., Ling, C. H., Meskers, C. G., de Craen, A. J., Stijnen, T., Westendorp, R. G., \& Maier, A. B. (2010). Patterns of muscle strength loss with age in the general population and patients with a chronic inflammatory state. Ageing Research Review, 9, 431-436.

Beliaeff, S., Bouchard, D. R., Hautier, C., Brochu, M., \& Dionne, I. J. (2008). Association between muscle mass and isometric muscle strength in well-functioning older men and women. Journal of Aging and Physical Activity, 16, 484-493.

Benedetti, M. G., Berti, L., Maselli, S., Mariani, G., \& Giannini, S. (2007). How do the elderly negotiate a step? A biomechanical assessment. Clinical Biomechanics, 22, 567573. 
Birch, K., MacLaren, D., \& George, K. (2005). Sport and exercise physiology. Abingdon: Taylor and Francis. pp. 219.

Blázquez, D. (1990). Evaluar en educación física. Barcelona: INDE. pp. 151.

Bogaerts, A. C. G., Delecluse, C., Claessens, A. L., Troosters, T., Boonen, S., \& Verschueren, S. M. P. (2009). Effects of whole body vibration training on cardiorespiratory fitness and muscle strength in older individuals (A 1-year randomised controlled trial). Age and Ageing, 38, 448-454.

Booth, F. W., Gordon, S. E., Carlson, C. J., \& Hamilton, M. T. (2000). Waging war on modern chronic diseases: Primary prevention through exercise biology. Journal of Applied Physiology, 88, 774-787.

Bortz, W. M. (1982). Disuse and aging. JAMA: The Journal of the American Medical Association, 248, 1203-1208.

Bosco, C., Cardinale, M., Tsarpela, O., Colli, R., Tihanyi, J., Von Duvillard, S. P., \& Viru, A. (1998). The influence of whole body vibration on jumping performance. Biology of Sport, 15, 157-164.

Bosco, C., Colli, R., Introini, E., Cardinale, M., Tsarpela, O., Madella, A., Tihanyi, J., \& Viru, A. (1999). Adaptive respsonses of human skeletal muscle to vibration exposure. Clinical Physiology-Oxford, 19, 183-187.

Bosco, C., lacovelli, M., Tsarpela, O., Cardinale, M., Bonifazi, M., Tihanyi, J., Viru, M., De Lorenzo, A., \& Viru, A. (2000). Hormonal responses to whole-body vibration in men. European Journal of Applied Physiology, 81, 449-454.

Bouchard, C., Blair, S. N., \& Haskell, W. L. (2007). Physical activity and health. Champaing IL: Human Kinetics Publishers. pp. 424.

Brandt, C., \& Pedersen, B. K. (2010). The role of exercise-induced myokines in muscle homeostasis and the defense against chronic diseases. Journal of Biomedicine and Biotechnology, 2010, 1-6.

Broadbent, S., Rousseau, J. J., Thorp, R. M., Choate, S. L., Jackson, F. S., \& Rowlands, D. S. (2010). Vibration therapy reduces plasma IL6 and muscle soreness after downhill running. British Journal of Sports Medicine, 44, 888-894.

Brod, S. A. (2000). Unregulated inflammation shortens human functional longevity. Inflammation Research, 49, 561-570.

Bruunsgaard, H. (2002). Effects of tumor necrosis factor-alpha and interleukin-6 in elderly populations. European Cytokine Network, 13, 389-391. 
Bruunsgaard, H. (2005). Physical activity and modulation of systemic low-level inflammation. Journal of Leukocyte Biology, 78, 819-835.

Bruunsgaard, H., Bjerregaard, E., Schroll, M., \& Pedersen, B. K. (2004). Muscle strength after resistance training is inversely correlated with baseline levels of soluble tumor necrosis factor receptors in the oldest old. Journal of the American Geriatrics Society, $52,237-241$.

Bruunsgaard, H., Ladelund, S., Pedersen, A. N., Schroll, M., Jorgensen, T., \& Pedersen, B. K. (2003). Predicting death from tumour necrosis factor-alpha and interleukin-6 in 80 year-old people. Clinical and Experimental Immunology, 132, 24-31.

Bruyere, O., Wuidart, M. A., Di Palma, E., Gourlay, M., Ethgen, O., Richy, F., \& Reginster, J. Y. (2005). Controlled whole body vibration to decrease fall risk and improve health-related quality of life of nursing home residents. Archives of Physical Medicine and Rehabilitation, 86, 303-307.

Buchner, D. M., \& De Lateur, B. J. (1991). The importance of skeletal muscle strength to physical function in older adults. Annals of Behavioral Medicine, 13, 91-98

Buford, T. W., Cooke, M. B., \& Willoughby, D. S. (2009). Resistance exercise-induced changes of inflammatory gene expression within human skeletal muscle. European Journal of Applied Physiology, 107, 463-471.

Calle, M. C., \& Fernandez, M. L. (2010). Effects of resistance training on the inflammatory response. Nutrition Research and Practice, 4, 259-269.

Carbonell, A., Aparicio, V., \& Delgado, M. (2009). Involución de la condición física por el envejecimiento. Apunts. Medicina del Esport, 162, 98-103.

Cardinale, M., \& Bosco, C. (2003). The use of vibration as an exercise intervention. Exercise and Sport Sciences Reviews, 31(1), 3-7.

Cardinale, M., \& Pope, M. H. (2003). The effects of whole body vibration on humans: Dangerous or advantageous? Acta Physiologica Hungarica, 90, 195-206.

Cardinale, M., \& Rittweger, J. (2006). Vibration exercise makes your muscles and bones stronger: Fact or fiction? Menopause International, 12, 12-18.

Cardinale, M., \& Wakeling, J. (2005). Whole body vibration exercise: Are vibrations good for you? British Journal of Sports Medicine, 39, 585-589.

Caspersen, C. J., Powell, K. E., \& Christenson, G. M. (1985). Physical activity, exercise, and physical fitness: Definitions and distinctions for health-related research. Public Health Reports, 100, 126-131. 
Castillo, M. (2007). La condición física es un componente importante de la salud para los adultos de hoy y del mañana. Selección, 17, 2-8.

Castillo, M. J., Ortega, F. B., \& Ruiz, J. R. (2005). La mejora de la forma física como terapia anti-envejecimiento. Medicina Clínica, 124, 146-155.

Cesari, M., Penninx, B. W., Pahor, M., Lauretani, F., Corsi, A. M., Rhys Williams, G., Guralnik, J. M., \& Ferrucci, L. (2004). Inflammatory markers and physical performance in older persons: The InCHIANTI study. The Journals of Gerontology, 59, 242-248.

Chung, H. Y., Cesari, M., Anton, S., Marzetti, E., Giovannini, S., Seo, A. Y., Carter, C., Yu, B.P., \& Leeuwenburgh, C. (2009). Molecular inflammation: Underpinnings of aging and age-related diseases. Ageing Research Reviews, 8, 18-30.

Chung, H. Y., Sung, B., Jung, K. J., Zou, Y., \& Yu, B. P. (2006). The molecular inflammatory process in aging. Antioxidants and Redox Signaling, 8, 572-581.

Clark, D. J., Patten, C., Reid, K. F., Carabello, R. J., Phillips, E. M., \& Fielding, R. A. (2011). Muscle performance and physical function are associated with voluntary rate of neuromuscular activation in older adults. The Journals of Gerontology Series A: Biological Sciences and Medical Sciences, 66, 115-121.

Cochrane, D. J. (2011). Vibration exercise: The potential benefits. International Journal of Sports Medicine, 32, 75-99.

Cochrane, D. J., \& Hawke, E. J. (2007). Effects of acute upper-body vibration on strength and power variables in climbers. Journal of Strength and Conditioning Research / National Strength \& Conditioning Association, 21, 527-531.

Cochrane, D. J., \& Stannard, S. R. (2005). Acute whole body vibration training increases vertical jump and flexibility performance in elite female field hockey players. British Journal of Sports Medicine, 39, 860-865.

Cochrane, D. J., Loram, I. D., Stannard, S. R., \& Rittweger, J. (2009). Changes in joint angle, muscle-tendon complex length, muscle contractile tissue displacement, and modulation of EMG activity during acute whole-body vibration. Muscle and Nerve, 40, 420-429.

Cochrane, D. J., Sartor, F., Winwood, K., Stannard, S. R., Narici, M. V., \& Rittweger, J. (2008a). A comparison of the physiologic effects of acute whole-body vibration exercise in young and older people. Archives of Physical Medicine and Rehabilitation, 89, 815821.

Cochrane, D. J., Stannard, S. R., Firth, E. C., \& Rittweger, J. (2010). Comparing muscle temperature during static and dynamic squatting with and without whole-body vibration. Clinical Physiology and Functional Imaging, 30, 223-229. 
Cochrane, D. J., Stannard, S. R., Walmsely, A., \& Firth, E. C. (2008b). The acute effect of vibration exercise on concentric muscular characteristics. Journal of Science and Medicine in Sport / Sports Medicine Australia, 11, 527-534.

Coin, A., Sergi, G., Minicuci, N., Giannini, S., Barbiero, E., Manzato, E., Pedrazzoni, M., Minisola, S., Rossini, M., Del Puente, A., Zamboni, M., Inelmen, E. M., \& Enzi, G. (2008). Fat-free mass and fat mass reference values by dual-energy X-ray absorptiometry (DEXA) in a 20-80 year-old Italian population. Clinical Nutrition, 27, $87-$ 94.

Colbert, L. H., Visser, M., Simonsick, E. M., Tracy, R. P., Newman, A. B., Kritchevsky, S. B., Pahor, M., Taaffe, D. R., Brach, J., Rubin, S., \& Harris, T. B. (2004). Physical activity, exercise, and inflammatory markers in older adults: Findings from the health, aging and body composition study. Journal of the American Geriatrics Society, 52, 10981104.

Cunningham, D. A., Paterson, D. H., Himann, J. E., \& Rechnitzer, P. A. (1993). Determinants of independence in the elderly. Canadian Journal of Applied Physiology, 18, 243-254.

De Luca, C. J. (1997). The use of surface electromyography in biomechanics. Journal of Applied Biomechanics, 13, 135-163.

De Salles, B. F., Simao, R., Fleck, S. J., Dias, I., Kraemer-Aguiar, L. G., \& Bouskela, E. (2010). Effects of resistance training on cytokines. International Journal of Sports Medicine, 31, 441-450.

De Vos, N. J., Singh, N. A., Ross, D. A., Stavrinos, T. M., Orr, R., \& Fiatarone Singh, M. A. (2005). Optimal load for increasing muscle power during explosive resistance training in older adults. The Journals of Gerontology.Series A, Biological Sciences and Medical Sciences, 60, 638-647.

Delecluse, C., Roelants, M., \& Verschueren, S. (2003). Strength increase after whole-body vibration compared with resistance training. Medicine and Science in Sports and Exercise, 35, 1033-1041.

Di Giminiani, R., Manno, R., Scrimaglio, R., Sementilli, G., \& Tihanyi, J. (2010). Effects of individualized whole-body vibration on muscle flexibility and mechanical power. The Journal of Sports Medicine and Physical Fitness, 50, 139-151.

Di Pietro, L. (1996). The epidemiology of physical activity and physical function in older people. Medicine and Science in Sports and Exercise, 28, 596-600.

Di Stefano, P. S., Curtis, R., \& Geddes, B. J. (2007). Insulin resistance, glycemic control and adiposity: Key determinants of healthy lifespan. Current Alzheimer Research, 4, 153-157. 
Dice, J. F. (1993). Cellular and molecular mechanisms of aging. Physiological Reviews, 73, 149-159.

Dina, O. A., Joseph, E. K., Levine, J. D., \& Green, P. G. (2010). Mechanisms mediating vibration-induced chronic musculoskeletal pain analyzed in the rat. The Journal of Pain, 11, 369-377.

Doriot, N., \& Wang, X. (2006). Effects of age and gender on maximum voluntary range of motion of the upper body joints. Ergonomics, 49, 269-281.

Edge, J., Mündel, T., Weir, K., \& Cochrane, D. J. (2009). The effects of acute whole body vibration as a recovery modality following high-intensity interval training in well-trained, middle-aged runners. European Journal of Applied Physiology, 105, 421-428.

Evans, W. J. (2002). Exercise as the standard of care for elderly people. The Journals of Gerontology Series A: Biological Sciences and Medical Sciences, 57, M260-M261.

Fajardo, J. T., \& Ferliú, G. M. (2004). Entrenamiento por medio de vibraciones mecánicas: Revisión de la literatura. Revista Digital,10, 1-25.

Fantin, F., Francesco, V. D., Fontana, G., Zivelonghi, A., Bissoli, L., Zoico, E., Rossi, A., Micciolo, R., Bosello, O., \& Zamboni, M. (2007). Longitudinal body composition changes in old men and women: Interrelationships with worsening disability. The Journals of Gerontology Series A: Biological Sciences and Medical Sciences, 62, 13751381.

Feland, J. B., Hawks, M., Hopkins, J. T., Hunter, I., Johnson, A. W., \& Eggett, D. L. (2010). Whole body vibration as an adjunct to static stretching. International Journal of Sports Medicine, 31, 584-589.

Ferri, A., Scaglioni, G., Pousson, M., Capodaglio, P., Van Hoecke, J., \& Narici, M. (2003). Strength and power changes of the human plantar flexors and knee extensors in response to resistance training in old age. Acta Physiologica Scandinavica, 177, 69-78.

Fiatarone, M. A., Marks, E. C., Ryan, N. D., Meredith, C. N., Lipsitz, L. A., \& Evans, W. J. (1990). High-intensity strength training in nonagenarians. JAMA: The Journal of the American Medical Association, 263, 3029-3034.

Fiatarone, M. A., O'Neill, E. F., Ryan, N. D., Clements, K. M., Solares, G. R., Nelson, M. E., Roberts, S. B., Kehayias, J. J., Lipsitz, L. A., \& Evans, W. J. (1994). Exercise training and nutritional supplementation for physical frailty in very elderly people. New England Journal of Medicine, 330, 1769-1775.

Fleg, J. L., Morrell, C. H., Bos, A. G., Brant, L. J., Talbot, L. A., Wright, J. G., \& Lakatta, E. G. (2005). Accelerated longitudinal decline of aerobic capacity in healthy older adults. Circulation, 112, 674-682. 
Flieger, J., Karachalios, T., Khaldi, L., Raptou, P., \& Lyritis, G. (1998). Mechanical stimulation in the form of vibration prevents postmenopausal bone loss in ovariectomized rats. Calcified Tissue International, 63, 510-514.

Forrest, K. Y. Z., Zmuda, J. M., \& Cauley, J. A. (2007). Patterns and correlates of muscle strength loss in older women. Gerontology, 53, 140-147.

Forrest, K., Zmuda, J., \& Cauley, J. (2005). Patterns and determinants of muscle strength change with aging in older men. The Aging Male, 8, 151-156.

Gabriel, D. A., Kamen, G., \& Frost, G. (2006). Neural adaptations to resistive exercise: Mechanisms and recommendations for training practices. Sports Medicine, 36, 133-149.

Garatachea, N. (2007). Actividad física y envejecimiento. Sevilla: Editorial Wanceulen. pp. 185 .

Garatachea, N., \& Gonzalez-Gallego, J. (2010). Effects of vibration training in older persons. En Muscle strength: Types, efficiency and drug effects. New York: Nova Science Publishers. pp. 285.

Garatachea, N., Molinero, O., Martínez-García, R., Jiménez-Jiménez, R., GonzálezGallego, J., \& Márquez, S. (2009). Feelings of well being in elderly people: Relationship to physical activity and physical function. Archives of Gerontology and Geriatrics, 48, 306-312.

Gerodimos, V., Zafeiridis, A., Karatrantou, K., Vasilopoulou, T., Chanou, K., \& Pispirikou, E. (2010). The acute effects of different whole-body vibration amplitudes and frequencies on flexibility and vertical jumping performance. Journal of Science and Medicine in Sport / Sports Medicine Australia, 13, 438-443.

Goodpaster, B. H., Park, S. W., Harris, T. B., Kritchevsky, S. B., Nevitt, M., Schwartz, A. V., Simonsick, E. M., Tylavsky, F. A., Visser, M., \& Newman, A. B. (2006). The loss of skeletal muscle strength, mass, and quality in older adults: The health, aging and body composition study. The Journals of Gerontology Series A: Biological Sciences and Medical Sciences, 61, 1059-1064.

Gottesman, L. E., \& Bourestom, N. C. (1974). Why nursing homes do what they do. The Gerontologist, 14, 501-506.

Griffin, M. J. (1996). Handbook of human vibration. New York: Elsevier. pp. 988.

Grimston, S. K., Nigg, B. M., Hanley, D. A., \& Engsberg, J. R. (1993). Differences in ankle joint complex range of motion as a function of age. Foot and Ankle, 14, 215-222.

Guadalupe-Grau, A., Fuentes, T., Guerra, B., \& Calbet, J. A. L. (2009). Exercise and bone mass in adults. Sports Medicine, 39, 439-468. 
Guette, M., Gondin, J., \& Martin, A. (2005). Time-of-day effect on the torque and neuromuscular properties of dominant and non-dominant quadriceps femoris. Chronobiology International, 22, 541-558.

Gusi, N., Raimundo, A., \& Leal, A. (2006). Low-frequency vibratory exercise reduces the risk of bone fracture more than walking: A randomized controlled trial. BMC Musculoskeletal Disorders, 7, 92-100.

Haigis, M. C., \& Yankner, B. A. (2010). The aging stress response. Molecular Cell, 40, 333344.

Häkkinen, K., Kraemer, W. J., Kallinen, M., Linnamo, V., Pastinen, U. M., \& Newton, R. U. (1996). Bilateral and unilateral neuromuscular function and muscle cross-sectional area in middle-aged and elderly men and women. The Journals of Gerontology Series A: Biological Sciences and Medical Sciences, 51, B21-B29.

Häkkinen, K., Newton, R. U., Gordon, S. E., McCormick, M., Volek, J. S., Nindl, B. C., Gotshalk, L. A., Campbell, W. W., Evans, W.J., Häkkinen, A., Humphries, B.J., \& Kraemer, W. J. (1998). Changes in muscle morphology, electromyographic activity, and force production characteristics during progressive strength training in young and older men. The Journals of Gerontology Series A: Biological Sciences and Medical Sciences, 53, B415-B423.

Hammett, C. J., Oxenham, H. C., Baldi, J. C., Doughty, R. N., Ameratunga, R., French, J. K., White, H. D., \& Stewart, R. A. (2004). Effect of six months' exercise training on Creactive protein levels in healthy elderly subjects. Journal of the American College of Cardiology, 44, 2411-2413.

Hardman, A. E., \& Stensel, D. J. (2009). Physical activity and health: The evidence explained (Ed. Segunda). London: Taylor and Francis. pp. 340.

Hawkins, S., \& Wiswell, A. (2003). Rate and mechanism of maximal oxygen consumption decline with aging: Implications for exercise training. Sports Medicine, 33, 877-888.

Hazell, T., Jakobi, J., \& Kenno, K. (2007). The effects of whole-body vibration on upper-and lower-body EMG during static and dynamic contractions. Applied Physiology, Nutrition, and Metabolism, 32, 1156-1163.

Hirose, L., Nosaka, K., Newton, M., Laveder, A., Kano, M., Peake, J., \& Suzuki, K. (2004). Changes in inflammatory mediators following eccentric exercise of the elbow flexors. Exercise Immunology Review, 10, 75-90.

Hollenberg, M., Yang, J., Haight, T. J., \& Tager, I. B. (2006). Longitudinal changes in aerobic capacity: Implications for concepts of aging. The Journals of Gerontology Series A: Biological Sciences and Medical Sciences, 61, 851-858. 
Hollman, J. H., Kovash, F. M., Kubik, J. J., \& Linbo, R. A. (2007). Age-related differences in spatiotemporal markers of gait stability during dual task walking. Gait and Posture, 26, $113-119$

Hollosky, J. O. (1983). Exercise, health, and aging: A need for more information. Medicine and Science in Sports and Exercise, 15, 1-5.

Hughes, S. L., Seymour, R. B., Campbell, R. T., Whitelaw, N., \& Bazzarre, T. (2009). Best-practice physical activity programs for older adults: Findings from the national impact study. American Journal of Public Health, 99, 362-368.

Hunter, G. R., McCarthy, J. P., \& Bamman, M. M. (2004). Effects of resistance training on older adults. Sports Medicine, 34, 329-348.

lannuzzi-Sucich, M., Prestwood, K. M., \& Kenny, A. M. (2002). Prevalence of sarcopenia and predictors of skeletal muscle mass in healthy, older men and women. The Journals of Gerontology Series A: Biological Sciences and Medical Sciences, 57, M772-M777.

INE. (2010a). Anuario estadístico de España. Revisado 16/03/2011 desde http://www.ine.es/prodyser/pubweb/anuarios mnu.htm

INE. (2010b). Instituto nacional de estadística. Revisado 16/03/2011 desde http://www.ine.es/jaxi/menu.do?type=pcaxis\&path=/t20/p251\&file=inebase\&L=

Issurin, V. B., \& Tenenbaum, G. (1999). Acute and residual effects of vibratory stimulation on explosive strength in elite and amateur athletes. Journal of Sports Sciences, 17, 177182

Issurin, V. B., Liebermann, D. G., \& Tenenbaum, G. (1994). Effect of vibratory stimulation training on maximal force and flexibility. Journal of Sports Sciences, 12, 561-561.

Iwamoto, J., Otaka, Y., Kudo, K., Takeda, T., Uzawa, M., \& Hirabayashi, K. (2004) Efficacy of training program for ambulatory competence in elderly women. The Keio Journal of Medicine, 53, 85-89.

Izquierdo, M., Ibanez, J., Calbet, J. A., Navarro-Amezqueta, I., Gonzalez-Izal, M., Idoate, F., Häkkinen, K., Kraemer, W. J., Palacios-Sarrasqueta, M., Almar, M., \& Gorostiaga, E. M. M. (2009). Cytokine and hormone responses to resistance training. European Journal of Applied Physiology, 107, 397-409.

Jacobs, P. L., \& Burns, P. (2009). Acute enhancement of lower-extremity dynamic strength and flexibility with whole-body vibration. Journal of Strength and Conditioning Research / National Strength and Conditioning Association, 23, 51-57.

Jankord, R., \& Jemiolo, B. (2004). Influence of physical activity on serum IL-6 and IL-10 levels in healthy older men. Medicine and Science in Sports and Exercise, 36, 960-964. 
Janssen, I., Heymsfield, S. B., Wang, Z. M., \& Ross, R. (2000). Skeletal muscle mass and distribution in 468 men and women aged 18-88 yr. Journal of Applied Physiology, 89, 81-88.

Jones, C. J., \& Rikli, R. E. (2002). Measuring functional. The Journal on Active Aging, 1, 2430.

Jordan, M. J., Norris, S. R., Smith, D. J., \& Herzog, W. (2005). Vibration training: An overview of the area, training consequences, and future considerations. The Journal of Strength and Conditioning Research, 19, 459-466.

Kaeding, T. S. (2009). Sarcopenia and whole body vibration training: An overview. Zeitschrift Fur Gerontologie Und Geriatrie: Organ Der Deutschen Gesellschaft Fur Gerontologie Und Geriatrie, 42, 88-92.

Kalache, A., \& Kickbusch, I. (1997). A global strategy for healthy ageing. World HealthGeneve, 50, 4-5.

Kawanabe, K., Kawashima, A., Sashimoto, I., Takeda, T., Sato, Y., \& Iwamoto, J. (2007). Effect of whole-body vibration exercise and muscle strengthening, balance, and walking exercises on walking ability in the elderly. The Keio Journal of Medicine, 56, 28-33.

Kelley, G. A., \& Kelley, K. S. (2006). Effects of aerobic exercise on C-reactive protein, body composition, and maximum oxygen consumption in adults: A meta-analysis of randomized controlled trials. Metabolism, 55, 1500-1507.

Kelly, M., Keller, C., Avilucea, P. R., Keller, P., Luo, Z., Xiang, X., Giralt, M., Hidalgo, J., Saha, A. K., Pedersen, B. K., \& Ruderman, N. B. (2004). AMPK activity is diminished in tissues of IL-6 knockout mice: The effect of exercise. Biochemical and Biophysical Research Communications, 320, 449-454.

Kerschan-Schindl, K., Grampp, S., Henk, C., Resch, H., Preisinger, E., Fialka-Moser, V., \& Imhof, H. (2001). Whole-body vibration exercise leads to alterations in muscle blood volume. Clinical Physiology, 21, 377-382.

Kim, H. J., Jung, K. J., Yu, B. P., Cho, C. G., Choi, J. S., \& Chung, H. Y. (2002) Modulation of redox-sensitive transcription factors by calorie restriction during aging. Mechanisms of Ageing and Development, 123, 1589-1595.

Komi, P. V. (1986). Training of muscle strength and power: Interaction of neuromotoric, hypertrophic, and mechanical factors. International Journal of Sports Medicine, 7, 10-15.

Koopman, R., Manders, R. J. F., Zorenc, A. H. G., Hul, G. B. J., Kuipers, H., Keizer, H. A., \& van Loon, L. J. C. (2005). A single session of resistance exercise enhances insulin sensitivity for at least $24 \mathrm{~h}$ in healthy men. European Journal of Applied Physiology, 94, 180-187. 
Kraemer, W. J., Fleck, S. J., \& Evans, W. J. (1996). Strength and power training: Physiological mechanisms of adaptation. Exercise and Sport Sciences Reviews, 24, 363-397.

Krol-Zielinska, M., Kusy, K., Zielinski, J., \& Osinski, W. (2011). Physical activity and functional fitness in institutionalized vs. independently living elderly: A comparison of $70-$ 80-year-old city-dwellers. Archives of Gerontology and Geriatrics, 53, e10-e16.

Krook, A., Long, Y. C., \& Zierath, J. R. (2007). Skeletal muscle AMP kinase as a target to prevent pathogenesis of type 2 diabetes. Expert Review of Endocrinology and Metabolism, 2, 477-485.

Kyle, U. G., Morabia, A., Schutz, Y., \& Pichard, C. (2004). Sedentarism affects body fat mass index and fat-free mass index in adults aged 18 to 98 years. Nutrition, 20, 255260.

Laemmli, U. K. (1970). Cleavage of structural proteins during the assembly of the head of bacteriophage T4. Nature, 227, 680-685.

Landers, K. A., Hunter, G. R., Wetzstein, C. J., Bamman, M. M., \& Weinsier, R. L. (2001). The interrelationship among muscle mass, strength, and the ability to perform physical tasks of daily living in younger and older women. The Journals of Gerontology Series A: Biological Sciences and Medical Sciences, 56, B443-B448.

Latham, N., Anderson, C., Bennett, D., \& Stretton, C. (2003). Progressive resistance strength training for physical disability in older people. Cochrane Database Syst Rev, 2, $1-10$.

Laufer, Y. (2005). Effect of age on characteristics of forward and backward gait at preferred and accelerated walking speed. The Journals of Gerontology Series A: Biological Sciences and Medical Sciences, 60, 627-632.

Laukkanen, P. I. A., Heikkinen, E., \& Kauppinen, M. (1995). Muscle strength and mobility as predictors of survival in 75-84-year-old people. Age and Ageing, 24, 468-473.

Lauretani, F., Russo, C. R., Bandinelli, S., Bartali, B., Cavazzini, C., Di lorio, A., Corsi, A. M., Rantanen, T., Guralnik, J. M., \& Ferrucci, L. (2003). Age-associated changes in skeletal muscles and their effect on mobility: An operational diagnosis of sarcopenia. Journal of Applied Physiology, 95, 1851-1860.

Lehmann, M. J., Lormes, W., Opitz-Gress, A., Steinacker, J. M., Netzer, N., Foster, C., \& Gastmann, U. (1997). Training and overtraining: An overview and experimental results in endurance sports. The Journal of Sports Medicine and Physical Fitness, 37, 7-17.

Levinger, I., Goodman, C., Peake, J., Garnham, A., Hare, D. L., Jerums, G., \& Selig, S. (2009). Inflammation, hepatic enzymes and resistance training in individuals with 
metabolic risk factors. Diabetic Medicine : A Journal of the British Diabetic Association, $26,220-227$.

Lexell, J., Taylor, C. C., \& Sjostrom, M. (1988). What is the cause of the ageing atrophy? total number, size and proportion of different fiber types studied in whole vastus lateralis muscle from 15-to 83-year-old men. Journal of the Neurological Sciences, 84, 275-294.

Liu, P. Y., Brummel-Smith, K., \& Ilich, J. Z. (2011). Aerobic exercise and whole-body vibration in offsetting bone loss in older adults. Journal of Aging Research, 2011, 1-9.

Livak, K. J., \& Schmittgen, T. D. (2001). Analysis of relative gene expression data using real-time quantitative PCR and the 2(-Delta Delta (CT)) Method. Methods, 25, 402-408.

Lobo, A., Carvalho, J., \& Santos, P. (2011). Comparison of functional fitness in elderlies with reference values by rikli and jones and after one-year of health intervention programs. The Journal of Sports Medicine and Physical Fitness, 51, 111-120.

López-Chicharro, J. L., \& Fernandez-Vaquero, A. (2006). Fisiología del ejercicio (Ed. Tercera). Madrid: Editorial Médica Panamericana. pp. 987.

Luo, J., McNamara, B., \& Moran, K. (2005). The use of vibration training to enhance muscle strength and power. Sports Medicine, 35, 23-41.

Machado, A., García-López, D., González-Gallego, J., \& Garatachea, N. (2010). Whole-body vibration training increases muscle strength and mass in older women: A randomized-controlled trial. Scandinavian Journal of Medicine and Science in Sports, 20, 200-207.

Madhavan, S., \& Shields, R. K. (2005). Influence of age on dynamic position sense: Evidence using a sequential movement task. Experimental Brain Research, 164, 18-28.

Marcell, T. J., McAuley, K. A., Traustadóttir, T., \& Reaven, P. D. (2005). Exercise training is not associated with improved levels of C-reactive protein or adiponectin. Metabolism, $54,533-541$.

Marín, P. (2011). Revisión de las relaciones entre la dosis y respuesta del entrenamiento con vibraciones sobre la fuerza y la potencia muscular. Revista Andaluza de Medicina del Deporte, 4, 29-37.

Marín, P. J., \& Rhea, M. R. (2010). Effects of vibration training on muscle strength: A metaanalysis. The Journal of Strength and Conditioning Research, 24, 548-556.

Marín, P. J., Herrero, A. J., Sáinz, N., Rhea, M. R., \& García-López, D. (2010). Effects of different magnitudes of whole-body vibration on arm muscular performance. The Journal of Strength and Conditioning Research, 24, 2506-2511. 
Márquez, R., Rodríguez, J., \& de Abajo, S. (2006). Sedentarismo y salud: Efectos beneficiosos de la actividad física. Apunts. Educación Física y Deportes, 83, 12-24.

Martí, D., Porta, J., Mas, J., Izquierdo, E., Aliga, J., \& Paredes, C. (2003). Efectos de una sesión de vibroestimulación en la fuerza máxima y explosiva de ciclistas y saltadores juniors. Red, 17, 9-14.

Martins, R. A., Neves, A. P., Coelho-Silva, M. J., Verissimo, M. T., \& Teixeira, A. M. (2010). The effect of aerobic versus strength-based training on high-sensitivity Creactive protein in older adults. European Journal of Applied Physiology, 110, 161-169.

Mathur, N., \& Pedersen, B. K. (2008). Exercise as a mean to control low-grade systemic inflammation. Mediators of Inflammation, 2008, 1-6.

Mattusch, F., Dufaux, B., Heine, O., Mertens, I., \& Rost, R. (2000). Reduction of the plasma concentration of C-reactive protein following nine months of endurance training. International Journal of Sports Medicine, 21, 21-24.

McCartney, N., Hicks, A. L., Martin, J., \& Webber, C. E. (1995). Long-term resistance training in the elderly: Effects on dynamic strength, exercise capacity, muscle, and bone. The Journals of Gerontology. Series A, Biological Sciences and Medical Sciences, 50, B97-B104.

McCartney, N., Hicks, A. L., Martin, J., \& Webber, C. E. (1996). A longitudinal trial of weight training in the elderly: Continued improvements in year 2. The Journals of Gerontology.Series A, Biological Sciences and Medical Sciences, 51, B425-B433.

McGeer, P. L., \& McGeer, E. G. (1995). The inflammatory response system of brain: Implications for therapy of alzheimer and other neurodegenerative diseases. Brain Research.Brain Research Reviews, 21, 195-218.

Meléndez, A. (2000). Actividades físicas para mayores. Madrid: Gymnos. pp. 200.

Merriman, H., \& Jackson, K. (2009). The effects of whole-body vibration training in aging adults: A systematic review. Journal of Geriatric Physical Therapy, 32, 134-145.

Mester, J., Kleinoder, H., \& Yue, Z. (2006). Vibration training: Benefits and risks. Journal of Biomechanics, 39, 1056-1065.

Mester, J., Spitzenfeil, P., Schwarzer, J., \& Seifriz, F. (1999). Biological reaction to vibration-implications for sport. Journal of Science and Medicine in Sport, 2, 211-226.

Mester, J., Spitzenpfeil, P., \& Yue, Z. (2003). Vibration loads: Potential for strength and power development. Strength and Power in Sport, 24, 488-501. 
Mikhael, M., Orr, R., \& Fiatarone Singh, M. A. (2010). The effect of whole body vibration exposure on muscle or bone morphology and function in older adults: A systematic review of the literature. Maturitas, 66, 150-157.

Miles, M. P. (2008). How do we solve the puzzle of unintended consequences of inflammation? systematically. Journal of Applied Physiology, 105, 1023-1025.

Miller, M. E., Rejeski, W. J., Reboussin, B. A., Ten Have, T. R., \& Ettinger, W. H. (2000) Physical activity, functional limitations, and disability in older adults. Journal of the American Geriatrics Society, 48, 1464-1472.

Mischi, M., \& Cardinale, M. (2009). The effects of a $28-h z$ vibration on arm muscle activity during isometric exercise. Medicine and Science in Sports and Exercise, 41, 645-653.

Mora, F. (1999). Envejecimiento. En Fisiologia humana (Ed. Segunda). Madrid: McGraw-HillInteramericana. pp. 1181.

Moran, K., McNamara, B., \& Luo, J. (2007). Effect of vibration training in maximal effort (70\% 1RM) dynamic bicep curls. Medicine and Science in Sports and Exercise, 39, 526533.

Morey, M. C., Sloane, R., Pieper, C. F., Peterson, M. J., Pearson, M. P., Ekelund, C. C., Crowley, G. M., Demark-Wahnefried, W., Snyder, D. C., Clipp, E. C., \& Cohen, H. J. (2008). Effect of physical activity guidelines on physical function in older adults. Journal of the American Geriatrics Society, 56, 1873-1878.

Morganti, C. M., Nelson, M. E., Fiatarone, M. A., Dallal, G. E., Economos, C. D., Crawford, B. M., \& Evans, W. J. (1995). Strength improvements with $1 \mathrm{yr}$ of progressive resistance training in older women. Medicine and Science in Sports and Exercise, 27, 906-912.

Morris, J. N., Heady, J. A., Raffle, P. A., Roberts, C. G., \& Parks, J. W. (1953). Coronary heart-disease and physical activity of work. Lancet, 21, 1053-1057.

Morris, M. E., \& Schoo, A. M. M. (2004). Optimizing exercise and physical activity in older people. Oxford: Butterworth-Heinemann. pp. 345.

Nassis, G. P., Papantakou, K., Skenderi, K., Triandafillopoulou, M., Kavouras, S. A., Yannakoulia, M., Chrousos, G. P., \& Sidossis, L. S. (2005). Aerobic exercise training improves insulin sensitivity without changes in body weight, body fat, adiponectin, and inflammatory markers in overweight and obese girls. Metabolism: Clinical and Experimental, 54, 1472-1479.

Nelson, M. E., Rejeski, W. J., Blair, S. N., Duncan, P. W., Judge, J. O., King, A. C., Macera, C. A., \& Castaneda-Sceppa, C. (2007). Physical activity and public health in 
older adults. recommendation from the american college of sports medicine and the american heart association. Circulation, 116, 1094-1105.

Newman, A. B., Kupelian, V., Visser, M., Simonsick, E. M., Goodpaster, B. H., Kritchevsky, S. B., Tylavsky, F. A., Rubin, S. M., \& Harris, T. B. (2006). Strength, but not muscle mass, is associated with mortality in the health, aging and body composition study cohort. The Journals of Gerontology Series A: Biological Sciences and Medical Sciences, 61, 72-77.

Noro, A., \& Aro, S. (1997). Comparison of health and functional ability between noninstitutionalized and least dependent institutionalized elderly in Finland. The Gerontologist, 37, 374-383.

Ogawa, K., Sanada, K., Machida, S., Okutsu, M., \& Suzuki, K. (2010). Resistance exercise training-induced muscle hypertrophy was associated with reduction of inflammatory markers in elderly women. Mediators of Inflammation, 2010, 171023.

Oja, P., Bull, F. C., Fogelholm, M., \& Martin, B. W. (2010). Physical activity recommendations for health: What should europe do? BMC Public Health, 10, 10-15.

Olson, T. P., Dengel, D. R., Leon, A. S., \& Schmitz, K. H. (2007). Changes in inflammatory biomarkers following one-year of moderate resistance training in overweight women. International Journal of Obesity, 31, 996-1003.

Ostojić, S., Pereza, N., \& Kapović, M. (2009). A current genetic and epigenetic view on human aging mechanisms. Collegium Antropologicum, 33, 687-699.

Pate, R. R., Pratt, M., Blair, S. N., Haskell, W. L., Macera, C. A., Bouchard, C., Buchner, D., Ettinger, W., Heath, G. W., \& King, A. C. (1995). Physical activity and public health. JAMA: The Journal of the American Medical Association, 273, 402-407.

Petersen, A. M. W., \& Pedersen, B. K. (2005). The anti-inflammatory effect of exercise. Journal of Applied Physiology, 98, 1154-1162.

Phillips, S. M. (2007). Resistance exercise: Good for more than just grandma and grandpa's muscles. Applied Physiology, Nutrition, and Metabolism, 32, 1198-1205.

Piatin, V. F., Shirolapov, I. V., \& Nikitin, O. L. (2009). Vibrational physical exercises as the rehabilitation in gerontology. Advances in Gerontology, 22, 337-342.

Pickup, J. C., \& Crook, M. A. (1998). Is type II diabetes mellitus a disease of the innate immune system? Diabetologia, 41, 1241-1248.

Ploeger, H. E., Takken, T., De Greef, M., \& Timmons, B. W. (2009). The effects of acute and chronic exercise on inflammatory markers in children and adults with a chronic inflammatory disease: A systematic review. Exercise Immunology Review, 15, 6-41. 
Portegijs, E., Kallinen, M., Rantanen, T., Heinonen, A., Sihvonen, S., Alen, M., Kiviranta, I., \& Sipilä, S. (2008). Effects of resistance training on lower-extremity impairments in older people with hip fracture. Archives of Physical Medicine and Rehabilitation, 89, 1667-1674.

Pou, K. M., Massaro, J. M., Hoffmann, U., Vasan, R. S., Maurovich-Horvat, P., Larson, M. G., Keaney, J. F. Jr., Meigs, J. B., Lipinska, I., Kathiresan, S., Murabito, J. M., O'Donnell, C. J., Benjamin, E. J., \& Fox, C. S. (2007). Visceral and subcutaneous adipose tissue volumes are cross-sectionally related to markers of inflammation and oxidative stress: The Framingham heart study. Circulation, 116, 1234-1241.

Prestes, J., Shiguemoto, G., Botero, J. P., Frollini, A., Dias, R., Leite, R., Pereira, G., Magosso, R., Baldissera, V., Cavaglieri, C., \& Perez, S. (2009). Effects of resistance training on resistin, leptin, cytokines, and muscle force in elderly post-menopausal women. Journal of Sports Sciences, 27, 1607-1615.

Rees, S. S., Murphy, A. J., \& Watsford, M. L. (2008). Effects of whole-body vibration exercise on lower-extremity muscle strength and power in an older population: A randomized clinical trial. Physical Therapy, 88, 462-470.

Rees, S., Murphy, A., \& Watsford, M. (2007). Effects of vibration exercise on muscle performance and mobility in an older population. Journal of Aging and Physical Activity, $15,367-381$.

Reeves, N. D., Narici, M. V., \& Maganaris, C. N. (2006). Musculoskeletal adaptations to resistance training in old age. Manual Therapy, 11, 192-196.

Rehn, B., Lidström, J., Skoglund, J., \& Lindström, B. (2007). Effects on leg muscular performance from whole-body vibration exercise: A systematic review. Scandinavian Journal of Medicine and Science in Sports, 17, 2-11.

Reid, K. F., Naumova, E. N., Carabello, R. J., Phillips, E. M., \& Fielding, R. A. (2008). Lower extremity muscle mass predicts functional performance in mobility-limited elders. The Journal of Nutrition, Health and Aging, 12, 493-498.

Reuben, D. B., Judd-Hamilton, L., Harris, T. B., Seeman, T. E., \& MacArthur Studies of Successful Aging. (2003). The associations between physical activity and inflammatory markers in high-functioning older persons: MacArthur studies of successful aging. Journal of the American Geriatrics Society, 51, 1125-1130.

Rikli, R. E., \& Jones, C. J. (2001). Senior fitness test manual. Champaign IL: Human Kinetics Publishers. pp. 161.

Rittweger, J. (2010). Vibration as an exercise modality: How it may work, and what its potential might be. European Journal of Applied Physiology, 108, 877-904. 
Rittweger, J., Just, K., Kautzsch, K., Reeg, P., \& Felsenberg, D. (2002). Treatment of chronic lower back pain with lumbar extension and whole-body vibration exercise: A randomized controlled trial. Spine, 27, 1829-1834.

Robinson, L. E., Buchholz, A. C., \& Mazurak, V. C. (2007). Inflammation, obesity, and fatty acid metabolism: Influence of n-3 polyunsaturated fatty acids on factors contributing to metabolic syndrome. Applied Physiology, Nutrition, and Metabolism, 32, 1008-1024.

Roelants, M., Delecluse, C., \& Verschueren, S. M. (2004). Whole-Body-Vibration training increases Knee-Extension strength and speed of movement in older women. Journal of the American Geriatrics Society, 52, 901-908.

Rohde, L. E. P., Hennekens, C. H., \& Ridker, P. M. (1999). Survey of C-reactive protein and cardiovascular risk factors in apparently healthy men. The American Journal of Cardiology, 84, 1018-1022.

Rønnestad, B. (2004). Comparing the performance-enhancing effects of squats on a vibration platform with conventional squats in recreationally resistance-trained men. The Journal of Strength and Conditioning Research, 18, 839-845.

Rosenberg, I. H. (1989). Summary comments. The American Journal of Clinical Nutrition, $50,1231-1233$

Rossi, A., Fantin, F., Di Francesco, V., Guariento, S., Giuliano, K., Fontana, G., Micciolo, R., Solerte, S. B., Bosello, O., \& Zamboni, M. (2008). Body composition and pulmonary function in the elderly: A 7-year longitudinal study. International Journal of Obesity, 32, 1423-1430.

Roth, S. M., Metter, E. J., Ling, S., \& Ferrucci, L. (2006). Inflammatory factors in agerelated muscle wasting. Current Opinion in Rheumatology, 18, 625-630.

Rubin, C. T., \& Lanyon, L. E. (1985). Regulation of bone mass by mechanical strain magnitude. Calcified Tissue International, 37, 411-417.

Rubin, C., Recker, R., Cullen, D., Ryaby, J., McCabe, J., \& McLeod, K. (2004). Prevention of postmenopausal bone loss by a Low-Magnitude, High-Frequency mechanical stimuli: A clinical trial assessing compliance, efficacy, and safety. Journal of Bone and Mineral Research, 19, 343-351.

Ruiz, J. R., Sui, X., Lobelo, F., Morrow Jr, J. R., Jackson, A. W., Sjöström, M., \& Blair, S. N. (2008). Association between muscular strength and mortality in men: Prospective cohort study. BMJ: British Medical Journal, 337, 92-95.

Runge, M., Rehfeld, G., \& Resnicek, E. (2000). Balance training and exercise in geriatric patients. Journal of Musculoskeletal and Neuronal Interactions, 1, 61-65. 
Russo, C. R., Lauretani, F., Bandinelli, S., Bartali, B., Cavazzini, C., Guralnik, J. M., \& Ferrucci, L. (2003). High-frequency vibration training increases muscle power in postmenopausal women. Women, 84, 1854-1857.

Ruuskanen, J. M., \& Ruoppila, I. (1995). Physical activity and psychological well-being among people aged 65 to 84 years. Age and Ageing, 24, 292-296.

Sale, D. G. (1988). Neural adaptation to resistance training. Medicine and Science in Sports and Exercise, 20, S135-S145.

Samson, M. M., Crowe, A., de Vreede, P. L., Dessens, J. A., Duursma, S. A., \& Verhaar, H. J. (2001). Differences in gait parameters at a preferred walking speed in healthy subjects due to age, height and body weight. Aging, 13, 16-21.

Santin-Medeiros, F., \& Garatachea Vallejo, N. (2010). Musculoskeletal effects of vibration training in the elderly. Revista Española De Geriatria y Gerontologia, 45, 281-284.

Sayer, A. A., Dennison, E. M., Syddall, H. E., Jameson, K., Martin, H. J., \& Cooper, C. (2008). The developmental origins of sarcopenia: Using peripheral quantitative computed tomography to assess muscle size in older people. The Journals of Gerontology Series A: Biological Sciences and Medical Sciences, 63, 835-840.

Schmid, A., Weiss, M., \& Heseker, H. (2003). Recording the nutrient intake of nursing home residents by food weighing method and measuring the physical activity. The Journal of Nutrition, Health and Aging, 7, 294-295.

Schroeder, J. M., Nau, K. L., Osness, H., \& Potteiger, J. A. (1998). A comparison of life satisfaction, functional ability, physical characteristics, and activity level among older adults in various living settings. Journal of Aging and Physical Activity, 6, 340-349.

Schultz, A. B. (1992). Mobility impairment in the elderly: Challenges for biomechanics research. Journal of Biomechanics, 25, 519-528.

Schultz, A. B. (1992). Mobility impairment in the elderly: Challenges for biomechanics research. Journal of Biomechanics, 25, 519-528.

Serra, J. A. (2006). Clinical consequences of sarcopenia. Nutricion Hospitalaria, 21, 46-50.

Serrano, A. L., Baeza-Raja, B., Perdiguero, E., Jardi, M., \& Munoz-Canoves, P. (2008) Interleukin-6 is an essential regulator of satellite cell-mediated skeletal muscle hypertrophy. Cell Metabolism, 7, 33-44.

Seynnes, O., Fiatarone Singh, M. A., Hue, O., Pras, P., Legros, P., \& Bernard, P. L. (2004). Physiological and functional responses to low-moderate versus high-intensity progressive resistance training in frail elders. The Journals of Gerontology Series A: Biological Sciences and Medical Sciences, 59, M503-M509. 
Sforza, C., Grassi, G. P., Fragnito, N., Turci, M., \& Ferrario, V. F. (2002). Threedimensional analysis of active head and cervical spine range of motion: Effect of age in healthy male subjects. Clinical Biomechanics, 17, 611-614.

Sigal, R. J., Kenny, G. P., Wasserman, D. H., Castaneda-Sceppa, C., \& White, R. D. (2006). Physical activity/exercise and type 2 diabetes. Diabetes Care, 29, 1433-1438.

Singh, M. A. F. (2002). Exercise comes of age. The Journals of Gerontology Series A: Biological Sciences and Medical Sciences, 57, M260-M262.

Skinner, J. S. (2005). Exercise testing and exercise prescription for special cases: Theoretical basis and clinical application (Ed. Segunda). Philadelphia: Lippincott Williams and Wilkins. pp. 418.

Sparrow, W. A., Begg, R. K., \& Parker, S. (2006). Aging effects on visual reaction time in a single task condition and when treadmill walking. Motor Control, 10, 201-211.

Stathokostas, L., Jacob-Johnson, S., Petrella, R. J., \& Paterson, D. H. (2004). Longitudinal changes in aerobic power in older men and women. Journal of Applied Physiology, 97, 781-789.

Stauffer, B. L., Hoetzer, G. L., Smith, D. T., \& DeSouza, C. A. (2004). Plasma C-reactive protein is not elevated in physically active postmenopausal women taking hormone replacement therapy. Journal of Applied Physiology, 96, 143-148.

Steib, S., Schoene, D., \& Pfeifer, K. (2010). Dose-response relationship of resistance training in older adults: A meta-analysis. Medicine and Science in Sports and Exercise, $42,902-914$.

Stewart, L. K., Flynn, M. G., Campbell, W. W., Craig, B. A., Robinson, J., Timmerman, K L., McFarlin, B. K., Coen, P. M., \& Talbert, E. (2007). The influence of exercise training on inflammatory cytokines and C-reactive protein. Medicine and Science in Sports and Exercise, 39, 1714-1719.

Stuck, A. E., Walthert, J. M., Nikolaus, T., Bula, C. J., Hohmann, C., \& Beck, J. C. (1999) Risk factors for functional status decline in community-living elderly people: A systematic literature review. Social Science and Medicine, 48, 445-469.

Sturnieks, D. L., George, R. S., \& Lord, S. R. (2008). Balance disorders in the elderly. Neurophysiologie Clinique/Clinical Neurophysiology, 38, 467-478.

Timiras, P. S. (1996). Bases fisiológicas del envejecimiento y geriatría. Barcelona: Elsevier. pp. 395. 
Torvinen, S., Kannus, P., \& Sievanen, H. (2002b). Effect of four-month vertical whole body vibration on performance and balance. Medicine and Science in Sports and Exercise, 34(9), 1523-1528.

Torvinen, S., Kannus, P., SievaÈnen, H., JaÈrvinen, T. A. H., Pasanen, M., Kontulainen, S., Järvinen, T. L., Järvinen, M., Oja, P., \& Vuori, I. (2002a). Effect of a vibration exposure on muscular performance and body balance. Randomized cross-over study. Clinical Physiology and Functional Imaging, 22, 145-152.

Totosy de Zepetnek, J., Giangregorio, L. M., \& Craven, B. C. (2009). Wholebody vibration as potential intervention for people with low bone mineral density and osteoporosis: A review. Journal of rehabilitation research and development, 46, 529-542.

Toussaint, O. (1993). La biología del envejecimiento celular: Convergencia de las teorías sobre el envejecimiento celular hacia el concepto de umbral crítico de acumulación de errores. Revista Gerontoogía, 3, 143-152.

Troen, B. R. (2003). The biology of aging. Mount Sinai Journal of Medicine, 70, 3-22.

Troke, M., Moore, A. P., Maillardet, F. J., \& Cheek, E. (2005). A normative database of lumbar spine ranges of motion. Manual Therapy, 10, 198-206.

U.S. Department of Health and Human Services. (1996). Physical activity and health executive summary. Revisado 16/03/2011 desde http://www.cdc.gov/nccdphp/sgr/index.htm

UN. Population Division. (2002). World population ageing 1950-2050. Revisado 16/03/2011, 2011, desde http://www.un.org/spanish/esa/population/unpop.htm

Van den Biggelaar, A. H., De Craen, A. J., Gussekloo, J., Huizinga, T. W., Heijmans, B. T., Frolich, M., Kirkwood, T. B., \& Westendorp, R. G. (2004). Inflammation underlying cardiovascular mortality is a late consequence of evolutionary programming. The FASEB Journal : Official Publication of the Federation of American Societies for Experimental Biology, 18, 1022-1024.

Van den Tillaar, R. (2006). Will whole-body vibration training help increase the range of motion of the hamstrings? Journal of Strength and Conditioning Research / National Strength and Conditioning Association, 20, 192-196.

Vassilakopoulos, T., Karatza, M. H., Katsaounou, P., Kollintza, A., Zakynthinos, S., \& Roussos, C. (2003). Antioxidants attenuate the plasma cytokine response to exercise in humans. Journal of Applied Physiology, 94, 1025-1032.

Verschueren, S. M. P., Roelants, M., Delecluse, C., Swinnen, S., Vanderschueren, D., \& Boonen, S. (2004). Effect of 6-Month whole body vibration training on hip density, 
muscle strength, and postural control in postmenopausal women: A randomized controlled pilot study. Journal of Bone and Mineral Research, 19, 352-359.

Visser, M., Goodpaster, B. H., Kritchevsky, S. B., Newman, A. B., Nevitt, M., Rubin, S. M., Simonsick, E. M., \& Harris, T. B. (2005). Muscle mass, muscle strength, and muscle fat infiltration as predictors of incident mobility limitations in well-functioning older persons. The Journals of Gerontology Series A: Biological Sciences and Medical Sciences, 60, 324-333.

Walsh, N. P., Gleeson, M., Shephard, R. J., Gleeson, M., Woods, J. A., Bishop, N. C., Fleshner, M., Green, C., Pedersen, B. K., Hoffman-Goetz, L., Rogers, C. J., Northoff, H., Abbasi, A., \& Simon, P. (2011). Position statement. Part one: Immune function and exercise. Exercise Immunology Review, 17, 6-63.

Weineck, J. (2005). Entrenamiento total. Barcelona: Editorial Paidotribo. pp. 686.

Weisberg, S. P., McCann, D., Desai, M., Rosenbaum, M., Leibel, R. L., \& Ferrante Jr, A. W. (2003). Obesity is associated with macrophage accumulation in adipose tissue. Journal of Clinical Investigation, 112, 1796-1808.

Weiss, E. P., Spina, R. J., Holloszy, J. O., \& Ehsani, A. A. (2006). Gender differences in the decline in aerobic capacity and its physiological determinants during the later decades of life. Journal of Applied Physiology, 101, 938-944.

Weiss, R. (2007). Fat distribution and storage: How much, where, and how? European Journal of Endocrinology, 157, S39-S45.

Wheat, G., Carter, A., McAfee, T., Thompson, R. S., Gayman, J., \& Meuchel, K. (1996). Addressing a neglected coronary heart disease risk factor in an HMO: Exercise counseling and fitness testing at group health cooperative. HMO Practice / HMO Group, $10,131-136$.

Włodarek, D., \& Kołota, A. (2009). Assessment of daily energy expenditure, physical activity and energy intake of aged women living in the nursing home-a short report. Polish Journal of Food and Nutrition Sciences, 59, 367-370.

World Health Organization. WHO. (1998). Growing older. staying well. ageing and physical activity in everyday life. Revisado 11/02/2011 desde http://www.who.int/ageing/publications/active/en/

World Health Organization. WHO. (2002). Envejecimiento activo: Un marco político. Revista Española de Geriatría y Gerontología, 37, 74-105.

Yaffe, K. (2007). Metabolic syndrome and cognitive disorders: Is the sum greater than its parts? Alzheimer Disease and Associated Disorders, 21, 167-171. 
Bibliografía

Yu, B. P., \& Chung, H. Y. (2006). Adaptive mechanisms to oxidative stress during aging. Mechanisms of Ageing and Development, 127, 436-443.

Yu, B. P., \& Yang, R. (1996). Critical evaluation of the free radical theory of aging. Annals of the New York Academy of Sciences, 786, 1-11. 


\section{Anexos}


ANEXO 1. CONSENTIMIENTO DE PARTICIPACIÓN POR ESCRITO

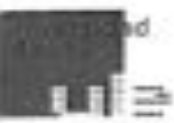

Thalo dol eatudio EFECTCS FISIOL OGICOS Y PSICOLOCICOS DEL EMTMENAMENTO DE FUERZA MEOUNTE PLATNFOPAM DE VERACIONES EN PERSCNAS MAYCRES OE CASTILA Y LEON

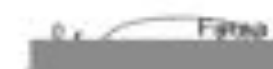




\section{ANEXO 2. TABLAS DE VALORACIÓN DE LA BATERÍA SENIOR FITNESS TEST}

La siguientes tablas expone el rango medio de la población anciana, con edades comprendidas entre los 60 y 94 años (Jones y Rikli, 2002).

Una ventaja de estas tablas es que normaliza los resultados obtenidos según sexo y rango de edad, lo que permite una comparación de los valores independiente de las dos variables mencionadas anteriormente (Lobo et al., 2011).

\section{Rangos normales de puntuación Hombres}

\begin{tabular}{|c|c|c|c|c|c|c|c|}
\hline & 00.84 & 6569 & 70.74 & 75.79 & 8084 & $85 \div 49$ & 8004 \\
\hline & 14.18 & $12 a 18$ & $12: 17$ & $11 a_{17}$ & $10: 15$ & 8014 & $7: 12$ \\
\hline & $16: 22$ & 21 & $14 a 21$ & 1381 & $13 a 19$ & 11.17 & 10 a 14 \\
\hline & $558 \mathrm{ab}$ & te & 6.09 & 2586 & 807 a 553 & & 9.457 \\
\hline & & & & & & & 6 \\
\hline & & & 3 & 22,8 & & 260,98 & $26,6 a+10,1$ \\
\hline & $6,3 a+10,1$ & $.7,6 a+7,6$ & $8,8 a+6,3$ & $10,1 a+5$ & $13,9 a+3,6$ & $.13,9 \mathrm{a}+1,2$ & $.16,5 a+1,2$ \\
\hline
\end{tabular}

\section{Rangos normales de puntuación Mujores}

\begin{tabular}{|c|c|c|c|c|c|c|c|}
\hline & $60-64$ & 65.69 & 70.74 & 76.79 & 8064 & 8589 & 9024 \\
\hline A & $12 a 17$ & 11 a 16 & 10 a 15 & 10.15 & $9 a 14$ & $8 a 13$ & $4 a 11$ \\
\hline B & $13 \mathrm{a} 10$ & $12 a 18$ & $12: 17$ & $11: 17$ & 10 a 16 & 10 a 15 & $8 a_{13}$ \\
\hline C & 498 a 604 & 457 a 581 & 439 а 562 & 393 a 535 & 352 a 494 & 311 a 466 & 251 a 402 \\
\hline 0 & $6,0,4,4$ & $6,4 a 4,8$ & $7,104,9$ & $7,4 \mathrm{a} 4,6$ & $7,6,5,2$ & $8,9,5,3$ & $10, a 6.2$ \\
\hline $\mathrm{E}$ & $-7,6 a+3,8$ & $-8,8 \mathrm{a}+3,8$ & $-10,1 a+2,5$ & $+12,7 a+1,2$ & $-13,9 a+0$ & $\cdot 17,7,7 \times 2,5$ & $-20,3 a+2,5$ \\
\hline$F$ & $4,2 a+12,7$ & $4,2 a+11,4$ & $2,5 \mathrm{a}+10,16$ & $3,8 a+8,89$ & $5 a+7,6$ & $6,3 a+6,3$ & $41,4 a+2,5$ \\
\hline
\end{tabular}

A. Sentarse y levantarse de una silla (repeticiones)

B. Flexiones de codo (repeticiones)

C: Test 6 minutos (motros)

D. Levantarse y caminat 2,44 m (segundos)

E: Alcanzar manos (contmetros)

F: Alcanzar pies (centimetros) 